Purdue University

Purdue e-Pubs

Open Access Dissertations

Theses and Dissertations

Spring 2015

\title{
Metacognitive Instruction in L2 French: An Analysis of Listening Performance and Automaticity
}

Shannon Becker

Purdue University

Follow this and additional works at: https://docs.lib.purdue.edu/open_access_dissertations

Part of the Education Commons, and the First and Second Language Acquisition Commons

\section{Recommended Citation}

Becker, Shannon, "Metacognitive Instruction in L2 French: An Analysis of Listening Performance and Automaticity" (2015). Open Access Dissertations. 420.

https://docs.lib.purdue.edu/open_access_dissertations/420

This document has been made available through Purdue e-Pubs, a service of the Purdue University Libraries. Please contact epubs@purdue.edu for additional information. 


\section{PURDUE UNIVERSITY \\ GRADUATE SCHOOL \\ Thesis/Dissertation Acceptance}

This is to certify that the thesis/dissertation prepared

By Shannon Becker

\section{Entitled}

METACOGNITIVE INSTRUCTION IN L2 FRENCH: AN ANALYSIS OF LISTENING PERFORMANCE AND AUTOMATICITY

For the degree of Doctor of Philosophy

Is approved by the final examining committee:

Jessica Sturm

Chair

April Ginther

Atsushi Fukada

Mariko Wei

To the best of my knowledge and as understood by the student in the Thesis/Dissertation Agreement, Publication Delay, and Certification Disclaimer (Graduate School Form 32), this thesis/dissertation adheres to the provisions of Purdue University's "Policy of Integrity in Research" and the use of copyright material.

Approved by Major Professor(s): Jessica Sturm

Approved by: Madeleine Henry 3/23/2015 

METACOGNITIVE INSTRUCTION IN L2 FRENCH:

AN ANALYSIS OF LISTENING PERFORMANCE AND AUTOMATICITY

\author{
A Dissertation \\ Submitted to the Faculty \\ of \\ Purdue University \\ by \\ Shannon Becker \\ In Partial Fulfillment of the \\ Requirements for the Degree \\ of \\ Doctor of Philosophy
}

May 2015

Purdue University

West Lafayette, Indiana 
For my Grampa. 


\section{ACKNOWLEDGMENTS}

Throughout my doctoral studies I have been surrounded by people in my personal and professional life who have given me more guidance, support, encouragement, and inspiration than they could possibly know. I have loved the French language since my first high school class, and the road that has led from there to my doctorate has been paved with the wisdom, prayers, and cheers of countless loved ones without whom I truly would not be where I am today.

I would like to thank Heather Carey for igniting my passion for the French language and culture and for being a shining example of what a French teacher should be. I would also like to thank Dr. Scooter Pégram for encouraging me to pursue my Ph.D. and for being there throughout this journey to offer kind words and professional advice.

I am sincerely grateful to the members of my dissertation committee for their guidance and for the time they have invested in my education. Dr. Mariko Wei has always greeted me with a smile and provided thoughtful advice to improve my research. Dr. Atsushi Fukada has graciously offered his time and wisdom to help me prepare the details of my study. Dr. April Ginther has been invaluable in her statistical prowess and forthright advice. I have been incredibly lucky to have such a well-rounded and accomplished group of faculty members helping me to complete this project. 
A discussion of my dissertation committee would not be complete without thanking my dissertation director, Dr. Jessica Sturm. It is impossible to articulate exactly how much she has helped me over the past five years. I could not be more grateful to her for believing in me, for being there when I needed her, for advising me every step of the way, and for truly caring not just about my education, but about me. She has been an incredible advisor, one I hope to emulate in my own career, and I thank her from the bottom of my heart.

My friends and family have been the foundation of my success. Tato, thank you for going through all of this with me. Matt and Ker, thank you for always being willing to listen and encourage me. Jess, thank you for countless hours of best friend cheerleading. Marie-Claude and Stéphanie, thank you for welcoming me into your family, for making me a better French speaker, and for changing my life.

Gramma, thank you for believing in me and encouraging me not just through the process of getting this degree, but always. You are a source of love and comfort, and I am so grateful to have you in my life.

Mom and Dad, thank you for always supporting my dreams and for working tirelessly to give me the opportunities that have led me here. Nothing I have done in my life would have been possible without you. You mean the world to me.

Finally, to my husband Steve, thank you for being my rock. I could never begin to put into words my gratitude for all you have done to get me to this point. Your love and support are beyond anything I could have ever dreamed of, and I am unbelievably grateful to have such an amazing partner in life. I love you. 
TABLE OF CONTENTS

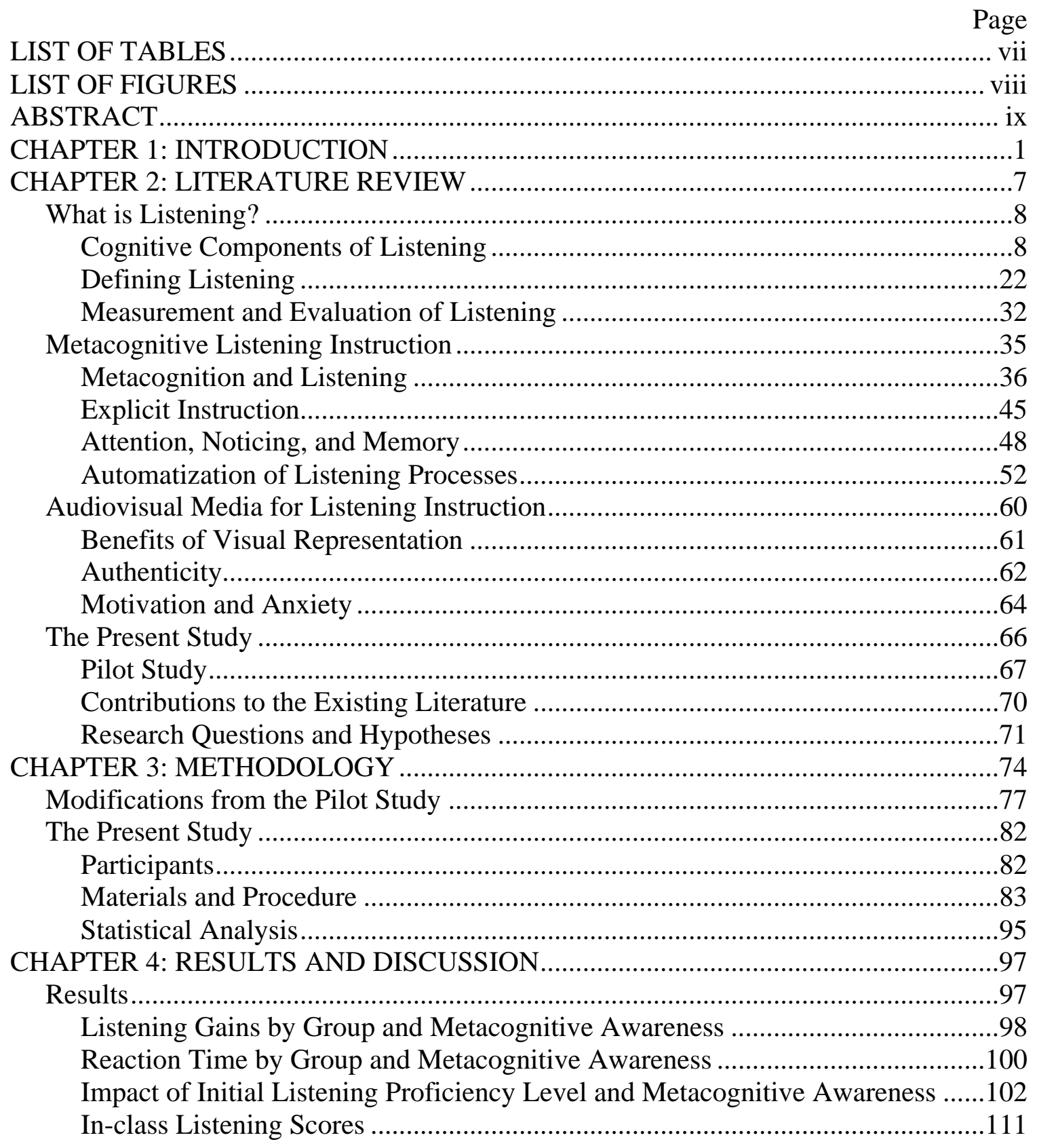




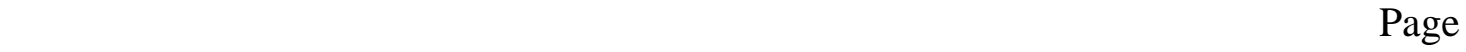

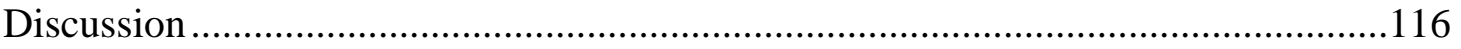

Listening by Listening Proficiency Subgroup ...................................................118

Reaction Time by Listening Proficiency Subgroup ...........................................119

Listening by Metacognitive Awareness Subgroup ............................................120

Reaction Time by Metacognitive Awareness Subgroup....................................123

In-class Listening Scores by Listening Proficiency Subgroup ............................125

In-class Listening Scores by Metacognitive Awareness Subgroup ......................128

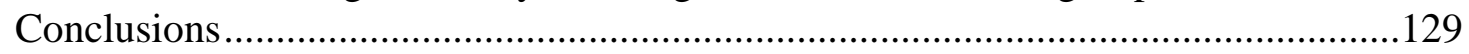

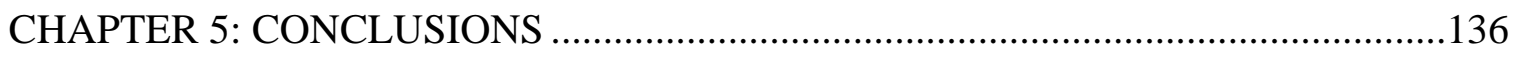

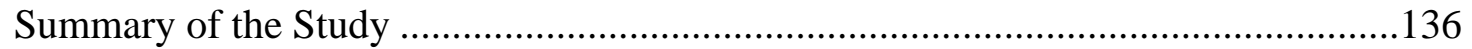

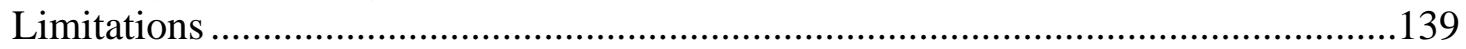

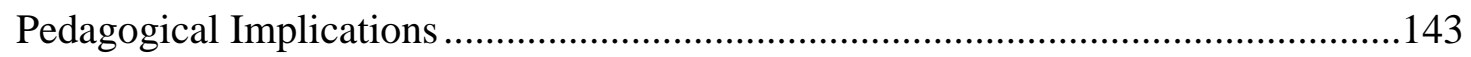

Directions for Future Research ...................................................................145

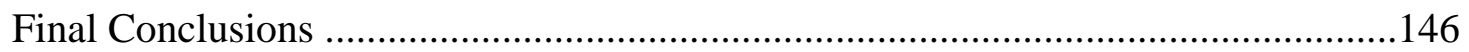

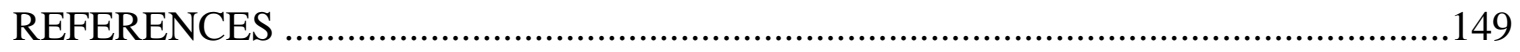

APPENDICES

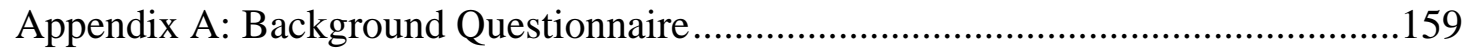

Appendix B: Transcripts and Listening Test Items ...........................................160

Appendix C: Metacognitive Awareness Listening Questionnaire ............................166

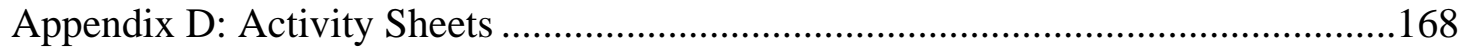

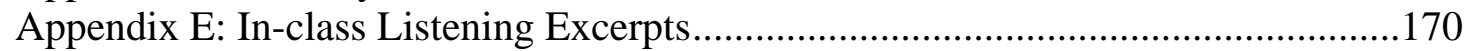

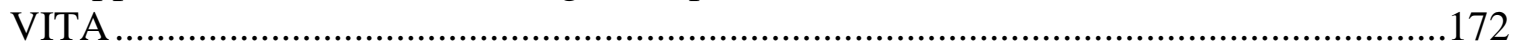




\section{LIST OF TABLES}

Table

Page

Table 1: Descriptive Statistics: Pilot Study ........................................................... 70

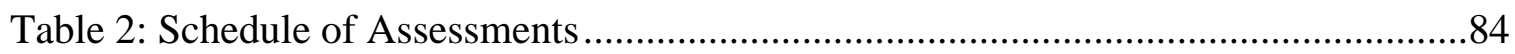

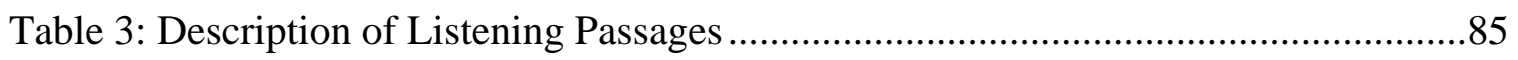

Table 4: Order of Listening Passages Across Tests.................................................... 85

Table 5: Descr. Stat.: Listening Gain Scores by Group and Metacognitive Awareness ...98

Table 6: Descr. Stat.: Reaction Time by Group and Metacognitive Awareness .............100

Table 7: Descr. Stat.: Listening Gain Scores by Listening Proficiency Subgroup ..........104

Table 8: Estimated Marginal Means: Listening Gains by Listening Prof. Subgroup ......105

Table 9: Descriptive Statistics: Reaction Time by Listening Prof. Subgroup .................107

Table 10: Est. Marginal Means: Reaction Time by List. Prof. Subgroup ......................107

Table 11: Descriptive Statistics: Listening Gains by Metacognitive Awareness ............109

Table 12: Est. Marginal Means: Listening Gains by Metacognitive Awareness.............109

Table 13: Descriptive Statistics: Reaction Time by Metacognitive Awareness ..............110

Table 14: Est. Marginal Means: Reaction Time by Metacognitive Awareness ..............111

Table 15: Correlation Analysis between Empirical and In-class Assessments ..............115

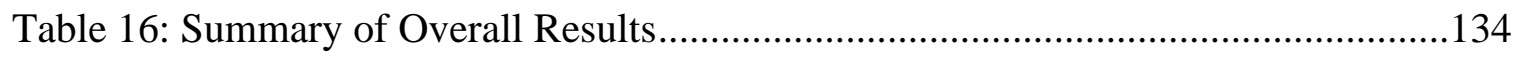




\section{LIST OF FIGURES}

Figure

Page

Figure 1: The process of learning implicit knowledge

Figure 2: Power law of practice .55

Figure 3: Listening performance by treatment condition

Figure 4: Reaction time by treatment condition .101

Figure 5: Listening gains by listening proficiency subgroup 106

Figure 6: In-class listening scores by listening proficiency subgroup. .112

Figure 7: Comparison of in-class scores by listening proficiency subgroup .114

Figure 8: In-class listening scores by metacognitive awareness subgroup

Figure 9: Comparison of in-class scores by metacognitive awareness subgroup 115

Figure 10: Reaction time by listening proficiency subgroup...................................120

Figure 11: Comparison of all listening scores by listening proficiency subgroup

Figure 12: Comparison of all listening scores by metacognitive awareness subgroup ...129 


\begin{abstract}
Becker, Shannon. Ph.D., Purdue University, May 2015. Metacognitive Instruction in L2 French: An Analysis of Listening Performance and Automaticity. Major Professor: Jessica L. Sturm.

The goal of the present study was to investigate the instructional potential of metacognitive strategies to improve listening comprehension and the automaticity of listening processes. Metacognition can be described as focusing attention on the cognitive processes one is currently using. In the classroom, metacognitive listening instruction means guiding learners in applying metacognition to learning by monitoring the mental strategies they use while listening, evaluating the relative success of these strategies, and planning for future listening experiences. I argue that providing students with these tools to monitor and regulate the perceptual and cognitive processes involved in listening contributes significantly to building toward the automaticity of those processes, leading to improved performance and reduced reaction time on listening assessments. In order to test this hypothesis, a pretest - treatment - posttest design was adopted and seven intact sections of second-semester French were randomly assigned to the control or experimental condition. The experimental groups were instructed in using metacognitive strategies to regulate the listening process while the control groups were simply exposed to the listening passages and asked to verify comprehension. Results
\end{abstract}


showed that treatment condition alone did not account for improvement in listening comprehension or automaticity. Differences were found, however, based on initial listening proficiency and metacognitive awareness: low proficiency learners in both conditions outperformed all high proficiency learners in listening gains over time. Initial level of metacognitive awareness had a significant impact on gains in listening performance, indicating that the learners in the experimental group who began the study with low metacognitive awareness achieved higher gains in listening. This suggests that increasing metacognitive awareness through instruction is effective in improving listening comprehension. A potential ceiling effect was indicated, however, since those who began the study with high metacognitive awareness in the control condition improved their listening more than those in the experimental condition. An analysis of reaction time gain scores suggested that automaticity was not affected by initial listening proficiency. On the other hand, it was the learners in the control condition with low initial metacognitive awareness who decreased their reaction time compared to other subgroups over the course of the study, suggesting that metacognitive abilities are indeed related to automaticity. On the whole, these results indicate that initial level of metacognitive awareness has a differential impact on listening comprehension gains as well as reaction time. This supports the idea that increasing metacognition can help learners to improve listening skills; however, further research must be done in order to clarify the nature of these interrelationships. 


\section{CHAPTER 1: INTRODUCTION}

The act of listening constitutes half of any communicative exchange. In order to appropriately respond to an interlocutor, it is imperative to correctly interpret his or her utterance. A breakdown in any part of this process, from the phonetic to the discourse level, can have major implications for the communicative event at hand. This is especially true in the case of communication in a second or foreign language (L2), where deficiencies in comprehension can cause a listener to lose track of the speech stream, resulting in total disruption of the listening process and subsequent breakdown in communication. Given its significance to oral communication, the skill of listening comprehension must be developed and honed to the same extent as speaking. Before this can be done, however, the cognitive processes involved in listening must be analyzed and documented. This is where listening diverges from the skills of speaking, reading, and writing, which have been more thoroughly studied. Because listening involves mental processes that cannot be observed, along with acoustic input that is fleeting and intangible, the cognitive processes that comprise it are less well understood.

Research, both theoretical and empirical, has, however, revealed some characteristics of the cognitive processes involved in listening. First, listening is an active process (Brown, 2011; Morley, 1999) that involves a certain level of conscious attention to the input in order to decipher acoustic signals, segment the speech stream, 
parse words, and apply background and contextual knowledge to aid in interpretation.

Second, listening requires both bottom-up processes, such as word segmentation, and topdown processes, such as applying contextual cues, in order to be successful. These processes "interact in parallel fashion as listeners create a mental representation of what they have heard" (Vandergrift, 2004, p. 4). Finally, a much greater proportion of listening is achieved automatically in one's native language (L1) than in one's L2. This is especially true in the beginning stages of L2 acquisition when one does not possess sufficient linguistic knowledge to rely on automatic processing for bottom-up information, which would free attentional resources for the interpretation of top-down information. This existing knowledge about the cognitive processes of listening can provide a solid foundation for the formation of hypotheses regarding how best to cultivate listening skills in the L2 classroom.

Foreign language learners consider the ability to communicate orally in the target language to be their primary goal in taking a language course (Harlow \& Muyskens, 1994; Rivera \& Matsuzawa, 2007), and foreign language instructors prioritize speaking second only after self-confidence (Harlow \& Muyskens, 1994). While for many oral proficiency in a language refers to the ability to speak the target language quickly, at a high level of proficiency, and with a native-sounding accent, this narrow focus on the skill of speaking can cause both learners and instructors to overlook the crucial role of listening in oral communication and language acquisition. The development of listening skills plays a crucial role in the establishment of oral proficiency since the processing and correct interpretation of the incoming message are essential to the flow of the conversation. Excessive pauses and requests for repetition will eventually break down 
communication. Additionally, when one is acquiring an L2, it is the target language input that will serve as an example of how that language is spoken, providing learners with clues to correct pronunciation and syntax, and furnishing examples of new lexical items and pragmatic competence. If this input is not correctly perceived and comprehended, speaking proficiency cannot follow. Instruction in L2 listening, then, is indispensable in the development of oral proficiency. However, despite the centrality of oral proficiency for both learners and instructors as well as the relevance of listening to successful L2 learning, "research in L2 listening instruction remains limited" (Vandergrift, 2004, p. 3).

In the current investigation, I analyze the effectiveness of metacognitive strategies in the instruction of L2 listening skills. The use of metacognitive instruction is hypothesized to provide learners with the controlled practice necessary to automatize listening skills, leading to swifter gains in listening comprehension scores as well as to a decrease in reaction time when responding to comprehension questions.

According to Vandergrift (2004), "students need systematic practice in listening strategies" (p. 12). Explicit instruction in the use of metacognitive listening strategies is a way to guide learners in controlling and practicing the cognitive processes of listening in order to aid in the eventual automatization of these processes. Metacognitive strategy instruction encourages learners to focus their attention on the mental strategies they use while listening, to evaluate the relative success of these strategies, and to plan for future listening experiences. Research has indicated that higher proficiency learners use more metacognitive strategies than lower proficiency learners (Goh, 1998, 2008; Vandergrift, 2003; Veenman \& Spans, 2005; Veenman, et al., 2006). In addition, a few initial studies 
have explored the effect of metacognitive instruction on listening comprehension, metacognitive awareness, and learner attitudes (Cross, 2011; Goh \& Taib, 2006; Rahimi \& Katal, 2012; Vandergrift \& Tafaghodtari, 2010). Despite a small number of empirical studies on the benefits of a metacognitive, process-based approach for listening comprehension, this technique has been supported in large part by anecdotal evidence and qualitative studies (Vandergrift, 2004, p. 12). In the present study, I seek to provide additional empirical evidence to support its use in L2 listening instruction.

The metacognitive instruction employed in the present study was delivered via online, audiovisual resources. Research has provided empirical support for the use of audiovisual media in listening instruction (Abraham, 2007; Jones, 2009; Jones \& Plass, 2002; Kost, Foss \& Lenzini, 1999; Londe, 2009), an advantage that can be attributed to the cognitive benefits of presenting information in both audio and visual modes. The dual modality of audiovisual media creates more routes to the information, strengthening the mental connections to the materials (Mayer, 1997). Additionally, audiovisual resources provide learners with highly contextualized authentic speech, exposing them to a variety of accents and speakers. This can result in more robust perceptual processes and make it easier for learners to transfer listening comprehension skills across contexts. Finally, audiovisual media itself can be a motivating factor for L2 learners due to its familiarity and its classification as entertainment.

The present study investigated the influence of metacognitive instructional techniques on the listening comprehension development of L2 learners of French. Using a pretest-treatment-posttest design, the listening performance of a metacognitive treatment group was compared to that of a control group that received no specialized 
listening instruction. The treatment applied in the experimental group was designed to illuminate the differences between listening instruction using simple comprehension questions and listening instruction using explicit training in metacognitive strategies. Differences between the control and treatment groups on listening comprehension and automaticity measures elucidated the effectiveness of metacognitive instruction in L2 listening.

Four research questions were developed to guide the empirical study:

- $\quad$ Research Question \#1: Does the use of explicit metacognitive instruction lead to an improvement in listening comprehension scores when compared to similar instruction given without explicit metacognitive strategy use?

- $\quad$ Research Question \#2: Does metacognitive instruction aid in the automatization of the perceptual and cognitive processes of listening as evidenced by a reduction in reaction time over time?

- $\quad$ Research Question \#3: How does initial metacognitive awareness impact listening comprehension and automaticity?

- $\quad$ Research Question \#4: What is the empirical validity of the listening measures from the study, as demonstrated through a comparison with the in-class assessments administered during the same time frame?

In the next chapter, previous research on listening comprehension, metacognition, and automatization will be discussed at it relates to the present investigation. In Chapter 3, the methodology of the present study will be described in detail, including participants, materials, procedure, and the changes necessitated by results of the pilot study. Chapter 4 will present the statistical analyses and results of the study and discuss them in further 
detail as they relate to existing second language acquisition research and language pedagogy. Finally, Chapter 5 will summarize the study as well as address its limitations and its pedagogical implications, and suggest directions for future research. 


\section{CHAPTER 2: LITERATURE REVIEW}

Listening is a difficult skill to define, because it occurs entirely via internal, invisible processes that are impossible to observe. Additionally, aural input is fleeting and changes with each repetition. The implications of this difficulty are apparent in several areas. First, it can be difficult to operationalize listening for empirical studies, an essential step in assuring the subsequent validity of the results. It also impacts the ability to measure listening comprehension proficiency thereby assessing the acquisition of listening skills in both second language environments and the L2 classroom.

To develop a better understanding of the construct under investigation in the present research study, this chapter serves as an introduction to listening and the diverse elements that comprise and affect it. In order to formulate a working definition of the construct of listening for the present study, I explore the perceptual and cognitive operations involved in listening. Next, I discuss ways in which these concepts may be applied to listening instruction via an introduction to metacognitive instruction and the theoretical perspectives that justify its use in the L2 classroom. I then briefly consider the usefulness of audiovisual media and technology to achieve these ends. Finally, I introduce the empirical study reported in the present paper by describing the findings from a pilot study, discussing how the present study contributes to existing literature, and presenting the research questions and hypotheses that were adopted for this research. 


\section{What is Listening?}

In advance of any discussion concerning the acquisition or instruction of a skill in a second or foreign language (L2), it is first necessary to establish a clear definition of the construct in question. For listening, this means breaking down the act of listening into its constituent perceptual and cognitive processes in order to develop a more thorough understanding of how listening occurs and how it may be affected by instruction. Implicit in this analysis is an exploration of top-down and bottom-up information processing strategies, automatic versus controlled perceptual processing, the ways in which L2 listening differs from L1 listening, and the impact of this difference on L2 listening instruction. These factors should be understood within the context of the way researchers in second language acquisition (SLA) define listening and how their understanding of the construct has evolved over time in order to operationalize the construct and determine how to measure it.

\section{Cognitive Components of Listening}

As a cognitive process, listening involves the reception, processing, and manipulation of many types of input. This includes the physiological act of receiving and processing the acoustic signal, holding the aural input in the working memory, parsing utterances into their component words, recognizing words and relating them to existing linguistic knowledge, decoding the syntax of the utterance, making inferences based on prior knowledge, and incorporating contextual information, among many other operations. Listeners may perform these operations in a top-down or bottom-up process, depending upon the situation and what they are hoping to glean from the input. For 
example, bottom-up processing is important for a listener who is searching for a specific detail in the passage, and involves the construction of meaning from the phoneme level up to the discourse level. Top-down processing, however, is more appropriate for a listener who is looking to understand the overall meaning of the input, and involves the activation of context and background knowledge to assist in the interpretation of the input (Vandergrift, 2007). It is important to note that rather than occurring in a fixed order, these processes may occur "in any order, or even simultaneously, and they are all capable of interacting and influencing each other" (Buck, 2001, p. 3).

Given this inherent complexity in the listening process, it is no wonder that scholars have developed many theories regarding the cognitive operations involved in listening and the mental representations that guide them (Anderson, 1995; Johnson-Laird, 1983; Levelt, 1995; Nagle \& Sanders, 1986; Van Dijk \& Kintsch, 1983). To provide an example, Anderson (1995) conceived of a three-phase model of listening: perceptual processing, parsing, and utilization. In the perceptual processing phase, the focus is on segmenting phonemes from the speech stream. The parsing phase involves segmenting words from the speech stream and constructing meaning from them. In the utilization phase, background knowledge is accessed in order to understand the intended meaning of the utterance (Vandergrift, 2007, p. 193-194).

The mental processes described by models of listening are impossible to observe and are constantly changing as a result of new input, making it difficult to obtain empirical evidence of the listening process. Where the process is examined, it can only be done indirectly through the use of methods such as questionnaires, stimulated recall, and interviews. Because these methods can be time-consuming and logistically difficult, 
and because quantitative data is typically considered more desirable than qualitative data, many researchers choose instead to focus on the product of listening. This involves eliciting discrete information from the input in order to evaluate listeners' level of comprehension. Product and process approaches to listening assessment will be discussed in further detail in the Methodology chapter. In order to present a complete picture of the process of listening, its cognitive components will be discussed in the following order: the processing of the acoustic signal, the use of top-down and bottom-up processes to extract meaning, and the degree of conscious control a listener has over these processes in their L2. Finally I will address the various differences between L1 and L2 language acquisition and how these affect the acquisition of listening skills in particular.

Auditory processing and speech perception. The first and arguably the most important step in listening comprehension is the conversion of the acoustic signal into meaningful sounds which can be further processed for linguistic information. It is during this part of the listening process that learners must accurately perceive the phonetic information of L2 input and recognize phonetic segments and sequences which they will then decode into words and phrases. The perception of L2 phonemes is important not only to L2 listening comprehension but to the acquisition of L2 pronunciation as well, since "phonetic segments in an L2 can be produced in a nativelike fashion only if they are perceived in a nativelike fashion" (Flege, MacKay \& Meador, 1999, p. 2982). Scholars working in L2 phonological perception have proposed various models of L2 speech 
perception, including the Speech Learning Model (SLM) (Flege, 1995) and the Native Language Magnet Model (NLM) (Kuhl, 2000).

In the speech learning model, Flege (1995) proposes that L2 phonetic segments that are the least similar to L1 segments will be easier to learn, because learners will create a new perceptual category in which to store the phonetic information. Conversely, it is the L2 phonetic segments which are more similar to L1 phonetic segments that are the most difficult to distinguish because they may be assigned to the existing L1 category instead of recognized as novel sounds. According to the SLM, it is possible for learners to develop new perceptual categories for L2 phonetic segments; however, this development becomes more difficult as one gets older.

In the native language magnet model, Kuhl (2000) argues that as infants and children are exposed to the sounds of their native language, they perform perceptual mapping of these sounds. In this model of L2 phonetic perception, the perceptual mapping of L1 speech sounds by an infant creates a "complex network, or filter, through which language is perceived" (Kuhl, 2000, p. 11854). Subsequent second language input presumably passes through this filter and is perceived in reference to previously existing sound categories, causing interference. The "perceptual attunement to L1 categories may later shape the perception of L2 speech sounds" (Flege \& MacKay, 2004, p. 4), leading to difficulty in perceiving L2 sounds that that are similar to those found in the L1. This experience-based interference in the acquisition of L2 phonemes makes it nearly impossible for adult L2 learners to develop native-like perceptual processes of L2 phonetic segments. 
Although Flege's (1995) model of L2 perceptual development paints a slightly more optimistic picture of the potential success L2 learners may have in perceiving L2 phonetic segments, both of the aforementioned models demonstrate the difficulty involved in successfully navigating even the first step of the listening comprehension process. Because of the difficulty learners may have in perceiving individual phonetic segments in the L2, it is all the more critical that they have recourse to additional strategies for interpreting aural input. In the event that bottom-up processing at the phonemic level fails, learners should be able to apply top-down processing in order to get an idea of the overall gist of the message.

Bottom-up vs. top-down processing. One of the most widely discussed elements of listening comprehension performance and instruction is the application of bottom-up and top-down approaches to processing input. Bottom-up processing is used to build meaning from smaller to larger units, starting with phonetic perception of auditory input and proceeding to interpretation of syntax and higher level linguistic elements. In other words, bottom-up strategies involve processing the input from the phonemic level up to the discourse level; putting sounds into words, words into sentences, and sentences into discourse. Top-down processing, on the other hand, can be described as looking at the bigger picture with regard to aural input. In top-down processing, learners listen for the gist of the input without focusing on individual speech sounds. This is accomplished through interpreting contextual cues and making inferences based on prior or global knowledge in order to decipher the intended message. 
Both bottom-up and top-down processing are important to successful L2 listening, especially at the beginner level. Bottom-up processing is vital for building skills such as phonetic perception and word segmentation, without which the overall meaning of the utterance cannot be interpreted. It is important, however, to ensure that beginning L2 learners do not get caught up in a literal translation of the input, focusing solely on processing from the bottom up, as this does not "leave L2 listeners with adequate attentional resources to construct meaning" (Vandergrift, 2007, p. 194). When listeners focus too intently on the individual sounds and words they are hearing, they miss much of what is being said. Top-down processing is thus crucial in expanding the amount of information that is taken in during the listening process. Listeners engaging in top-down processing strategies will, for example, use linguistic clues to aid them in the interpretation of unknown words within the context of the sentence, rather than focusing narrowly on the word itself and losing the thread of the input.

To achieve a better understanding of the relationship between bottom-up and topdown strategies, consider some studies that have been conducted with regard to this question. Goh (2000) and Hasan (2000) conducted studies of listener difficulties, and both discovered problems involving bottom-up processing due to the rate of speech and unclear pronunciation. Goh (2000) conducted her study using Anderson's (1995) threephase framework for language comprehension. She elicited data from $40 \mathrm{~L} 1$ Chinese learners of English using learner diaries, small group interviews, and think-aloud protocol. The students were tasked with analyzing their use of metacognitive strategies in these elicitations, though a good deal of what they reported had to do with the various 
listening difficulties they encountered. These problems were identified, coded in the data, summarized, and tallied.

Of the ten such difficulties encountered, five of them occurred during the perceptual processing stage of Anderson's model. "Problems experienced at the perception stage had mainly to do with recognising sounds as distinct words or groups of words" (Goh, 2000, p. 59). Students also reported missing subsequent information because they spent too much time focusing on the previous words, missing the beginning of texts, not recognizing words they know, and having problems with concentration. When they were divided into low and high proficiency groups, it became apparent that the low proficiency students had greater difficulty with word segmentation skills.

While students in both proficiency levels reported getting stuck on problematic parts of the input, Goh reports that high proficiency students were able to use directed attention to get back on track while low proficiency students did not use these strategies. Goh's suggestion for remedying these listening comprehension problems was to instruct students not to rely solely on bottom-up processing and to encourage them to accept some ambiguity by concentrating on understanding the overall meaning through top-down processing. In addition, she recommended the use of cognitive, metacognitive, and social-affective strategies to aid students in managing the problems they encounter during listening.

Despite reporting some of the same learner difficulties in his 2000 study, Hasan arrived at a different conclusion than Goh (2000) regarding how to resolve these problems. Hasan's (2000) study involved 81 native speakers of Arabic enrolled in an intensive three-month English course, about halfway through which the experiment was 
performed. The study was designed to explore whether students' difficulty in listening comprehension was based on their use of ineffective listening strategies or other factors such as ineffective tasks or problems with the speaker. The participants completed a questionnaire containing 34 questions using a five-point Likert scale, followed by two open-ended questions asking them to list factors that aid them in listening and factors that make listening difficult.

In the main body of the questionnaire, results indicated that students engaged in the appropriate top-down strategies of activating schemata prior to listening (29.6\% Often and $45.6 \%$ Always) and application of background knowledge (40.7\% Often and 33.4\% Always). However, they also engaged to a considerable extent in bottom-up strategies like listening for every detail (32\% Sometimes, $18.5 \%$ Often, and 8.9\% Always) (Hasan, 2000, p. 141). Additionally, when asked to elaborate on factors that either aided or hindered listening comprehension, participants focused on the presence or absence of familiar vocabulary as well as the desire to read the text before listening to it. These factors indicate a reliance on bottom-up strategies that may be preventing students from focusing on the gist of the message.

Whereas Goh (2000) responded to learner difficulties stemming from overuse of bottom-up strategies by endorsing the use of both types of information processing in L2 listening instruction, Hasan (2000) concluded that instructors should focus exclusively on top-down processing. Hasan (2000) suggests that instructors encourage their students to "pay attention to the overall message rather than listen to every single word in order to come to a better understanding of the text" (p. 150). He goes on to suggest that even in cases of unfamiliar vocabulary or grammatical structures, students should be advised to 
use inductive reasoning to interpret the intended meaning. While this may be an effective strategy for higher proficiency learners who have already developed phonological perception routines and moderate lexical knowledge of the target language, lower level learners need to be instructed in the phonetic and phonological features of the language until such skills are sufficiently developed.

Empirical research into specific types of top-down processing has indicated that it is indeed an effective tool in language learning. This research has been undertaken in studies on metacognitive awareness, metacognitive strategy use, and metacognitive instruction (Goh, 2002; O’Malley \& Chamot, 1990; Vandergrift, 2003; Vandergrift \& Tafaghodtari, 2010; Vogely, 1995; Zhang \& Goh, 2006). These strategies have been met with positive reactions from students, and the studies have produced results which suggest that metacognitive instruction is indeed an effective technique for improving listening comprehension. While I will address the majority of these studies in the section on metacognition below, it will be helpful to discuss one such study here as an example of empirical research on top-down processing.

Vogely (1995) performed a study in order to evaluate the relationship between perceived strategy use and listening comprehension. The university-level participants $(N$ = 83) came from first-, second-, third-, and fourth-semester Spanish courses. Because of small class sizes, the third- and fourth-semester groups were combined. Participants completed the listening comprehension section of the Spanish placement exam on the first day of the study. On the second day they performed recall tasks for three authentic video programs and completed the Metacognitive Awareness Strategy Questionnaire 
(MASQ), which was created by Carrell (1989) to assess reading and was modified by Vogely for listening.

Results indicated that the first-semester students perceived themselves as the most strategic listeners, followed by the combined third- and fourth-semester group, and finally the second-semester students. Scores on tasks 1 and 3 revealed significant differences between the combined third- and fourth-semester group and each of the other two groups $(p<.01)$, but no significant difference between the first- and second-semester groups. In her discussion of the results of the modified MASQ, Vogely (1995) noted that while most participants acknowledged the importance of using top-down strategies such as understanding the gist, a significant number did not report using this strategy (p. 52). In addition, students tended to rate top-down processing strategies as the most important in comprehending a text, while they considered bottom-up processing more effective as a repair strategy.

These studies by Goh (2000), Hasan (2000), Vogely (1995) and others (Liu, 2008; Osada, 2001) have important implications for listening instruction. Conducting more qualitative research into the types of problems encountered by L2 listeners makes it possible to pinpoint the perceptual processes that disrupt listening comprehension at different levels of instruction. By identifying the strategies learners perceive themselves to be using, researchers can develop ways to compare this information with quantitative results of listening comprehension tests to investigate the efficacy of those strategies.

Research indicates that top-down listening strategies are more effective in comprehending aural input than are bottom-up strategies, which tend to cause listeners to get caught up in trouble spots, thereby missing important input which follows 
immediately thereafter. As Goh (2000) stressed, however, it is important to exercise caution in applying only one type of strategy to the listening process. As was proposed by both Flege (1995) and Kuhl (2000), problems in phonetic perception can arise from L2 phonetic segments being processed as belonging to L1 phonetic categories. It is still important, then, to instruct learners in the perception of individual L2 speech sounds in order to strengthen their ability to recognize these in the speech stream. While listening for overall comprehension, this knowledge of the L2 phonetic system can only aid students in improving their listening performance. While L2 speech sounds may at first require conscious effort to recognize and interpret, with sufficient listening practice it may be possible to achieve automatic processing of these operations, leaving the learner with more attentional resources at their disposal to interpret the meaning of the utterance.

Automatic vs. controlled processing. Listening consists of both automatic and controlled processing. Processes which are automatic do not require the listener's conscious attention and do not interfere with other cognitive processes such as thinking and planning. Controlled processes, on the other hand, are performed through conscious effort on the part of the listener and require effort and attentional resources. To provide an example from listening, once a listener has reached a certain level of proficiency, much of the process of listening can become automatic. The listener can hold a conversation while performing another cognitive task, such as taking notes, and can think about how she will respond even while she continues to receive aural input. When a listener encounters unfamiliar lexical items in the input, however, controlled processing 
takes over to search for contextual clues or background knowledge that will aid in the interpretation of the new word(s).

In her model of automatic selective perception (ASP), Strange (2011) refers to phonetic perception that has become automatic as a 'selective perception routine' ( $\mathrm{p}$. 456). These selective perception routines (SPRs) represent procedural knowledge of phonological sequences; in other words, they are the automatic comprehension processes that develop with repeated exposure to certain combinations of phonological segments in the language. These sequences are processed and decoded at such a fast rate that they are treated as chunks of meaningful language, rather than individual units of meaning. An additional feature of automatic processes, such as these selective perception routines, is their robustness. A given speaker will pronounce the same phoneme in a slightly different way every time she produces it, depending on a myriad of factors, including the influence of adjacent sounds, whether she is eating or drinking while speaking, and what sentiment she is trying to convey. Despite this inherent variability in a speaker's production, the use of SPRs will almost always result in seemingly effortless comprehension on the part of the listener.

In the ASP model, selective perception routines are employed while listening in the phonological mode, as distinct from the phonetic mode. Strange uses the terms phonological and phonetic modes of processing to describe automatic and controlled processes, respectively. The phonological mode is activated, for instance, when an L1 listener processes a continuous utterance from a person who uses the same dialect as they do. In this case, because the L1 listener uses SPRs to process the majority of the phonetic input, she need only concentrate on "...sufficient [emphasis mine] phonologically 
relevant contrastive information for word-form identification" (Strange, 2011, p. 460). This results in the automatic processing typical of L1 listeners which allows them to concentrate on the meaning of the input rather than its phonetic properties and to do so even in suboptimal conditions. The phonetic mode, on the other hand, is used when the listener must interpret allophonic variation, as when the interlocutor comes from a different dialect community or has a nonnative accent. Strange (2011) hypothesizes that this mode is activated by L2 listeners for phonetic sequences which are not present in the L1 or which are produced differently in the L1 and L2. The phonetic mode is activated in these instances because L2 listeners have not yet developed enough L2 SPRs to operate in the phonological mode in the target language.

Despite devising the binary terms phonological mode and phonetic mode to describe what are generally referred to as automatic and controlled processes, Strange (2011) acknowledges an important caveat to this terminology: the cognitive processes that guide perception, or comprehension, are not dichotomous. Rather, they lie on a continuum of perception that can be affected by many variables. In order to clarify this hypothesis, Strange (2011) poses a question regarding whether one can design an empirical study to distinguish degrees of automaticity in L1 phonological processing by using distorted versions of previously mastered L1 contrasts. If one can succeed in interrupting the automatic processing of a native speaker's listening comprehension process, this would be a strong indicator that automaticity is not a permanent feature of information processing, supporting the notion of automatic and controlled processes as a continuum of effort. 
By directly addressing speech perception as "lying along a continuum of effort" (p. 461), Strange (2011) provides a framework within which it may be possible to distinguish relative levels of automatic and conscious processing, i.e. where they lie along the continuum, as well as to identify factors that have the potential to affect this processing. This has important implications in language teaching and learning, since determining a learner's approximate stage of development in terms of automatic processing is an essential step in developing a plan to enhance that development. According to Strange's ASP model, learning is conceptualized as the formation of selective perception routines in the L2. Formation of these routines can be helped along by extra practice in structured listening activities. This is further supported by Strange's (2011) observation that in other studies as well as her own, length of stay in the target language country did not correlate significantly with vowel perception performance, indicating that mere immersion does not sufficiently account for the development of L2 SPRs.

These last two observations are relevant to the present study because of their implications for listening comprehension instruction. The fact that immersion is not sufficient to develop selective perception routines in the L2 lends support to the hypothesis that instruction in metacognitive strategies can improve listening comprehension by aiding learners in developing the procedural routines necessary to automatize listening processes. Conceiving of learning as the development of selective perception routines means that any instructional techniques which provide input and practice in developing these routines should enhance the learning process. While the concept of the automatic selective perception model has so far been tested only in the 
case of vowel contrasts, it is clear through the wording of the model and its constructs that it can be used to measure and evaluate global listening comprehension performance as well.

Having discussed some of the cognitive processes that are involved in listening, as well as the concept of automatic and controlled processing, I turn now to a discussion of those elements which are necessary in order to define the construct of listening for the present study. This begins with a very brief outline of the way in which listening has been approached and defined over time by applied linguists, followed by a discussion of the differences between L1 and L2 listening. Because L1 and L2 acquisition can occur at different times in our lives, for different purposes, and in different environments, the cognitive processes involved in L2 listening are expected to vary in quality and quantity as well. Finally, the entirety of these factors is considered in order to provide an operationalization of the construct of listening for the present study. It is this definition that will inform the instructional and listening tasks of the study as well as providing a basis for assessing listening performance.

\section{Defining Listening}

A brief history of second language listening. While both theoretical and classroom researchers have been involved in the study of listening comprehension for many years (Froehlich, 1988; Krashen \& Terrell, 1983; Meccarty, 2001; Rubin, 1994), their understanding of the process of listening has changed considerably in that time. 
Some of the issues that have been explored include whether listening is a passive or an active skill, whether it involves top-down or bottom-up processing, whether or not it is influenced by the L1, how it can best be measured, and which instructional methods are most effective in helping learners to develop it as a competence. While for many years listening was considered a passive process or indeed ignored altogether, applied linguists have gradually come to the realization that listening is in fact active. That the processing and comprehending of aural input requires a great deal of attentional resources on the part of the learner has been supported by research on attention, noticing, input versus intake, and enhanced input (Corder, 1967; Gass \& Selinker, 1994; Jensen \& Vinther, 2003; Robinson, 1995; Schmidt, 1995). This shift in perspective regarding listening mirrors that of the language process as a whole. As cognitive processing has gained theoretical ground in linguistics, the respective complexity of the four skills that make up language proficiency has increased along with it, and more attention has been paid to the development of each of these skills. Listening has continued to lag behind the other skills in this regard, however, perhaps because of the difficulty inherent in understanding the mental processes that comprise it.

As Brown (2011) asserted, second language listening is a skill to be developed. It is an active process that requires effort on the part of the learner. The effort that must be invested and the cognitive operations that must be practiced repeatedly in learning to listen in a L2 make up a complex cognitive process. While some parts of the process may become automatic, the performance of this process is conscious and active. A listener must constantly monitor the incoming aural input and determine whether or not she is comprehending it as the speaker intended. In order to better understand the 
complexity of L2 listening and its relation to instruction, I now turn to a discussion of the issues inherent in learning a second language as compared to first language (L1) acquisition.

L1 vs. L2 listening. There are several factors that impact the way language is acquired by a child L1 learner versus an adult L2 learner. Some examples of these factors are differences in the initial state of language acquisition, differences in the amount of input received, and social/affective factors such as situational context and issues of identity. One of the most extensively studied of these factors is the initial state of the learner, which refers to the fact that whereas children begin the L1 acquisition process as blank slates (with or without an innate language acquisition device, depending upon one's theoretical orientation) and develop their language abilities from the ground up, adults have the advantage (and the disadvantage) of beginning L2 acquisition with a fully developed linguistic system in place, providing them with linguistic knowledge and experiences to draw upon as they begin the L2 acquisition process. Three consequences of the difference in initial states can be identified: almost all children completely acquire their native language while adult L2 learners generally do not achieve this level of proficiency in their second language; adult learners experience transfer, both positive and negative, from their L1 as they attempt to acquire an L2; and adults are able to draw upon general cognitive abilities to aid them in understanding the target language.

These differences have significant implications for the ultimate attainment of listening comprehension skills in an L2. As Flege (1999) and Kuhl (2000) have both stated, phonetic perception in an L2 is greatly influenced by the existing speech sounds of 
one's native language. Flege (1995) believes it is still possible for adults to attain nativelike perceptual processes, especially for L2 phonetic segments that differ considerably from L1 sounds, while Kuhl (2000) takes a less optimistic view regarding this interference in perception.

These theoretical arguments regarding L2 phonetic perception are critical to a discussion of L2 learners' potential to become highly proficient listeners in the target language. According to these theories, children, who learn their native language from birth (in fact, scholars say, even before birth), are at a distinct advantage from a phonological perspective, since they create novel categories for every sound they hear. Adult L2 learners, on the other hand, must struggle to perceive L2 speech sounds through a pre-established filter of L1 sounds (Kuhl, 2000, p. 11854). Based on this difficulty in perception, adult L2 learners are expected to have more difficulty and take longer to develop listening comprehension skills, because "the later L2 learning begins, the less likely L2 learners are to establish new categories for vowels in the L2" (Flege, Mackay, \& Meador, 1999, p. 2974). This is based on the premise that as people mature, the L1 phonetic categories they have established only get stronger, resulting in higher levels of L1 interference in the mapping of L2 speech sounds. Another result of L1 interference in phonological perception is that learners will tend to become more absorbed in bottom-up processing while listening, because they encounter a larger proportion of unknown sounds. When this happens, comprehension can break down as learners focus on the unfamiliar segments and miss subsequent input. Finally, learners will develop fewer selective perception routines in the $\mathrm{L} 2$ than they possess in the $\mathrm{L} 1$, because fewer phonological sequences come to be performed through automatic processing. 
Whereas the vast majority of $\mathrm{L} 1$ speakers reach a level of near-complete automaticity in listening comprehension with very little controlled processing necessary, L2 listeners rely much more on controlled processing while they build up enough contact with the target language to develop automaticity. Only small amounts of input are able to be processed automatically in these beginning stages. Consequently, “.... large proportion of what they hear may be lost, given the speed of speech and the inability of working memory to process all the information within the time limitations" (Vandergrift, 2007, p. 193). It is only through repeated exposure to the spoken language that L2 learners can become sufficiently accustomed to the syntactic structure as well as the phonological features and lexical inventory of the L2 to process it automatically. In the meantime, they must rely upon inferential processes in order to guess the meaning of input they do not understand. This is where adults experience an advantage, because they are able to apply their general cognitive abilities to the task of listening, engaging in the top-down strategies that are so important to understanding the overall meaning of input. The speed and efficiency with which automatic processing subsequently develops is dependent upon the individual's working memory capacity, the context of language acquisition, and degree of exposure to the language.

The amount of input received by learners is another important difference in L1 versus L2 acquisition. In an L1 situation, children are exposed to language input for "many hours of passive listening before they seriously need to attend to the messages they hear" (Richards, 2005, p. 27). Babies typically do not begin to babble until between four and six months of age, and they produce words in their L1 at about one year old. This means that they spend a great deal of time listening to the sounds around them and 
beginning to make connections to their meanings. In contrast, adult L2 learners in both classroom and natural environments are expected to start producing language from the very beginning of the acquisition process. Consequently, they do not benefit from the same extensive listening practice that L1 speakers of the target language receive before beginning to speak. While unfortunate, it is logical that this might be the case. After all, adult L2 learners are usually studying the language to achieve a particular goal, whether that is to pass a university language course or to develop language proficiency in order to work in another country. In either case, since the ultimate goal of much adult language learning is communicative proficiency in the target language, most people do not have the time to spend several months simply listening.

This last example represents the social and affective factors that influence L2 acquisition. Adults and children learn language in very different environments. Children are surrounded by input from parents, family, neighbors, friends, and teachers for many years with very little responsibility other than the acquisition of their native language. In terms of motivation, language is essential to children in order to make contact with the world around them, and as they get older, to develop friendships. The motivation and environment of adult L2 learners is markedly different, especially in a foreign language context. This situational context plays an important role in second language acquisition and must therefore be acknowledged. Context is frequently addressed in the literature by making a distinction between second and foreign language contexts (Richards \& Schmidt, 2002). A foreign language context is one that exists outside of the target language environment. Foreign language learning can take place in a classroom or in a home where a language other than the majority L1 is spoken. 
A foreign language classroom instructor may or may not be a native speaker of the target language. Second language learning, on the other hand, refers to language acquisition that occurs while one is living in the target language setting. This may occur entirely via the natural environment of daily interaction solely in the L2, such as in the workplace, or it may involve a combination of natural and instructed settings. The important feature in a second language context is that the L2 represents the majority language of the area. This contextual distinction is important because it involves variations in the amount of contact time with the target language, the quality of language to which learners are exposed, frequency of opportunities for practice, and the application of implicit versus explicit learning strategies, and motivation, among other factors.

Many adults, e.g. college students, learn their L2 in a foreign language context. They are surrounded by other L1 speakers and have many responsibilities in their lives aside from learning a second language. In addition, their motivations can be very different from those of children. Rather than learning language as an indispensable tool for communicating with those around them, adults may be taking a mandatory university course to fulfill a requirement or developing language proficiency to benefit their career trajectory. Finally, identity plays a major role in the discrepancy in language acquisition success between adults and children. Adults already have a fully developed L1 identity and may have varied and complicated feelings about how this will be affected by learning an L2.

Due to the difference in initial states between L1 and L2 learners, the individualized development of automatic versus controlled processing, amount of contact with the language, and social and affective factors, it is difficult to predict with any 
certainty whether a given adult will be successful in acquiring a second language. A question that has thus arisen regarding how L2 skills are acquired is whether they develop as a function of increasing proficiency in the L2 or whether they are transferred from the L1 and applied to the novel linguistic input.

In his 2006 paper, Vandergrift explored the relative contributions of L1 listening comprehension ability and overall L2 proficiency to the development of L2 listening comprehension ability. In so doing, he was testing two existing hypotheses from SLA reading research: the linguistic threshold hypothesis (Cummins, 1976) and the linguistic interdependence hypothesis (Cummins, 1979). The linguistic threshold hypothesis (LTH) posits that learners must achieve a certain level of overall proficiency in the L2 before they are able to develop reading (and in this case, listening) abilities. According to the LTH, L2 proficiency is the key factor in developing these specific skills. The linguistic interdependence hypothesis ( $\mathrm{LIH})$, on the other hand, states that one's L1 reading proficiency serves as the crucial element in developing L2 reading proficiency. In other words, learners transfer the existing L1 skill to a new linguistic context when learning the L2.

In order to determine which of these hypotheses better represents what occurs in L2 listening acquisition, Vandergrift (2006) developed a study involving 75 students from Grade 8. They were considered either high proficiency or low proficiency based on previous immersion experience or interaction with a French-speaking parent, and were tested on their English and French listening comprehension abilities. The data was submitted to a multiple regression analysis, and the results showed that both L1 listening and L2 proficiency were significant $(p=.0001)$. While L1 listening and L2 proficiency 
together accounted for 39\% of the variance in L2 listening, L2 proficiency was the stronger of the two factors, accounting for $25 \%$ of the variance on its own. When the questions were broken down according to type, L2 proficiency was the stronger indicator of L2 listening for literal questions, and it was the only indicator for questions that required listeners to make inferences. These results demonstrate a slight edge for L2 proficiency in determining L2 listening skills.

Vandergrift's (2006) study represents a first step in applying the linguistic threshold hypothesis and the linguistic interdependence hypothesis to L2 listening where they had previously been applied only to reading. While the results do not allow for a conclusive decision as to which hypothesis better explains L2 listening acquisition, they do seem to give a preliminary indication that L2 proficiency has a stronger influence on L2 listening than do L1 listening abilities. This advantage could not, however, be explored in a meaningful way, according to Vandergrift (2006, p. 14), because there was no continuous variable with which to evaluate L2 listening proficiency. Rather, students were placed in the low or high group based on a dichotomous variable: whether or not they had participated in an immersion program or lived with a French-speaking parent.

The value of Vandergrift's study lies in both its contribution to the literature on L2 listening and its potential application to the development of L2 instructional and testing materials. Concerning L2 listening research, scholars have asserted that although a moderate amount of research has been conducted in L2 listening, it still remains one of the least studied skills (Mendelsohn, 1994, 1998; Richards, 2005; Vandergrift, 1997). By applying hypotheses from other areas to the skill of listening, this type of study takes a small step toward a more unified theory of second language acquisition. It also provides 
an insight into to how listening occurs, taking us beyond the product of comprehension and into the process. Finally, the results of this type of study can have important implications in the development of teaching and testing materials, because when researchers, textbook authors, and test writers better understand how L2 listening skills develop, they will be able to apply this knowledge in a practical way in their materials.

Operationalization of listening for the present study. Having analyzed the historical treatment of listening in the applied linguistics and SLA literature, as well as its distinction from L1 acquisition and the various cognitive procedures involved in listening comprehension, the next critical step is to operationalize the term listening as it will be used in the present study. This operationalization has been informed by the research presented above and by the goals of the investigation at hand in order to provide a sound theoretical basis on which to build the empirical study.

Given the many cognitive operations that come into play in the process of L2 listening, from the phonemic level to the discourse level, it is possible to approach listening research from a micro or macro perspective. For instance, researchers in phonology are working with listening comprehension from a micro perspective when they focus their research at the phonemic level by studying perception of target language vowel contrasts. Researchers working at the phonological/morphological level of listening broaden this view as they investigate phonological segmentation and perception of word boundaries. Scholars in discourse analysis employ a macro perspective to investigate areas of learner difficulty in listening comprehension at the discourse level and to examine the ways in which interlocutors indicate listening comprehension failure 
to one another. The focus of the present study is on a global understanding of the input, i.e. understanding the gist, which falls somewhere between these extremes.

I have chosen to focus on learners' ability to comprehend the basic meaning of the text as evidenced by their responses to questions requiring both general and specific information directly from the input. This input comes in the form of one- to two-minute multiple-speaker texts rather than from instances of discrete phonetic segments or interactive discourse. In other words, I am focusing somewhat between the micro and macro levels of listening comprehension. Listening is operationalized for the present study as the ability to process auditory input and to subsequently employ a combination of bottom-up and top-down processes to arrive at an understanding of the intended message. This is in harmony with the definition of listening O'Malley et al. (1989) elaborated: an active process in which individuals focus on selected aspects of aural input, construct meaning from passages, and relate what they hear to existing knowledge. Proof of successful listening comprehension will be assessed by participants' responses to multiple choice questions concerning various aspects of the input. Having defined the construct of listening for the present study, I now turn to a brief discussion on how to measure this construct.

\section{Measurement and Evaluation of Listening}

A complicated consideration in choosing the methods to be used in measuring listening performance is whether the test items elicit responses that correspond to the product or the process of the construct. An analysis of existing listening studies reveals that the assessment of listening comprehension has been achieved for the most part by 
evaluating the product of listening, rather than the process used to achieve comprehension (Goh, 2002). This product takes the form of learner responses to inquiries about the listening passage. In these questions learners are required to extract key information from the input to prove that comprehension has occurred. Researchers are evaluating the product of comprehension when they choose test items that involve multiple choice questions, short-answer questions, cloze or gap-filling exercises, and information transfer tasks, among others. In each of these cases, the researcher is only able to see the end result of listening rather than the process of perception, segmentation, decoding, and contextual analysis that led the learner to a particular answer. Scholars can make an argument against certain of these item types since learners may be able to correctly answer them using skills other than listening, such as logic or strategic guesses. This is the case with multiple choice questions for which learners may be able to eliminate options based on logic and subsequently choose the correct answer by chance. Another example can be found in short-answer questions or fill-in-the-blanks, where the learner may be able to guess the logical answer based on contextual cues from the sentence itself. Instances like these decrease or eliminate the construct validity of the test, since it is not able to reliably test the skill it was designed to test.

The 'process' of listening, while potentially richer as a source of insight into learners' level of comprehension, is more difficult to measure given the nature of the internal processes that comprise it. The process of listening involves complex psychological and cognitive operations that cannot be empirically studied and in all likelihood cannot be disentangled. Researchers have attempted to investigate these processes through qualitative methods such as questionnaires, think-aloud protocols, 
diaries, and interviews (Goh, 1997, 2000; Goh \& Taib, 2006; Vandergrift, 2002; Zhang \& Goh, 2006). These methods are indirect, however, and rely upon the testimony of the listeners involved, who may or may not be aware of the cognitive and metacognitive processes they use to achieve comprehension. From a practical standpoint these methods are also more time-consuming and labor-intensive than most process-based, quantitative methods and are difficult to code reliably.

Although knowledge of the processes that take place during listening is essential to our understanding of the overall competence, evaluation of the product is more feasible at present. Despite the fact that evaluations of the product of listening lack insight into the mental processes involved in listening, it can still be possible to conduct an appropriate listening evaluation based on the product of listening. As long as the researcher is aware of the possible pitfalls and takes steps to ensure the construct validity of the instrument, a product-based assessment can be a valid and reliable tool. Until such time as methods are invented to peer into the processes of listening, it will have to suffice.

Having examined the history of listening in SLA and classroom instruction and having operationalized the construct of listening for the present study, I now focus on the aspects of listening instruction that were applied in the present study. Metacognition is a strategic skill that is used by high proficiency learners (Goh, 2008) to manage learning, and it may be applied consciously or unconsciously. It is discussed here with regard to its potential to aid learners in developing automaticity in listening comprehension through explicit training of the cognitive processes that manage input and development of selective perceptual routines. The goal of the experimental treatment was to investigate 
instruction in metacognitive strategy use as a way to develop and automatize listening skills, which was assessed through a pretest-posttest design. Online audiovisual media resources were chosen as an effective tool for delivering this metacognitive instruction due to their similarity to real-life communication, their use of differing degrees of L2 speech authenticity, and the efficacy of adding a visual component to aural training.

\section{Metacognitive Listening Instruction}

The goal in conducting such an extensive investigation into the nature of listening and its cognitive components is to be able to take the knowledge gained from that investigation and apply it in a practical way to the instruction of L2 listening in a foreign language classroom context. By developing an understanding of the intricacies of listening as a cognitive process in this manner, it is possible to then propose effective instructional choices that are motivated by a theoretical understanding of listening and how it is developed and improved. In this section I propose that explicit, metacognitive instruction can improve listening comprehension by calling learners' attention to the cognitive processes necessary to successfully interpret input. This also leads them to develop automatic perceptual procedures in listening, increasing the amount of input that is processed automatically and freeing up attentional resources to use top-down and bottom-up strategies for consciously processing unfamiliar input. In order to support this hypothesis, I draw from existing research in metacognition, explicit instruction, attention and noticing, memory, and automaticity. 


\section{Metacognition and Listening}

Metacognition was defined by Flavell (1976) as “one’s knowledge concerning one's own cognitive processes and products or anything related to them, e.g. the learningrelevant properties of information or data" (p. 232). In other words, any time we are consciously aware of what we are thinking and processing, or acknowledge that a piece of information will add to our knowledge base, we are participating in metacognition. Flavell also asserted that metacognition "refers, among other things, to active monitoring and consequent regulation and orchestration of these processes in relation to the cognitive objects or data on which they bear..." (p. 232). Metacognition, then, involves not only an awareness of our cognitive processes, but also an active effort to manage those processes in a way that promotes learning. This includes monitoring one's effort and making the necessary adjustments to enhance cognition.

Research investigating the link between metacognition and learning has increased in recent years not only in the field of applied linguistics, but in other fields as well. These include reading (Gourgey, 1998; Margolin \& Hover, 2011), mathematics (Gourgey, 1998; Mevarech \& Amrany, 2008), and nursing (Worrell, 1990). This increased interest in the role that metacognition has to play in the way people learn has culminated in the creation of a relatively new peer-reviewed journal called Metacognition and Learning, which brings together studies on metacognition from a wide variety of research fields and paradigms.

In the inaugural issue of the journal, Veenman, Van Hout-Wolters, and Afflerbach (2006) compiled a list of problems that need to be addressed in the research on metacognition. The problem that is most pertinent to the present discussion of listening 
instruction concerns the lack of a unified definition of metacognition and its components. A multitude of terms have been employed to refer to the metacognitive processes of learning, including, but not limited to, "metacognitive beliefs, metacognitive awareness, metacognitive experiences, metacognitive knowledge...metacognitive skills, executive skills...learning strategies, heuristic strategies, and self-regulation," among others (Veenman et al., 2006). In order to make connections between empirical studies, it will be necessary for researchers to reach a consensus on how to operationalize metacognition for the purposes of research.

For the purposes of the present study four distinct terms will be used. These are metacognition, metacognitive strategies and strategy use, metacognitive instruction, and metacognitive awareness. Metacognition will be operationalized as an umbrella term to include any aspect of the knowledge of one's own cognitive processes, including the ability to identify and evaluate those processes, the ability to pinpoint knowledge that one possesses or does not possess, and the ability to organize and manage one's cognitive processes as they are performed (the "regulation and orchestration" to which Flavell referred). A metacognitive strategy will be operationalized as the conscious application of metacognition to a given situation in order to regulate the cognitive processes involved. For instance, reflection is a metacognitive strategy by which learners evaluate the cognitive processes they applied to a particular listening situation and assess whether that strategy proved successful in order to plan for subsequent listening experiences. Metacognitive instruction is a term borrowed from Goh (2008), used to refer to the process by which an instructor presents and trains L2 learners in the use of several metacognitive strategies. This technique is designed to call learners' attention to the 
process of listening. The experimental treatment period of the present study involved presenting learners with multiple metacognitive strategies to be used together in order to guide the process of listening comprehension. Finally, metacognitive awareness refers to the extent to which students self-report use of metacognitive strategies during listening.

In assessing the importance of metacognition to L2 learning, some scholars have focused on learners' awareness of the metacognitive strategies available to them, subsequently comparing this awareness to their actual use of metacognitive strategies during the listening process (Vogely, 1995; Zhang \& Goh, 2006). The results of these studies have generally indicated that even when learners are aware of metacognitive strategies, "they either do not know when to use them or do not know how to use them" (Vogely, 1995, p. 54). This has been especially true of lower level learners.

Research has indicated, on the other hand, that more highly skilled listeners have in common the ability to apply metacognitive strategies, that they use these strategies in combination rather than in isolation, and that use of metacognitive knowledge accounts for a large amount of the variance in learning performance (Goh, 1998; Murphy, 1985; Vandergrift, 2003; Veenman \& Spans, 2005; Veenman, et al., 2006).

Building upon these results, further studies have incorporated metacognitive strategy use into the instruction of listening and subsequently measured listening comprehension, metacognitive awareness, and attitudes toward language learning (Cross, 2011; Goh \& Taib, 2006; Rahimi \& Katal, 2012; Vandergrift \& Tafaghodtari, 2010). The implementation of this type of study is necessary in establishing the efficacy of metacognition as an aid to listening comprehension development. Since highly proficient L2 learners use metacognitive strategies and all learners believe them to be important for 
learning, it is crucial to incorporate them into an empirical study to test their potential effect on subsequent language skills.

An example of research into metacognitive instruction comes from Vandergrift and Tafaghodtari (2010), who designed a study to examine the effects of using a processbased approach to metacognitive instruction in L2 listening. Over the course of a semester, students $(N=106)$ from six intact sections of French participated in either the control group $(n=47)$ or the experimental group $(n=59)$. Both groups listened to the assigned listening texts the same number of times. The experimental group was instructed using a methodology that included several metacognitive processes, including predicting/planning, monitoring, evaluating, and problem solving, while the instruction in the control group did not include any conscious attention to the process or strategies of listening. In addition, all participants completed the Metacognitive Awareness Listening Questionnaire (MALQ) at the beginning, middle, and end of the semester to demonstrate how metacognitive awareness was affected by the experimental treatment.

The results indicated that the experimental group significantly outperformed the control group on the assessment of listening comprehension at the end of the semester, supporting the researchers' main hypothesis that metacognitive instruction would improve participants' listening skills. A closer look revealed that on the listening comprehension measure the less-skilled listeners in the experimental group outperformed the less-skilled listeners in the control group $(p<.0001)$ as well as making greater gains than the more-skilled listeners in the experimental group $(p<.0001)$. While the moreskilled listeners from the experimental group outperformed the more-skilled listeners from the control group, the difference was not significant $(p=.07)$. A hypothesis 
regarding the MALQ was partially supported: less-skilled listeners in the experimental group were expected to make greater gains in metacognitive awareness as measured by the MALQ, but this only proved true in two of the five factors: problem solving and mental translation.

The results of the Vandergrift and Tafaghodtari (2010) study have implications for using metacognitive instruction techniques in L2 listening instruction. Most importantly, the results provide empirical support for the use of metacognitive instruction in L2 listening. This suggests that incorporating a combination of metacognitive strategies into the listening instruction of a L2 classroom may prove more effective than methods that do not guide learners in focusing their attention on the process of listening. Additionally, since the less-skilled listeners from the experimental group outperformed every other subgroup, this suggests that metacognitive instruction is particularly beneficial for lower-level learners who are still in the early stages of developing their language skills. This is further supported by the fact that although the more-skilled listeners in the experimental group outperformed those in the control group, the difference was not significant, suggesting that more skilled L2 listeners did not benefit quite as much from the metacognitive instruction. Previous research indicates that this is because more skilled listeners are already incorporating metacognitive strategies and therefore did not have as much to learn from the experimental treatment.

Returning to Vogely's (1995) study of perceived strategy use among universitylevel Spanish students mentioned in the earlier section on bottom-up versus top-down processing, it was stated that students considered top-down strategies to be the most important for listening comprehension. However, one of Vogely's conclusions was that 
although learners may possess the ability and awareness to use certain metacognitive strategies, they were not necessarily able to apply those strategies to the listening tasks at hand. This discrepancy between declarative knowledge and procedural knowledge indicates an area of learning that can benefit from explicit instruction in metacognitive strategies to train learners how to listen. Vogely's (1995) results were echoed in a subsequent study by Zhang and Goh (2006).

Zhang and Goh (2006) conducted a study of the relationship between knowledge of strategies and perceived strategy use, this time with a group of Singaporean students $(N=278)$ learning English as a Second Language (ESL) with an average age of 15 years old. Forty listening and speaking strategies were included in the questionnaire, and they were divided into four subgroups: use-focused learning strategies, form-focused learning strategies, comprehension strategies, and communication strategies. Of these, over half of the learners considered 32 strategies useful or very useful, but reported using only 13 of them frequently.

The results of the questionnaire indicated that students believe use-focused learning strategies to be more important than form-focused learning strategies. All ten of the use-focused strategies were viewed as useful by the students, while only five of them were reported as frequently used. Students considered seven out of ten form-focused learning strategies to be useful, and only reported using one of them often. In the category of comprehension strategies, which included both cognitive and metacognitive strategies for listening, despite rating almost all as useful, participants only reported using three of them on a regular basis. These were 'trying to get the overall meaning of the spoken text,' 'paying attention to the details of the spoken text,' and 'concentrating on the 
listening task in spite of difficulty' (p. 212). This indicates a reliance on the most basic of the top-down as well as the bottom-up strategies, with no use of the more nuanced strategies in between. As Zhang and Goh point out, "though showing awareness of the usefulness of prior knowledge or schemata related strategies for facilitating comprehension, the students did not indicate using them often" (p. 212).

Zhang and Goh's (2006) results serve to reinforce previous research indicating that awareness of metacognitive strategies does not necessarily translate into use of those strategies. While attempts to explain this lack of application of strategy use can only be speculative, studies such as those by Vandergrift and Tafaghodtari (2010) and the present investigation can demonstrate the power of metacognitive instruction to narrow the gap between metacognitive awareness and application of metacognitive strategies. Repeated use of these strategies through guided metacognitive listening instruction can give students the confidence to use them more often in communicative contexts and can aid in the automatization of the perceptual and cognitive processes involved.

Rather than performing an empirical study, Goh (2008) provides a synthesis of research into the metacognitive approach from the fields of both education and second language acquisition in order to provide a theoretical foundation for the use of metacognitive instruction in L2 listening. She proposes the use of the term 'metacognitive instruction,' which incorporates Flavell's (1979) original concept of metacognitive knowledge and the concept of metacognitive strategies, and which can be situated within the broader framework of Bruer's (1998) model of the cognitive and social processes that make up learning. Goh created her metacognitive instruction techniques with the goal of satisfying Veenman et al.'s (2006) principles for 
metacognitive activities: embedding it into the subject matter, informing students of its usefulness, and providing prolonged training to ensure that learners continue to employ metacognitive strategies in the classroom and beyond. These principles are meant to maximize the efficacy of metacognitive instruction in the classroom as well as ensure that learners will continue to develop their metacognitive skills in other communicative contexts.

Goh's (2008) metacognitive instruction methodology requires the use of ‘integrated experiential listening tasks' (p. 199) and 'guided reflections on listening' (p. 200). An integrated experiential listening task involves the integration of metacognitive materials into the everyday textbook listening activities the students complete, requiring them to seek information and construct meaning. The main advantage of the integrated experiential listening task is to guide the student in becoming aware of the processes they use in listening so they may apply these processes outside of the classroom. Guided reflections on listening allow students to contemplate the listening strategies they are currently using, determine whether they are effective, and plan ahead for how they will listen in the future. The implementation of these activities into the regular L2 listening curriculum is predicted to increase the use of metacognitive listening strategies, thereby increasing listening comprehension performance.

By constructing her definition of metacognitive instruction according to theoretical principles and previous research, Goh (2008) has provided a framework for successful implementation of metacognitive instruction in listening that can be used in empirical studies to test its efficacy. In addition, she has furnished a detailed and clear operationalization of the construct of metacognitive instruction, thereby satisfying one of 
the problems identified by Veenman et al. (2006) in their discussion of metacognition and its diverse terminology.

What is clear through the empirical studies mentioned above is that while students recognize the importance of metacognitive processes to regulate their learning, they are in need of guided instruction in the use of these strategies. This is especially true of listeners in the beginning levels of language learning. Metacognitive instruction has the potential to provide the necessary cognitive scaffolding for L2 learners as they develop language proficiency and also helps them to increase their use of metacognitive strategies. While a good deal of research has been done on the relationship between metacognition and L2 reading, the relationship between metacognition and L2 listening is less well understood. More studies are needed to establish a connection between metacognitive instruction and improved performance on subsequent listening comprehension measures.

Veenman et al. (2006) and Goh (2008) have provided a theoretical framework for the use of metacognition in learning by identifying issues of operationalization that must be resolved and by suggesting a structure for the creation of metacognitive instructional techniques, respectively. Several additional theoretical perspectives underlie metacognitive strategy use and serve to justify the use of process-based metacognitive instruction in the L2 classroom. I will first address the benefits of employing explicit instruction, especially in the acquisition of skills such as listening. I will then discuss how metacognition is related to issues of attention, memory, and noticing in listening tasks. Finally, I will explain how these attentional factors contribute to the automatization of listening processes through the medium of metacognitive instruction. 


\section{Explicit Instruction}

The context of L2 acquisition is a factor that can have an important impact on the ultimate attainment of the target language. For example, the setting of the present study was a postsecondary foreign language French classroom in the United States. This context has distinct advantages and disadvantages, and certain instructional methods are therefore better suited to it. One of the most important characteristics of instructional settings is that they afford learners the opportunity to benefit from explicit instruction in the more difficult aspects of the language.

The advantages of explicit instruction have been demonstrated in studies on error correction (Ellis, Loewen \& Erlam, 2009), L2 grammar (de Graaff, 1997; Robinson, 1997), pronunciation (Sturm, 2013), oral production (Tavakoli, Dastjerdi, \& Esteki, 2011), L2 writing (Abbuhl, 2012), and pragmatic competence (Ifatidou \& Matsui, 2013). Explicit instruction is beneficial because it serves to call learners' attention to features of the input that do not currently belong to their linguistic repertoire. In the case of listening, explicit instruction can help listeners to focus on and correctly perceive phonological sequences that may have previously seemed indecipherable. Explicit instruction in listening strategy use can also give students the ability to consciously apply the top-down or bottom-up processing strategies that they deem important but have had difficulty utilizing.

The effectiveness of explicit versus implicit instruction is a controversial topic in SLA research, with strong opinions both for and against the method. Those who reject explicit instruction argue that the rules of a language are best learned through use. It is thus through communicative exercises that model and necessitate a given structure that 
learners internalize the rules of the language, enabling them to incorporate these into their linguistic repertoire for future use. This is an important debate and one that contributes to meaningful language instruction; however, it is important to note that this argument is most often applied to the acquisition of grammar in the L2. What is under consideration in the present paper is the application of explicit instruction to the acquisition of L2 listening; that is to say, a linguistic skill rather than a particular rule or form in the target language.

That being said, in discussing explicit L2 instruction it is crucial to heed two warnings, given by R. Ellis (2009) and MacWhinney (1997). Ellis calls attention to the importance of establishing a distinction between implicit or explicit knowledge and implicit or explicit instruction. The difference between implicit and explicit knowledge refers to what one knows implicitly but cannot say versus what one knows and is able to articulate. Implicit versus explicit instruction, on the other hand, refers to whether an instructor presents the material and allows the students to process it in their own way or whether the instructor calls attention to the linguistic point in question, sometimes providing a direct explanation of the point. Similarly, MacWhinney proposes that there should be a clear distinction between explicit instruction and explicit learning. This distinction is similar to Corder's (1967) concept of input versus intake in that although explicit instruction is provided by the instructor and heard by the student (input), it can only be considered explicit learning if the student is successful in understanding and internalizing the lesson contained therein (intake).

The three constructs of explicit instruction, explicit learning, and explicit knowledge are closely interrelated, but do not necessarily always occur in tandem as they 
should. In an ideal situation, an instructor provides explicit instruction to a learner, who through intake and comprehension of that instruction engages in explicit learning, leading to the development of explicit knowledge. However, as MacWhinney (1997) points out, this chain of events is not a foregone conclusion. It is entirely possible that the instructor may provide an explicit explanation of the material that is overly complicated, poorly articulated, and incomprehensible to the learner, in which case explicit learning does not occur and the learner does not gain explicit knowledge. Explicit instruction, then, must be buoyed by additional theoretical support and practical application beyond the mere fact of being explicit.

Assuming that explicit listening instruction can be appropriately prepared and delivered, its use is beneficial for listening comprehension development in part because it enables the instructor to call learners' attention to aspects of the input they may have misinterpreted or failed to notice. For example, in a language pair where the prosody of the target language differs considerably from that of the learner's native language, the learner may attempt to identify word or sentence boundaries based on the prosodic cues of her native language, resulting in a breakdown in comprehension. The L1 English/L2 French language pair is a prime example of the importance of prosodic elements. While in English lexical stress is variable and frequently affects the meaning of words, French does not have lexical stress. Rather than placing stress on syllables, prosodic stress in French is placed on the final syllable of a phrase or sentence. This contrast, in combination with the processes of liaison, elision, and enchaînement that occur in French, can make it very difficult for L1 English learners of French to identify the word boundaries in an utterance. Through explicit instruction in metacognitive listening 
strategies, such as predicting and evaluating, learners can hone the cognitive processes of listening through repetition and learn to recognize phonological sequences and prosodic features in the target language. This requires the learner to attend to the process of listening, which is supported in the literature on attention, noticing, and consciousness.

\section{Attention, Noticing, and Memory}

An important theoretical discussion in second language acquisition is the relative significance of conscious versus unconscious attention. Krashen (1981) proposed a distinction between acquisition and learning, asserting that acquisition happens unconsciously while learning is a conscious process. He further contended that anything that is learned consciously can never become unconscious knowledge. In other words, this knowledge can only be used to monitor output and will not be used spontaneously in oral production. Since then, however, the importance of consciousness and attention in L2 acquisition has been studied extensively, starting with Schmidt's (1990) noticing hypothesis, which claims that in fact L2 acquisition is largely a conscious process and requires learners to notice features of the input. Scholars in attention and noticing contend that input must be noticed in order to be transformed into intake and thus incorporated into the language system. This concept has since been extended to include not only noticing of features of the input, but "noticing the gap" (Schmidt \& Frota, 1986) in one's own linguistic knowledge as well.

According to Robinson (1995), attention, awareness, and noticing must be understood within a framework of memory, since memory systems underlie information processing which in turn relies on attention. In Robinson's view of attention, noticing 
must be defined more precisely as the combination of detection (which may occur with or without awareness) plus rehearsal in the short-term memory: "Noticing is a consequence of encoding in the short-term memory, and is necessary for learning" (p. 298).

Information is then encoded in the long-term memory through a combination of this rehearsal plus elaboration of the concept, known as conceptually driven processing. Ellis (1997) clarified this notion by creating a model of the learning of implicit knowledge (p.

119). This model provides a visual representation of Robinson's assertion by showing the operations that are at work in the developing interlanguage system from input to output, including the role of memory systems.

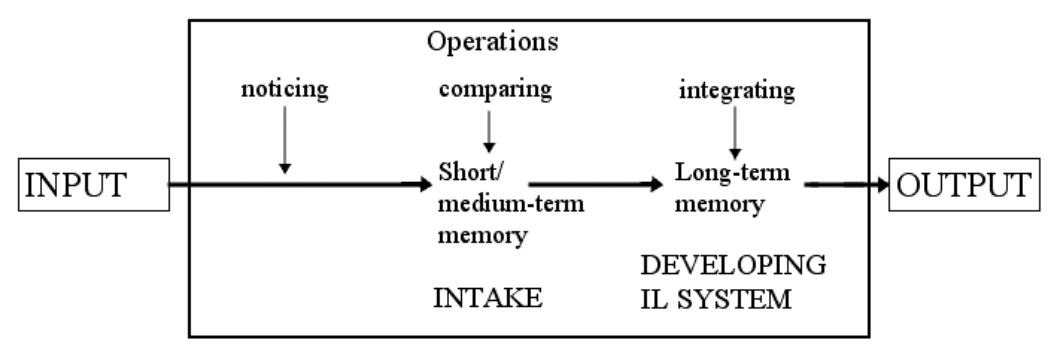

Figure 1: The process of learning implicit knowledge. Reproduced by permission of Oxford University Press From OAL: SLA Research \& Language Teaching by Rod Ellis @ Oxford University Press 1997.

Robinson further notes that noticing of instances in the input results in establishing "a knowledge base that can prompt retrieval sufficiently fast to outperform algorithm-based processing" (p. 307). In other words, by building up a collection of information in both the short- and long-term memory systems through noticing, rehearsal, and elaboration, one can increase the speed of retrieval, thereby increasing the automaticity of this process. This is supported by research in working memory, which posits that working memory tasks require conscious control (Ercetin \& Alptekin, 2013, p. 
734). It is through a combination of fast retrieval from the long-term memory and attentional control in the working memory that comprehension occurs.

Robinson's (1995) theory has important implications for L2 learning since, as Robinson states, the "attentional demands of pedagogical tasks and individual differences in memory and attentional capacity both affect the extent of noticing" (p. 284). It is incumbent upon instructors, then, to develop pedagogical tasks that take into account differential memory capacity in order to facilitate noticing for learners. Jin (2011) echoes this assertion in her analysis of Schmidt's noticing hypothesis: “...instruction may play an important role in priming learners to notice features by establishing expectations for language" (p. 130). In preparing learners via tools such as explicit listening strategies, instructors can prime them to pay attention to the input, allowing them to notice certain features and potentially mitigating the effects of differential memory and attentional capacity. Indeed, de la Fuente (2014) asserts that “...the use of listening comprehension tasks that promote learners' attention, noticing, and awareness of non-salient forms in the input may be of value in the instructional setting" (p. 262).

While many empirical studies of attention and noticing have focused on its effect on oral and written output (Egi, 2004; Hanaoka, 2007; Izumi, 2002; Mennim, 2007; Uggen, 2012), it is an important factor in reading and listening comprehension as well. For instance, Chen (2009) found that incidental noticing in text-based computer-mediated communication with native English speakers facilitated intake and memory retention for L1 Taiwanese learners of L2 English. In a study of Hungarian secondary learners of English as a Foreign Language (EFL), Peckham (2001) found that specific grammar and 
vocabulary instruction resulted in greater noticing when compared to incidental exposure to these same features in written input.

In one of the few studies that has investigated noticing as it relates to listening comprehension, de la Fuente (2014) sought to examine “...differential effects of medium of delivery of aural input during listening tasks on learners' noticing and type of comprehension (top-down and bottom-up) of Spanish object pronouns during focus on form listening tasks" (p. 261). Specifically, she wanted to see if there was a difference between instructor manipulated language learning (IMLL), wherein the instructor is in charge of determining the number of repetitions of aural input, how fast or slow it will be, and at what point it will be stopped, and mobile assisted language learning (MALL), wherein students are provided with a mobile device such as an iPod or smartphone, and are allowed to manipulate the input as they wish while they complete the listening tasks.

In her study, de la Fuente (2014) used two listening comprehension measures (one top-down and one bottom-up) and self-reports of noticing in order to test her hypothesis that MALL would lead to greater noticing. Her results in fact indicated that the MALL group outperformed the IMLL group in noticing, top-down listening questions, and bottom-up listening questions. She concluded that "(i)n terms of listening tasks, the design needs to guarantee not only learners' attention to target forms, but also noticing and awareness" (p. 273).

The language surrounding attention and noticing suggests that this concept is usually evoked with regard to grammar. Terms such as items, rules, features, noticing the gap, and attention to form imply that noticing is particularly essential for learning the rules of a language that will subsequently be applied to output. Where listening is 
concerned, attention and noticing can take on a different function. Whereas explicit metacognitive instruction does indeed, through priming, help learners notice grammatical or phonological features of the input as they listen, it is also a means of guiding their attention to their own cognition as they process this input. As Jin (2011) stated, “...attention tied to processes is a resource, not a product, which is used as a continuum between explicit knowledge and implicit knowledge" (p. 131). It is attention to processes that facilitates learning; in this case, learning how to listen effectively.

\section{Automatization of Listening Processes}

The term automaticity refers to the point at which a skill is performed without conscious effort on the part of the learner. This terminology is an extension of the distinction between automatic and controlled processing. In other words, the term automaticity is used to describe a situation in which a learner has moved from conscious processing to automatic processing in a given skill. In this state, performance of a skill, such as listening, can be performed simultaneously with other cognitive processes, is frequently initiated unconsciously, and is unaffected by imperfect listening conditions such as background noise. The process of developing automaticity in a given skill is referred to as automatization. Dropoffs in reaction time and error rate are typically taken as signs of the automatization of a skill, although the mechanisms of automatization are not yet understood and there is some debate about whether a speedup necessarily indicates automaticity of explicit knowledge as opposed to a faster "execution of algorithmic rules" (Hulstijn, 2002, p. 211). 
The feasibility and extent of automatization in second language learning has been explored in various areas, including applied linguistics, neurolinguistics, and phonological perception studies (Mayor, 2009; Rodgers, 2011; Sato, Matsunuma \& Suzuki, 2013; Segalowitz \& Segalowitz, 1993; Skotara, Kügow, Salden, Hänel-Faulhaber \& Röder, 2011). Where second language learning is concerned, automatization, like metacognition, has been studied more thoroughly in reading comprehension and word recognition than it has in listening (Favreau \& Segalowitz, 1983; Logan, 1997; McLeod \& McLaughlin, 1986; Segalowitz, 1998). This emphasis on reading comprehension over listening might be explained by the ephemeral nature of listening. Due to the presence of a physical text, reading allows learners to re-read the parts they find to be most difficult, making it easier for them to engage in the top-down processing necessary to infer meaning from context. This is not the case in listening, where learners must struggle to hold the meaning of the input they have already decoded in their working memory as they continue to process the speech stream. In fact, research has shown (Goh, 2000; Hasan, 2000) that students identify forgetting what they have heard because they are concentrating on new input (Goh, 2000, p. 6) as a frequent problem for them in L2 listening exercises. Because of the more difficult cognitive processes involved in listening, as exemplified by this problem, it may be more difficult to perfect this competence to the point of automatization.

In order to examine the potential relationship between metacognitive instruction and the development of automaticity in listening, it will first be necessary to investigate how scholars have defined automaticity and what counts as evidence. Once this has been established, I will proceed by analyzing several studies of automatization of L2 reading 
and listening, and make an argument for the use of metacognitive instruction to aid learners in developing automaticity in L2 listening.

DeKeyser's (2001) synthesis of criteria for automaticity that were suggested between 1974 and 1997 demonstrated a marked lack of agreement among scholars regarding what features are necessary to declare a process automatic. These criteria included speed, effort, intentionality, necessity of attention (wherein the process is unconscious), and the role of memory retrieval, among others (DeKeyser, 2001, p. 128). Since around the mid-1980s, two significant changes in the definition of automaticity were observed. The first was a shift from the inclusion of numerous criteria in the definition to a focus on far fewer criteria, sometimes only one or two. The second and, according to DeKeyser (2001), the most important change in the treatment of automaticity was that it shifted from an issue of attention to an issue of memory.

DeKeyser (2001) proposes that in order to gain a clearer understanding of automaticity, one must study the process of automatization. He makes an important clarification regarding the relationship between the two constructs when he states that researchers have begun to view automaticity "as the end result of a process of automatization (which has well-known characteristics) rather than of automatization as the process leading up to automaticity" (p. 130). This distinction may at first seem difficult to understand, but it becomes clearer when one conceives of automatization as a process which follows the power law of practice. The power law of practice describes a mathematical function in which extensive practice leads to reduced reaction time and error rates (DeKeyser, 2007). The graphical representation of the power function is characterized by a steep drop in the initial portion of the curve, followed by a very long 
tail (see Figure 1). The initial steepness represents the point at which knowledge is transformed from declarative to procedural, while the flatter area of the curve represents the process of automatization (DeKeyser, 2007, p. 99-100).

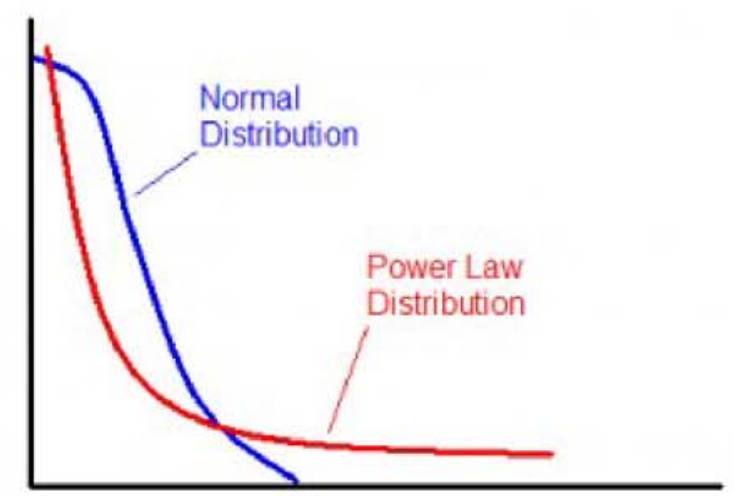

Figure 2: Power law of practice.
An analysis of the power law curve reveals the reasoning behind DeKeyser's (2001) claim that automaticity is the end result of automatization as opposed to automatization leading to automaticity. According to the mathematical function of the power law of practice (Newell \& Rosenbloom, 1980), the long, flat area of the curve, known as the tail, never touches the $\mathrm{x}$-axis. This reflects the reality that full automaticity of a cognitive skill is never achieved. Even during the execution of highly automatic cognitive or physiological processes, situational or psychological factors can interfere in the process and cause us to stumble over otherwise automatic procedures (DeKeyser, 2007). This means that even native L1 speakers can never be said to have achieved a state called automaticity, since automatic processing does not succeed $100 \%$ of the time.

In their discussion of automatization, R. Ellis (2009) expand upon Krashen's (1981) distinction between learning and acquisition by asserting that procedural knowledge is implicit, while declarative knowledge is explicit. As such, only implicit knowledge can be utilized in unplanned use, while explicit knowledge requires attentional resources, although R. Ellis (2009) concede that some learners may be able to 
automatize explicit processes through practice. In response to Hulstijn's (2002) argument that speeding up the application of explicit rules does not necessarily indicate automatization of explicit processes, the authors refer to N. Ellis' (1994) suggestion that it is not in fact the rules themselves which are automatized, but rather the linguistic sequences that are produced according to those rules. In other words, it is the procedural, implicit knowledge which has become automatized as a result of practicing the declarative, explicit rule knowledge (R. Ellis, 2009, p. 12-13).

So what does this mean for L2 listening? It is clear through the language they use that R. Ellis (2009) are referring to the production of spoken language and grammar rules in their discussion of automatization. The explicit rules to which they refer are those which guide the production of syntactically correct sentences. If, however, we apply this line of reasoning to L2 listening instruction, we can consider metacognitive listening strategies as the explicit knowledge through which the perception of new sequences of aural input can be automatized. Further, strings of sounds which are already processed automatically can be considered implicit knowledge of listening. In addition, since automatic and controlled processes are better represented as existing on a continuum of effort, it is reasonable to assume that as the process of automatization develops, the same input sequence may be processed consciously or automatically depending upon the linguistic environment and the context, until that sequences reaches the point of ultimate (if not full) automaticity.

In a survey of neurolinguistic research into the automaticity of spoken stimuli, Shtyrov (2010) discussed the results of several experiments in which participants' attention was modulated and event-related brain activity was recorded. In these 
neurophysiological studies, subjects' brain activity was monitored as they processed auditory stimuli and they were asked to either pay attention to or ignore the stimuli. The results of these studies indicated that there is some degree of automaticity in language processing. This automatic processing can be explained by the "robustness of strongly connected linguistic memory circuits in the brain that can activate fully even when attentional resources are low" (p. 255), but this level of automaticity is only activated in the very early stages of linguistic processing.

In an fMRI study, Friederici, Meyer, and von Cramon (2000) explored the activation of different areas of the brain as participants were exposed to semantic versus syntactic information. Eighteen subjects were presented with four stimulus types: normal speech (semantically and syntactically correct), syntactic speech (syntactically correct sentences using pseudo words), real-word lists, and pseudo-word lists. All pseudo words were phonologically permissible, neither word list contained syntactic or semantic information, and all words in the lists were preceded by articles to ensure consistency of the linguistic category. Each participant received 144 stimuli and performed judgment tasks throughout the trial in order to maintain their attention.

The results of the fMRI indicated that the pattern of brain activation changed according to the type of auditory input, showing increased activation in response to abnormal input. Friederici et al. (2000) explained the results as follows:

"When considering the present activation pattern, it appears that the frontal regions, but not the temporal regions, vary as a function of the input's deviance from normal speech. First, the left junction area (inferior frontal sulcus and inferior precentral sulcus) showed no significant activation in the normal speech condition but was significantly activated in the three other conditions. Second, the activation in the right junction area was particularly increased when subjects processed lexical information under unusual speech input, i.e., 
the presence of content words (real-word lists) and the presence of function words (syntactic speech). Third, the activation in the frontal operculum increased as a function of syntactic information under unusual input conditions, i.e., for syntactic speech. These data demonstrate that additional computational resources of frontal regions are required when processing speech stimuli which deviate from normal speech input" (p. 298).

In all four instances, patterns of activation in the respective areas of the brain were extremely weak in the presence of normal input. The authors interpreted these results to be reflective of the automatic processes used for normal auditory input, which require only minimal activation in the brain. Conversely, brain activation increased in respective areas of the brain in the presence of unfamiliar input. Automaticity of normal input would also explain this increased brain activation in the presence of input that deviates from normal patterns. These results provide empirical evidence for the existence of automaticity in language processing.

Taken together, the studies by Shtyrov (2010) and Freiderici et al. (2000) provide a modest indication that the processing of spoken language involves a degree of automaticity, as demonstrated by activation in certain areas of the brain while working with auditory input. These results were achieved in different ways in the two studies, but with complementary results. It is important to note that both of these studies were performed using native speakers listening to L1 input. However, although automaticity may be more quickly and easily achieved in an L1, there is no reason to believe it is not possible in an L2 as well. For that reason, the conclusions of Shtyrov (2010) and Friederici et al. (2000) are relevant to the present study. It would nonetheless be valuable to replicate this type of study using L2 listeners to compare levels of automaticity and location of brain activation. 
In summary, repeated exposure to and practice with comprehensible linguistic input can lead to the automatization of listening comprehension by proceduralizing the perception of phonological sequences and building up the amount of L2 input that is treated as 'normal' by the brain, thereby requiring less activation to process it. By helping L2 learners assess and manage the cognitive processes involved in listening, metacognitive instruction provides a structured way to build toward the automatization of listening comprehension by exposing them to repeated input and calling their attention to unfamiliar phonological sequences. Since perception/comprehension procedures are considered procedural, implicit knowledge that can be accessed unconsciously (as opposed to declarative facts, which are considered explicit knowledge) (R. Ellis, 2009), the repeated performance of these procedures can lead to their automatization. In addition, the application of metacognition to this process focuses the learner's attention on difficult to interpret linguistic sequences, increasing the likelihood of transforming these sequences into familiar phonological input.

Proceeding from this hypothesis that metacognitive instruction will help learners improve and develop automaticity in their listening performance, a further element to consider is what type of auditory input would be best suited for use in metacognitive instruction. Instructors typically have a few options in this regard, depending on the policies of their university and department, the demographics of their students and the resources at their disposal in the classroom. An instructor may choose to read a passage aloud on their own, play the listening passages from the audio materials that accompany the textbook, introduce students to music in the target language, for example. In the present paper, I propose that audiovisual resources represent the ideal medium for 
implementing metacognitive exercises in listening instruction. They are available to anyone with a computer, an Internet connection, and a projector, and they add a crucial visual component to the auditory input as well as plentiful samples of authentic target language speech.

\section{Audiovisual Media for Listening Instruction}

Research into the effectiveness of audiovisual input, in contrast to audio-only input, has indicated that it is an advantageous medium for delivering listening instruction. The dual modality of audiovisual resources helps learners make extra connections to the meaning of the input. They simulate real-life situations by giving the learner access to contextual cues such as the physical setting and other visual cues such as gestures, facial expressions, and body language, in addition to the aural input of the speakers. Just as in authentic communication, the learner is able to draw on these additional resources to activate background knowledge about the topic and to make inferences about meaning based on visual cues.

'Audiovisual media' or 'audiovisual resources' are deliberately broad terms that can encompass any text with simultaneous auditory and visual components. This goes beyond film to include music videos, movie trailers and excerpts, television shows, web series, vlogs, commercials, recorded lectures, and newscasts, to name a few possibilities. The common thread running through these various types of audiovisual media is their ability to deliver authentic language in familiar contexts with the benefit of linguistic and paralinguistic cues to the meaning of the input. 
Some additional benefits to employing audiovisual media in the L2 classroom include the accessibility, through the Internet, of thousands of potential audiovisual texts, the motivational factor of introducing students to the language via a medium that already plays an important role in their daily lives and which they can access independently for additional training, and the ability to easily replay entire clips or specific sections as necessary for comprehension.

\section{Benefits of Visual Representation}

The most salient benefit of audiovisual resources is the addition of a visual component to aid in comprehension. Much research has been conducted into the beneficial effects of including a visual component in L2 listening instruction and testing (Abraham, 2007; Ginther, 2002; Jones, 2009; Jones \& Plass, 2002; Kost, Foss \& Lenzini, 1999; Londe, 2009; Mueller, 1980). According to Mayer's (1997) Generative Theory of Multimedia Learning (GTML), the use of multiple modes of representation helps learners to make additional mental connections to the material. These mental connections create various routes to the information, aiding in recall and comprehension.

This theory was tested by Jones and Plass in their 2002 study of the effects of multimedia annotations on the listening and vocabulary acquisition of postsecondary French students. Four groups were tested: no annotations, written annotations only, pictorial annotations only, and both written and pictorial annotations. After listening to a text (2:20 in length) with their respective annotation type, the four groups were administered a vocabulary posttest and a written recall posttest, both of which were repeated as delayed tests three weeks later. Results of the study supported Mayer's 
(1997) GTML, indicating that those participants who received visual support in the form of both text and pictures performed better than those whose support was only written or only pictorial, as well as those who had no visual support.

In addition to increasing the number of mental routes to information, thereby facilitating retrieval, the visual element of audiovisual media provides important clues to the context of the interaction, such as the age of the interlocutors and the setting of the conversation. The setting, both geographical and situational, can provide clues to the linguistic content of the discourse. For example, in French, if the two participants in a conversation are of differing age groups students can expect to hear more formal language from the younger interlocutor, including use of the subject pronoun vous and formal grammatical features such as the use of inversion in question formation. The facilitating effect of context in audiovisual media is closely related to another important aspect for L2 listening: the authenticity of the input.

\section{Authenticity}

That it is essential for L2 learners to be exposed to authentic input in the target language is indisputable. Authentic input gives learners the opportunity to become familiar with the sounds and cadence of the target language. It allows them to observe how native speakers use their language, which lexical items are popular at a given time and in a given social group, which syntactic elements are used often versus which elements are generally avoided, and how personal relationships affect language use. The difficulties associated with such texts are more easily overcome in the classroom environment due to the support of the instructor. The use of authentic input also 
conforms to the goals of communicative language teaching by providing students with opportunities to interpret and respond to native speech.

Incorporating authentic language into the classroom requires an answer to the question: How does one define authenticity? This may seem straightforward at first glance; however, many elements can potentially affect the authenticity of a listening passage. The term authenticity encompasses at once content, speaker, intended audience, rate of speech, context, and spontaneity. A given listening passage will fall somewhere along a continuum of authenticity that depends upon its adherence to these elements. At the most authentic end of the spectrum are excerpts of language by a native speaker speaking at her natural rate in an everyday situation, without a script, to an audience of other native speakers, with no modifications to the phonological, syntactic or lexical features of her output to accommodate nonnative speakers.

The question of authenticity in empirical research has been treated in one of two ways: it has either been operationalized in disparate ways depending upon the author, or it has been ignored altogether. Brown (2011) argues that a satisfactory definition of authenticity has yet to be elaborated and in response to this lack of definition he has created a model of authenticity that includes five levels. This model addresses some of the elements of authenticity outlined above, namely speaker, content, rate of speech, and intended audience. In Brown's model, native speech that has been recorded for purposes unrelated to L2 instruction is considered to have genuine input authenticity. If change is made that does not affect the meaning of the aforementioned text, such as decreasing the speed, this is referred to as altered input authenticity. Next, adapted input authenticity refers to text that has been adapted by the teacher in other ways, perhaps through the 
substitution of difficult lexical items with easier ones. A text is considered to have simulated input authenticity if it is created specifically for the classroom but mimics the style and format of authentic texts. Finally, if a text has been created for the classroom and makes no attempt to copy native speech, this is considered inauthenticity.

In the present study, authenticity must be addressed both in the texts that were used for the assessment of listening comprehension and for the passages that were included in the metacognitive instruction for the experimental treatment group. Based upon the accepted importance of authentic materials and using terminology from Brown's (2011) model of authenticity, the passages which are included in the experimental treatment will be categorized as having either genuine input authenticity or altered input authenticity. This means the videos that were chosen for inclusion in the experimental group's lesson plans were created by native speakers for native speakers, and they may be slowed down and/or repeated as necessary to facilitate the metacognitive activities constructed around them. Due to the nature of listening comprehension measurement, however, the listening texts chosen for the pre- and post-treatment listening assessments were considered to have simulated input authenticity. This is because they were recorded for the purposes of testing, and have been adapted to the students' level of language instruction. These listening texts will be discussed in further detail in the Methodology chapter.

\section{Motivation and Anxiety}

Students report that listening to authentic materials has a positive effect on their motivation. According to Dupuy (1999), L2 learners find that working with authentic 
listening materials helps to improve their linguistic skills and their confidence.

Vandergrift (2003) also noted that "being able to access authentic texts is motivating for students because they learn to understand language as it exists naturally" (p. 472). While students may initially find authentic texts more difficult to understand due to the high rate of speech, overcoming this concern to ultimately achieve comprehension can be very motivating. This is because as students build up small successes, they gradually decrease their anxiety over listening and increase their confidence in working with the target language (Elkhafaifi, 2005).

Gardner (2010) asserts in his socio-educational model of second language acquisition that the learning of an L2 is unlike any other academic subject, in that it "involves making features of another cultural community part of one's own repertoire" (p. 3). Certain learners may find this to be a positive experience while for others it can cause anxiety. Film and other audiovisual media can help to mitigate this feeling of anxiety by exposing the learner to the new culture through a medium that is familiar to them and relevant to their own experiences. Additionally, according to Guikema (2009), an important factor in teaching is connecting with students in ways that are relevant to them. Audiovisual formats and devices are highly relevant to the experiences of university-level students, because they use them every day. This familiarity has the potential to reduce the anxiety they may feel when using authentic materials, aiding them in achieving success in listening comprehension and therefore increasing their motivation for language learning.

The instruction of L2 listening can be greatly improved through the use of explicit instruction in metacognitive strategies which give students the tools and practice 
necessary to automatize the perceptual and cognitive processes of listening in a second language. Through this practice, students will develop selective perception routines in the $\mathrm{L} 2$ and will begin to perform the procedures of listening via automatic processing. Audiovisual materials such as television programs, web series, and music videos provide a medium for delivering metacognitive instruction that is familiar to students. As they develop their metacognitive strategies and experience gradually larger successes in comprehension of authentic materials, learners will increase their level of motivation, which can only aid in further improvement.

\section{The Present Study}

In the present study I evaluate the effectiveness of explicit metacognitive listening instruction for improving the listening comprehension performance and automaticity of a group of L1 English students in the second semester of L2 French. More specifically, participants will be instructed in the application of metacognitive strategies to the process of L2 listening in order to plan, monitor, evaluate, and organize the cognitive processes involved in the execution of this skill. Based on the power law of practice and existing knowledge regarding automatization, the use of explicit metacognitive instruction is expected to lead participants toward the automatic perceptual processing of L2 phonological segments, resulting in improved listening performance and reduced reaction time. Due to the documented advantages of adding visual elements to aural input, as well as the motivational and proficiency-related benefits of using authentic materials in the L2 classroom, diverse audiovisual media represents an ideal medium for this type of instruction. 


\section{Pilot Study}

A pilot study of the current research was conducted in the Fall 2013 semester. In this section, I describe the pilot study and its results. Subsequent modifications that were made to the research design in order to address the concerns raised by the pilot study are addressed in the Methodology chapter.

Participants. The pilot study involved four sections of French 102 taught by three different instructors, none of whom were involved in the research project. Instructors were all graduate teaching assistants of French. All were nonnative speakers of French, and had received similar training in language instruction through a required departmental course. Participants were recruited on the first day of the study during the third week of the semester, and class sections were assigned randomly to either the control or treatment condition. In the control group, instructors were asked to refrain from using audiovisual media in any listening activities they may have used in their classroom during the treatment period (four weeks). The instructors for the treatment condition were provided with daily audiovisual-based listening activities and were instructed on how to run the activities.

Out of 62 initial participants, four were excluded for having a native language other than English and seven did not complete the posttests. The total sample $(N=51)$ was divided into a control group $(n=23)$ and a treatment group $(n=28)$. The average age of participants was 19 years old. The experimental treatment was applied as part of the curriculum and data on listening scores was collected only from those students who chose to participate in the research. Participants were aware they were that they were 
participating in a study about how they learn French, but they were not aware that their daily lessons were a part of the research.

Materials and procedure. Recruitment took place on the third Thursday of the semester in order to allow time for enrollment to normalize. On the day of recruitment, students were assured that participation was voluntary and that their decision would not affect their relationship with the department. Those who chose to participate filled out a brief background questionnaire and took part in the listening pretest. The treatment period began the next day and continued for four weeks at the end of which participants completed the immediate listening posttest. The delayed posttest was administered one week after the immediate posttest to determine whether the treatment effect endured.

The listening tests were created by the researcher, and used listening passages from an educational French web site. All passages consisted of a dialogue between two speakers, one male and one female, and lasted approximately one minute. The listening tests consisted of six open-ended questions requiring participants to provide simple information directly from the dialogue. Participants were not asked to do more advanced comprehension tasks such as making inferences or identifying moods or relationships between interlocutors.

During the four-week treatment period, instructors for the two classes in the experimental condition were provided with daily structured listening activities using audiovisual media. Using various online videos, these exercises incorporated pre- and post-listening activities in order to aid students in activating background knowledge and in incorporating new vocabulary and grammatical structures into their linguistic 
repertoire. The exercises also included strategic metacognitive tasks to accomplish during the viewing as a means of focusing students' attention on the relevant information in the input. During the same time period, instructors of the control groups were advised to run their classes as they normally would but to refrain from activities involving audiovisual media or instruction in metacognitive strategies.

Results. Scores from the three tests were inputted into IBM SPSS statistical software and were submitted to an analysis of covariance with the pretest as covariate and the immediate posttest and delayed posttest as dependent variables. Using the pretest as a covariate controls for students' initial proficiency, which would otherwise be present as uncontrolled variation in the results (Field, 2013). By controlling for the pretest in this manner, any significant results that were obtained could be more appropriately attributed to the treatment. Running the pretest through a two-tailed t-test before proceeding with the ANCOVA assured that the analysis had not violated the assumptions of independence of the covariate and the treatment effect. The results of this t-test confirmed that there were no significant differences between groups on the pretest $(p=.273)$.

Once the results of the pretests were analyzed, the results from the two posttests were submitted to the ANCOVA. Although a visual comparison of means indicated that the experimental group performed higher than the control group (see Table 1 for descriptive statistics), no significant differences were found for the variable 'group' on either the immediate or the delayed posttest ( $p=.203$ and $p=.539$, respectively). 
Table 1

Descriptive Statistics: Pilot Study

\begin{tabular}{llllc}
\hline & & N & Mean & Standard Deviation \\
\hline Posttest & Control & 23 & 41.67 & 16.04 \\
& Experimental & 28 & 49.28 & 18.45 \\
Delayed & Control & 23 & 54.76 & 14.95 \\
& Experimental & 28 & 58.70 & 18.72 \\
\hline
\end{tabular}

These results were not able to provide conclusive support for the effectiveness of the experimental treatment, although they showed some indication of its impact. An in-depth analysis of the pilot study was performed in order to determine its limitations and improve the experimental design with regard to treatment conditions, instructor preparation, and listening assessments. These modifications will be addressed in the Methodology chapter.

\section{Contributions to the Existing Literature}

The present study is expected to contribute to the listening literature by providing empirical evidence for the usefulness of instruction in metacognitive strategies as a technique for improving listening comprehension. This is not meant to act as an overarching teaching method, since research has shown that the complexity of language learning precludes a one-size-fits-all solution to acquisition problems. Rather, it is suggested as a tool to be used in the specific context of listening instruction.

Additionally, the results of the present study are expected to provide a starting point for the study of automatization processes in L2 listening by providing an example of an instructional technique that provides the focused practice necessary to push conscious, controlled processes along the continuum of effort toward automatic processing. Finally, 
this study is expected to lend additional support to the use of technology in the foreign language classroom by demonstrating the effectiveness of audiovisual media in delivering a particular type of instruction.

The contributions described above fill three gaps in the existing literature. These include the relative lack of interventional listening studies, of studies exploring the relationship between metacognition and listening skills (as compared to reading skills), and of studies involving the application of metacognitive instruction as a concept. The use of an interventional approach differs from much of the existing research on listening in that it incorporates the experimental treatment into the learning environment of the participants. The present study is therefore considered higher in ecological validity with regard to L1 English students learning French in a foreign language instructional context. Secondly, the present study contributes to the literature on the role of metacognition in the acquisition of L2 listening skills, an area which has remained relatively unexplored when compared to the skill of L2 reading. Finally, while research has been conducted into the relationship between learners' awareness of metacognitive strategies and their subsequent use of them, only a small number of studies have gone beyond the question of awareness to explore the application of these strategies in L2 listening instruction.

\section{Research Questions and Hypotheses}

Given the numerous considerations outlined in this chapter and summarized above, the following research questions and their attendant hypotheses were examined in the present study. These hypotheses address the effect of metacognitive listening instruction on both listening comprehension and automaticity of listening processes. 
- Research Question \#1: Does the use of explicit metacognitive instruction lead to an improvement in listening comprehension scores when compared to similar instruction given without explicit metacognitive strategy use?

- Hypothesis \#1: The group that receives explicit metacognitive instruction will outperform the control group on both the immediate and delayed posttests in terms of listening comprehension performance.

- Research Question \#2: Does metacognitive instruction aid in the automatization of the perceptual and cognitive processes of listening as evidenced by a reduction in reaction time over time?

- Hypothesis \#2: The metacognitive treatment group will experience a decrease in reaction time on the immediate and delayed posttests, indicating increasing automaticity. This decrease in reaction time will be significantly steeper than that of the control group.

- Research Question \#3: How does initial metacognitive awareness impact listening comprehension and automaticity?

○ Hypothesis \#3: Because students with high metacognitive awareness will outperform those with low metacognitive awareness in the same condition on both measures at the beginning of the study, students with low metacognitive awareness in both conditions will have stronger gains in both listening performance and reaction time compared to their high-level counterparts. This will be more marked in the experimental condition.

- Research Question \#4: How do measures of listening comprehension from inclass assessments compare to those created for the present study? 
○ Hypothesis \#4: Student performance will not vary significantly based on listening assessment. In other words, the listening assessments created for the study will prove as effective as those used in the classroom based on correlation analyses.

The comparison between the control and the metacognitive treatment groups is meant to support the overall argument that the explicit instruction of metacognitive strategies in listening activities is more effective for acquisition of listening skills than a simple discussion of comprehension questions because of its potential to guide learners in automatizing the perceptual and cognitive processes involved.

In Chapter 3 I will discuss the experimental design of the present study, including the changes applied to the present methodology based on the results of the pilot study and the participants, materials, procedure, listening assessments, and statistical analyses that were used to carry out the experiment. 


\section{CHAPTER 3: METHODOLOGY}

The present experiment was designed to compare the effects of simple exposure to audiovisual media input and the enhancement of this input with metacognitive instruction on the acquisition of global listening comprehension skills. The investigation is an extension of my own previous work (Becker, 2012) on implementing audiovisual media into listening comprehension instruction. Additionally, the methodology of the present study was inspired by a paper by Vandergrift and Tafaghodtari (2010), in which the authors focused on a metacognitive, process-based approach to listening, incorporating not just one but a variety of metacognitive strategies into the treatment condition. Because previous studies have indicated a relationship between visual aids and improved listening comprehension (Desmarais et al., 1997/1998; Jones \& Plass, 2002; Jung, 2003), audiovisual media was deemed an effective means of delivering the listening input throughout the learning phase of the current study.

Vandergrift and Tafaghodtari (2010) sought to demonstrate the power of metacognitive strategies to improve L2 listening skill development. To accomplish this, their control and experimental groups were exposed to the same audio-only listening passages the same number of times once each week over the course of a semester. In the control group, the listening session was followed by a teacher-led discussion to confirm comprehension, while in the experimental group students participated in extensive 
predictive and reflective exercises throughout the listening process. When the experimental group outperformed the control group in terms of gains in listening scores, the difference was attributed to the metacognitive instruction used in the experimental group.

The present study differs from that of Vandergrift and Tafaghodtari (2010) in four important ways. First, rather than using audio-only input during the treatment phase of the present study, I have chosen to use audiovisual media. Based on existing work on visual and audiovisual contextual support for L2 learning (Abraham, 2007; Jones \& Plass, 2002; Kost, Foss \& Lenzini, 1999; \& Li, 2006) and supported by Mayer's Generative Theory of Multimedia Learning (1997), audiovisual media may be considered superior to audio-only for the instruction of L2 listening due to the additional contextual information it provides to the meaning of the input. This information may aid learners in recall of information, strengthening their listening comprehension performance.

Secondly, because I seek to explore the effectiveness of metacognitive strategies in improving both listening comprehension and automaticity, I added a reaction time component to the listening assessments. Not only was participants' listening comprehension evaluated based on a numerical score, but the time they took to answer the questions at each stage of testing was also assessed. In existing research, which focuses mainly on learners' oral production, automaticity is operationalized as a decrease in reaction time as well as error rate. In the current listening test, however, it was not possible to establish a calculation of error rate. This is addressed further in the discussion of limitations and directions for future research. 
Next, rather than using the results of the MALQ as a dependent variable and analyzing how metacognitive awareness changed over time in each group, I chose to focus on how students' initial level of metacognitive awareness affected their performance over the course of the study. To do this, level of initial metacognitive awareness (low or high) was determined by the MALQ and was used as an independent variable. I then investigated how this factor influenced the dependent variables of listening comprehension and automaticity as well as whether it represented a main effect or interacted with other independent variables.

Finally, because I had a more limited time frame and needed to provide learners with as much contact as possible with the experimental treatment, I chose to implement listening activities into every class session during the study. This means that participants were exposed to the treatment (or not) four days a week for eight weeks (with the exception of mandatory exams and oral evaluations). This totaled approximately 6.25 contact hours.

As in the Vandergrift and Tafaghodtari (2010) study, two groups were created for the present investigation: control and treatment (metacognitive). The treatment group participated in a metacognitive listening activity four days a week for eight weeks. The control group was exposed to the same listening passages as the treatment group and was asked to verify comprehension through a brief discussion with the instructor, but they did not receive instruction regarding the process of listening and they did not participate in brainstorming, comparison, or reflection exercises. This procedure will be discussed in further detail in the Methodology section below. 


\section{Modifications from the Pilot Study}

The current research design also reflects the changes necessitated by an analysis of the pilot study, which was performed during the Fall 2013 semester. The main concern regarding the pilot study was the lack of statistically significant results. Much of this can be attributed to logistical issues as well as to the need to create a more sensitive research design. The main issues that have been addressed in the modified design are: changing the treatment conditions, providing better training for the instructors involved, and enhancing the sensitivity of the listening comprehension assessment instrument.

The most important change in design concerns the treatment conditions. The pilot study involved two conditions: absence of experimental listening activities (control group) and presence of experimental listening activities (treatment group). Two main concerns arose due to this design. First, since the researcher was not the instructor of any of the classes involved in the pilot study, it was not possible to determine whether the instructors of the treatment groups were appropriately integrating the audiovisual activities or whether the instructors of the control groups were in fact avoiding such activities. Even if significant results had been obtained, it would have been difficult to attribute them to the treatment because of this uncertainty. Additionally, because the treatment condition involved both audiovisual media and metacognitive instructional techniques, both of which were absent in the control condition, these two variables were confounded in the statistical analysis. In order to appropriately analyze the individual contribution of metacognitive instruction to the improvement of listening comprehension skills, it was necessary to control for the audiovisual variable in the experimental design. 
In an effort to address the first limitation, instructors of both conditions attended an intensive training session for their condition before the start of the study in order to assure that they were prepared to implement the activities appropriately. During these training sessions, all instructors were provided with a list of links for the listening passages, the dates they were to be used, and the precise excerpts to be played from each passage (e.g. 0:18-1:43). They were also shown a sample of the listening sheets to be used in each lesson with specific instructions on how to guide students in completing the sheet depending on condition. Instructors in the control condition were instructed to play the excerpt three times and to lead a brief discussion in order to ascertain what the students had comprehended. They were reminded to avoid all discussion of strategies and reflections on the process of listening. Instructors in the treatment condition, on the other hand, were given detailed instructions regarding the use of brainstorming, comparison, and reflection exercises to be done with each passage of the excerpt. All instructors were sent copies of these materials via e-mail after the training session and stayed in constant contact with the researcher during the study period to address questions or issues as they arose.

With regard to the second limitation, that of distinguishing between the variables of audiovisual media and metacognitive instruction in the statistical analysis, the design was adjusted to incorporate audiovisual media into both groups. Both the control and the treatment group were exposed to listening passages via audiovisual media. The sole difference between the two conditions was the use of metacognitive instruction in the treatment group. In other words, the control group participated in listening exercises focusing on the product of listening (i.e. answers to comprehension questions) while the 
treatment group focused on the process of listening through the explicit use and discussion of metacognitive strategies. The content of the listening passages was identical, and the time spent on them in class was roughly equivalent.

The issue of the sensitivity of the listening comprehension instrument was more difficult to correct. Due to the length of the listening passages used in the pilot study, only six questions were developed for these listening tests. While this was appropriate given the length of the excerpts and the information contained therein, it did not result in a sufficiently sensitive instrument for measuring listening comprehension. This led to many participants achieving the same scores, making it practically impossible to compare the subtle differences in their listening performance. A longer test of listening comprehension was necessary.

In addition, due to the brevity of the treatment period (four weeks) of the pilot study, it was necessary to use different passages for each of the three listening assessments in order to eliminate the possibility of participants improving on the posttests because of increasing familiarity with the input rather than as a result of the experimental intervention. Given the longer timeframe of the present study (eight weeks), this practice effect was deemed less likely and the same listening passage and instruments were used for all tests. Using the same instrument allowed for an analysis of listening gains over time.

In order to address the concern regarding the length of the test, I chose to model the pre- and post-treatment listening assessments in the present study after the listening section from the university's French placement exam. Due to its extensive use in a university setting, the placement exam has already proven to be a sensitive and reliable 
instrument for measuring listening comprehension skills. Some modifications of the instrument were necessary, however, in order to accommodate logistical issues such as time constraints on test days and the timing of the study within the semester.

The current format of the listening section of the university placement exam consists only of multiple choice questions. There are practical concerns with the use of multiple choice questions since test takers can apply reasoning skills in order to guess the correct answer despite a lack of comprehension of the input relating to the question. This concern is, however, mitigated in the current format of the exam, because each possible answer is quite detailed. That is to say, each question in the placement exam has four possible answers, all of which provide detailed information regarding the input.

Similarly, I have formulated the questions in the present study such that the four possible answers are equally feasible based on the input, requiring participants to listen carefully in order to determine which of these is correct.

The university's French placement exam is conducted on the computer. Students navigate to the first page of the listening section, where they see several multiple choice questions listed. The audio begins to play immediately and students must choose their answers as they listen, clicking Next at the bottom of the page when they are finished. This process continues for three pages, each of which includes a different listening passage. The present study will follow the same format using four brief (one minute) listening passages with their respective questions. A key difference is that the audio passages in the present study will be played two times each, with a pause of several seconds in the middle. 
Buck (2001) argues that although some researchers consider repetition of the input inauthentic, real-life communication often involves repetition and requests for clarification (p.171). Requiring students to comprehend the full meaning of the input after hearing it only one time is not therefore reflective of authentic communication and may also cause undue stress in the testing situation. In addition, there are practical concerns such as ambient noise at the testing site that may cause participants to miss key information. It is appropriate, therefore, to provide one repetition of the input to ensure that all participants have clearly heard the input and have been thus given the same opportunity to successfully complete the assessment.

Finally, although the listening assessment for the present study was modeled after the university exam, different texts were used for the audio passages. This is a logistical decision that was made because the study took place early in the fall semester. Many students in French 102 had recently taken the placement exam, giving them a potential advantage over students who were continuing from French 101, due to familiarity with the material. In order to approximate the texts of the placement exam as closely as possible in content and format, as well as to maintain consistency across passages, the testing excerpts were taken from the supplementary material provided by the publisher of the second-semester textbook. This was also considered an effective way to expose students to a variety of genders and vocal patterns, since robust listening skills should be applicable across speakers. 


\section{The Present Study}

The modifications discussed above serve to improve the research design of the present study by eliminating some of the logistical issues that affected the pilot study, including improving the training provided to the instructors and increasing the consistency of the listening exercises across treatment conditions. They also improve the format of the study by creating two treatment groups that differ in only one variable and by implementing an enhanced listening comprehension instrument based on an existing design. The research design of the present study is thus as follows.

\section{Participants}

Participants $(N=69)$ were recruited from seven intact class sections of the second semester of French. Participants were recruited on the third Friday of the semester and were divided by intact class section, each of which was randomly assigned to either the control or experimental (metacognitive) condition. In order to control for language background, only those participants whose native language is English were included in the analysis. Participants did not know to which group they belonged, only that they were participating in a study on French listening. The instructors that had been assigned to teach second-semester French were trained in the use of the relevant materials and were in charge of implementing the experimental teaching methodology in their own section. The researcher was not involved in the instruction of the classes.

One hundred students were involved in the study and 18 of these were excluded because they reported a native language other than English. The mean age of the remaining 82 participants who completed the pretest was 19 , with a range from 18 to 27 . 
Sixty-nine of these participants were present for and completed the posttest. All of them reported some prior contact with French, mostly in high school. Twenty-one participants reported some contact with a language other than French; these included studying Latin or Spanish in high school and having parents who speak other languages at home. Three participants reported speaking Spanish fluently or having studied or lived abroad in a Spanish-speaking country. Five participants reported varying levels of ability in other languages due to contact through the family (Vietnamese, Greek, Mandarin, Tagalog/Visayan, and Cantonese).

\section{Materials and Procedure}

On the day of recruitment, participants were asked to fill out a background questionnaire, perform the pretest of listening comprehension, and complete the Metacognitive Awareness Listening Questionnaire (Vandergrift, Goh, Mareschal, \& Tafaghodtari, 2006). The background questionnaire included name, age, native language, prior experience with French, and any contact with other languages. Participants were assured that their decision whether or not to participate in the study had no bearing on their relationship with the department. The classroom listening activities were performed regardless of participation in the study, but students had the option to request that their data be excluded from the analysis. Extra credit was offered to those students who participated in all three listening tests, and an opportunity for an equivalent amount of extra credit was offered to those who did not wish to participate.

Materials for the current study included the audiovisual excerpts and exercises that were used during the eight-week treatment period; the audio-only listening passages 
and corresponding measurement instruments to be used for the pretest, posttest, and delayed posttest; and the Metacognitive Awareness Listening Questionnaire. The background questionnaire, transcripts and listening tests, and MALQ can be found in Appendices A-C.

Instruments. The instruments used during the listening assessments included a background questionnaire, a listening assessment, and the Metacognitive Awareness Listening Questionnaire. These instruments were uploaded to the survey website Qualtrics and were incorporated into three different files to be accessed on separate days depending upon the point in the study (see Table 2). Using the Qualtrics software facilitated the administration and scoring of the assessments, allowed students to work at their own pace to complete the measures, and enabled the researcher to collect reaction time data for the listening tests.

Table 2

Schedule of Assessments

\begin{tabular}{llll}
\hline Day 1 & 8 Weeks & Day 2 & Day 3 \\
Background questionnaire & Treatment & Listening posttest & Delayed \\
$\begin{array}{l}\text { Listening pretest } \\
\text { MALQ }\end{array}$ & Period & MALQ & listening test \\
\hline
\end{tabular}

Listening texts and assessments. As mentioned above, the listening portion of the French placement exam at the university acted as a model for the creation of the instrument used to measure listening comprehension proficiency for the pretest, immediate posttest, and delayed posttest. This model was modified by increasing the number of texts, obtaining the texts themselves from the textbook materials rather than 
from the placement exam files, and repeating each text for maximum opportunity to perceive the aural input.

Four listening texts were chosen from the supplementary textbook materials to be employed in the listening tests. Each text featured two to three people having a conversation in varying contexts, was approximately one to two minutes in length, included a repetition and a pause in the middle, and involved male and female speakers. The four texts are described in Table 3 below:

Table 3

Description of Listening Passages

\begin{tabular}{llll}
\hline Text & Characters & Length & Subject \\
\hline 1 & Jean and Léa & $1: 16$ & Léa's typical day at university \\
2 & Vincent and Alice & $2: 24$ & Vincent invites Alice to the movies \\
3 & Kathy and brother & $1: 02$ & Kathy asks her brother about his weekend \\
4 & 2 tourists and waitress & $2: 12$ & Two men discuss what to order for dinner \\
\hline
\end{tabular}

The same four listening passages were used for the pretest, posttest, and delayed posttest. In order to control for practice effects as well as fatigue, the order of passages was counterbalanced across the three tests. This is demonstrated in Table 4.

Table 4

Order of Listening Passages Across Tests

\begin{tabular}{ccc}
\hline Pretest & Posttest & Delayed posttest \\
\hline 1 & 3 & 2 \\
2 & 1 & 4 \\
3 & 4 & 1 \\
4 & 2 & 3 \\
\hline
\end{tabular}

Following Graham and Macaro’s (2008) suggestion, the listening test for the present study was developed in order to be markedly different from any of the activities involved in the treatment phase of the study. This is done to ensure that the test is not 
biased in favor of any individual group. Since multiple choice questions were not used in any condition during the learning phase of the study, this format should not provide an advantage to the members of any group.

Further, the listening tests consisted of texts presented in an audio-only format. Since both groups were exposed to audiovisual excerpts throughout the treatment phase of the study, neither should have been unduly favored by the audio-only format of the assessments. In addition, building upon the distinction between listening teaching and listening testing, the purpose of the pretest and posttests was to evaluate the product of listening rather than the process, namely the participants' responses to comprehension questions eliciting specific information. Because this is the case, it was important that during these assessments the participants focus on the aural input only without the potential distraction of reading subtitles or seeing images.

Empirical validity of the listening test created for the present study was established through its correlation with the scores of the five regular, in-class listening assessments used during the same semester. Students in both treatment conditions achieved similar scores in relation to each other across all listening assessments. These correlations were significant at the $p<.01$ level. This will be discussed in further detail in the results and discussion sections of Chapter 4.

\section{Metacognitive Awareness Listening Questionnaire (MALQ). The Metacognitive}

Listening Questionnaire was completed by participants at the time of the pretest and the immediate posttest as a means of assessing initial level of metacognitive awareness and investigating how this awareness affected listening and automaticity based on treatment 
condition. The MALQ was created by Vandergrift, Goh, Mareschal, and Tafaghodtari (2006) and measures five factors related to metacognition: problem solving, planning and evaluation, mental translation, person knowledge, and directed attention. These five factors account for $44.5 \%$ of the variance in the instrument (p. 443). Further, it has been found to have a respectable level of internal reliability (p. 446) and to explain up to $13 \%$ of the variance in listening comprehension according to a correlation and regression analysis of MALQ data and listening comprehension scores $(r=.36, p<.001)(\mathrm{p} .449)$.

Listening passages and exercises. During the eight-week treatment period, all sections participated in daily listening exercises consisting of short listening passages and comprehension activities. In a given week, instructors of all sections used the same audiovisual excerpts for the listening activities but varied the accompanying exercises based on treatment condition. This means that the instructors for the control groups played the excerpt three times and discussed comprehension questions. Meanwhile, the instructors of the metacognitive group played the excerpt three times while guiding students through specific prediction, clarification, and reflection exercises meant to focus their attention on the cognitive processes they were using.

The listening passages were obtained from the online video repository YouTube due to its wide variety of foreign language content and its accessibility in the classroom (all classrooms are equipped with a computer connected to the Internet and a projection system). These audiovisual passages took the form of news reports, television shows, web series, documentaries, or home videos, just to name a few examples. Twenty-five excerpts were used in all. Twenty-two of these were found on YouTube and in three 
instances videos were chosen from the supplemental material in the textbook. The class calendar for French 102 was consulted and all excerpts were chosen to correspond with the general theme of what was being learned that week. In this way any disturbance caused by the study was diminished by using materials that contributed to the goals of the course.

The two most important additional factors in choosing these listening passages were that they reflected the approximate level of the participants and they contained authentic use of the target language. The concept of authenticity in second language learning has been a topic of debate in the field, both in terms of what can be considered authentic and of the relative usefulness of materials that are considered less than authentic (Brown, 2011). For the purposes of the in-class listening passages, the term "authentic" will be operationalized as anything that was created for a native-speaker audience of the target language, a definition that corresponds to "genuine input authenticity" according to Brown (2011). Materials that fit this description are considered useful because they have not been altered in content or speed in order to accommodate nonnative speakers of the language. As such, they are reflective of the type of speech that learners are likely to encounter in their experiences in the target language environment.

Some researchers consider materials that are scripted inauthentic; however, it can be argued that the intended audience is a more reasonable indicator of authenticity than the spontaneity of the speech. Scripted speech that is intended for a native speaker audience is delivered at a faster rate than that which has been modified for nonnative speakers. Even in situations where native-target scripted speech is delivered at a slower 
rate, it maintains the syntactic and lexical features of natural speech, and as such is useful in the L2 classroom. Finally, it is important for second language learners to be exposed to the wide range of speech styles they may encounter in the L2. It is therefore equally beneficial for them to hear scripted and deliberate speech as it is for them to become accustomed to spontaneous speech.

Given these considerations of authenticity, the majority of the materials chosen for the learning phase of the present study were considered authentic. The only exceptions to this were the three videos that were chosen from the textbook. Because they were created for nonnative speakers as an educational tool, they are considered to have a lesser degree of authenticity. They were chosen when the topic of a given week proved difficult to find in a more authentic context. For example, the seventh week of the study involved vocabulary related to dining and restaurants. Many of the videos online on this topic were either inappropriate for the level of the learners or made by high school students for class projects. In this case, I chose to use the textbook video since it presented the appropriate material at the right level.

The listening passages chosen for the present study were no longer than two minutes in length. The first reason for this is logistical: the excerpts were played three times in class. By choosing excerpts of one to two minutes, the entire activity would not exceed approximately 15 total minutes, leaving the instructors sufficient time to complete the rest of their lessons. The second reason is that it was important not to overwhelm students with the sheer volume of aural input, which may have ended up shutting down comprehension. 
In order to illustrate how such listening passages can be integrated into the language curriculum, consider the following example from an online video series about tips and tricks for household cleaning. The title of the series is "Les trucs et astuces de Shiva," and each episode is between one and two minutes in length. Because the hostess is providing step-by-step instructions for different cleaning tasks, she speaks slowly and clearly. Below is a transcript of an episode in which she describes how to remove a red wine stain from a white dress shirt:

« Notre défi du jour: supprimer la tache de vin sur votre chemisier préféré. La soirée fut délicieuse : un verre de vin rouge dans une main, un petit four dans l'autre et 'vlan' une belle tache de vin rouge sur mon chemisier préféré. Pas de panique, une solution, traiter le mal par le mal. Vous prenez votre chemisier, vous prenez du vin blanc, vous versez généreusement votre vin blanc sur votre tache de vin rouge, et vous laissez agir un certain temps. Puis vous rincez la tache de votre chemisier à l'eau claire et il est prêt pour le pressing ou la machine à laver. A bientôt pour un nouveau conseil Shiva. »

"Our daily challenge: getting rid of a wine stain on your favorite shirt. The party was delicious: a glass of red wine in one hand, a petit four in the other and 'wham' a nice red wine stain on my favorite shirt. No need to panic, there's a solution: fight fire with fire. Take your shirt, take some white wine, generously pour your white wine on your red wine stain, and let it sit for a while. Then rinse the stain on your shirt in clear water and it's ready for the dry-cleaner or the washing machine. See you soon for a new piece of advice from Shiva." (my translation)

This video contains vocabulary pertaining to cleaning as well as to clothing and

food, which can facilitate its inclusion at several potential points of the language

curriculum. It is articulated slowly and clearly, making it easier to use in the level of instruction that took part in the study. Finally, it consists of authentic material in that it was created with a French-speaking audience in mind. Most of the audiovisual clips used in the treatment period of the present study satisfied these three conditions. 
The example of Shiva described above also serves as a helpful way of illustrating the exercises that accompanied the listening passages in the control and treatment conditions. In each group, participants were told the topic of the passage before it was played. The control group then listened to the passage three times, after which they participated in a 10-minute discussion, either as a class or in pairs, of several comprehension questions related to the passage. The metacognitive group, on the other hand, participated in several exercises throughout the listening activity, all meant to activate background knowledge and to call their attention to the metacognitive strategies available to them for helping to understand the input. This came in the form of predicting, identifying, evaluating, and reflecting. The procedure, outlined below, is drawn from the research of Vandergrift and Tafaghodtari (2010) with a few modifications.

- Instructor introduces the topic of the listening passage to students. Students write down the topic and brainstorm with a partner about what information will be presented, what vocabulary will be used, etc. Both partners write down their ideas.

- First viewing: students put checkmarks next to their predictions when they hear them in the passage and make notes about things they didn't understand or would like to clarify. They then compare notes with a partner to see how they differed in what they heard and understood.

- Second viewing: students pay careful attention to the parts they found difficult. They also make notes of new information they heard. The instructor then leads a 
discussion of the listening strategies students used, whether they were successful, and what they understood from the text.

- Third viewing: students verify what has been discussed and then work individually to make notes on how the listening went and what they plan to do next time to improve their performance.

The procedure used in the experimental groups fulfilled the requirements of Goh's (2008) definition of metacognitive instruction as well as Veenman's (2006) principles for metacognitive activities. The activities were embedded into the subject matter, and learners were informed of their usefulness and were provided with prolonged training to ensure that they would continue to employ them beyond the classroom.

Procedure. Classes were divided randomly by intact section into one of two groups: control or treatment (metacognitive). Instructors were provided with one listening passage per day for eight weeks to incorporate into their lesson plan. In addition, they participated in a training session on how to implement the activities for their treatment condition. They received an e-mail with the list of listening excerpts by date as well as a copy of the appropriate activity sheet for their condition (see Appendix D for the activity sheets for the control and treatment conditions) with notes inserted to remind them what to do and say during each repetition of the listening passage.

On the day of recruitment, the third Friday of the semester, I went to each section at the beginning of the class session and informed students that I was performing a study on how people learn to listen in French. I told them that if they chose to participate, they 
would complete a couple of activities that day and on two days later in the semester. I also made it clear that participation was completely voluntary, but that those who participated in all three tests would receive ten points of extra credit in the course and those who chose not to participate could also earn this credit by viewing a French movie screening and writing a three-page paper on the film. Out of the seven sections involved, only a couple of students chose not to participate.

The background questionnaire, listening pretest, and first MALQ took place on the same day as recruitment. This was followed by a posttest at the end of the eight-week treatment period and a delayed posttest one week after that (see Table 2). The listening tests each took place on a Friday (the computer laboratory day) and occurred at the beginning of the class session via Qualtrics surveys. Recruitment and pretest took approximately 15 minutes while the remaining two testing days took only 10 minutes.

I read the instructions in English before providing participants with a URL for the Qualtrics survey for that day. Before completing the assessment, participants were asked to go to the URL and read the instructions carefully. They were told that they could look briefly through the questions for each listening passage before pressing the Play button to start. They were also reminded that they would hear each passage twice and they should do the best they could with that amount of input, so they should not use the pause button at any time and they should not press play again once the passage had ended. They were reminded that they were not being graded on their performance, so they should only do the best they could.

When the URL was entered, students navigated through several pages. The first page thanked them for participating and reiterated that the study was entirely confidential 
and anonymous. The second page asked for the participant's name and course section (e.g. Jane Doe, 10:30). Additional demographic questions were included on the first day of the study only (age, native language, contact with French and other languages). The next page gave the following instructions:

On each of the following 4 pages, you will hear an audio passage and will be presented with multiple choice questions about its content. When the page loads, you can briefly read the questions first. When you are ready to listen, press the Play button. You will automatically hear the passage twice with a 6-second pause in the middle. When the audio is finished, do not play it again. Do not use the Pause button at any time. Once you have answered the questions, you may continue to the next page. Please answer the questions to the best of your ability and do not worry if you are unsure of your answers.

Participants then completed each of the four pages of listening assessments. On the day of the pretest and the immediate posttest, participants were directed to one final page where they answered a series of Likert items about their metacognitive awareness (the MALQ). Finally, they arrived at a page thanking them for their participation.

All classes at this level of instruction meet Tuesday through Friday for 50 minutes each. In order to maximize contact with the experimental treatment, it was administered every day except in instances of a chapter test, oral evaluation, or university break. This added up to twenty-five class sessions of the experimental treatment. Instructors were advised to situate the listening exercise near the middle of the class session so that students who were late to class did not miss the exercise. These measures were expected 
to minimize the occurrence of students missing treatment sessions, which could have a negative impact on the results of the study.

Scores on the multiple-choice items were calculated automatically through Qualtrics for each listening passage and added up for a total score out of 20. The survey software also tallied the total score for the MALQ with a lowest possible score of 21 and a highest possible score of 126 . The Qualtrics surveys were designed to record the first and last clicks on each of the four pages of listening assessments, allowing for a rough calculation of the reaction time of each participant on each listening passage. These four numbers were added up to obtain a total reaction time, in seconds, for the pretest, the immediate posttest, and the delayed posttest. Finally, participants' listening scores from in-class assessments were collected as a comparison measure. These data were compiled in an Excel spreadsheet where they were used to calculate further information such as gains scores and categorical assignments (e.g. high or low metacognitive awareness and high or low initial listening proficiency). This overall data was then transferred to IBM SPSS Statistics to conduct statistical analyses.

\section{Statistical Analysis}

Data were submitted to a two-way mixed factorial analysis of variance (ANOVA) to investigate the effects of the independent variables (group and metacognitive awareness) on the dependent variables (listening test scores and reaction times). Subsequently, treatment groups were divided into subgroups by initial listening proficiency (low or high based on the pretest) and by metacognitive awareness (low or high based on the Metacognitive Awareness Listening Questionnaire) and the analyses of 
variance were repeated with these independent variables in order to investigate the differences in listening performance and reaction time in the resulting listening and MALQ subgroups (experimental low, experimental high, control low, and control high).

Differences that were indicated by the ANOVA were then submitted for pairwise comparisons, and a Bonferroni correction was applied to guard against a Type I error. Finally, participants' scores on in-class listening assessments throughout the semester were analyzed by subgroup in order to provide additional information about the possible effects of the treatment on listening comprehension performance. 


\section{CHAPTER 4: RESULTS AND DISCUSSION}

\section{Results}

The first three hypotheses of the present study concerned the effect of treatment condition and initial level of metacognitive awareness on subsequent listening comprehension performance and measures of automaticity (reaction time). I hypothesized that the group that was instructed in the use of metacognitive strategies would outperform the control group on measures of listening gains as well as reaction time. Specifically, I expected the treatment group to see higher gains in listening performance across tests and negative gains in reaction time (reflecting decreased time to complete the listening tasks). With respect to metacognitive awareness, I expected to find interaction between the two independent variables. More precisely, I anticipated that learners with a low level of initial metacognitive awareness in the experimental group would display higher positive gains in listening and higher negative gains in reaction time compared to their high awareness counterparts as well as compared to the low awareness control condition.

In order to test these hypotheses, data were submitted to a two-way mixed factorial analysis of variance (ANOVA) with group (experimental versus control) and metacognitive awareness (low versus high) as the independent variables and both listening gains and reaction times as dependent variables. This analysis allowed me 
to examine the main effects of treatment condition and metacognitive awareness as well as any interaction between the two independent variables. Results indicated that in fact it was an interaction of the two variables that led to gains in listening and reaction time.

\section{Listening Gains by Group and Metacognitive Awareness}

The highest gain score from the pretest to the posttest (i.e. the end of the treatment period) was that of the combination of the control condition and a high level of metacognitive awareness. This changed, however, from the posttest to the delayed posttest, where the interaction between experimental condition and low metacognitive awareness led to higher listening improvement. Finally, throughout the entire period of the study (i.e. from the pretest through the delayed posttest), it remained the control/high combination that seemed most effective.

Table 5

Descriptive Statistics: Listening Gain Scoresby Group and Metacognitive Awareness

\begin{tabular}{llllll}
\hline & Group & MALQ & N & Mean & SD \\
\hline Pre-Post & Experimental & Low & 11 & 1.00 & 2.32 \\
& & High & 22 & .95 & 1.89 \\
& Control & Low & 15 & .93 & 1.22 \\
Post-Del & & High & 11 & 2.91 & 2.30 \\
& Experimental & Low & 11 & 1.36 & 1.86 \\
& & High & 22 & .68 & 1.55 \\
& Control & Low & 15 & .60 & 1.35 \\
& & High & 11 & .45 & 1.13 \\
Pre-Del & Experimental & Low & 11 & 2.36 & 1.57 \\
& & High & 22 & 1.77 & 1.95 \\
& Control & Low & 15 & 1.53 & 1.96 \\
& & High & 11 & 3.36 & 1.63 \\
\hline
\end{tabular}

Results of the ANOVA indicated potential main effects during the period from the pretest to the posttest for group $\left(F=3.29, p=.075, \eta_{p}^{2}=.056\right)$ and for level of 
metacognitive awareness $\left(F=3.44, p=.069, \eta_{p}^{2}=.059\right)$; however, these results did not achieve significance. Additionally, main effects are not interpreted when there is an interaction between the independent variables. In this case, there was interaction between group and metacognitive awareness in listening gain scores from the pretest to the posttest $\left(F=3.77, p=.057, \eta_{p}^{2}=.064\right)$ and from the pretest to the delayed posttest $(F=$ 5.94, $\left.p=.018, \eta_{p}^{2}=.097\right)$. This demonstrates that while there was a visual difference between groups from posttest to delayed posttest in favor of the experimental/low combination, this difference was not significant. On the other hand, the combination of the control condition and high metacognitive awareness was significant in the overall period of the study (pretest to delayed posttest) and approached significance from pretest to posttest. Standard deviation of listening gain scores was acceptable relative to the sample means throughout the study in all groups.

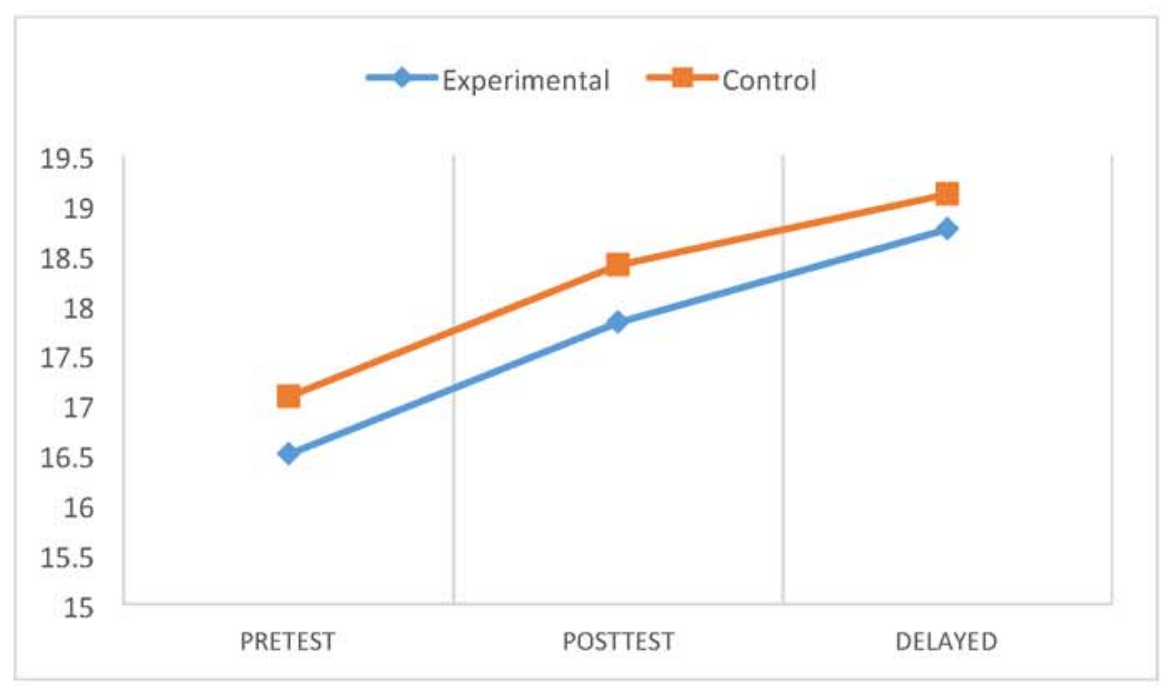

Figure 3: Listening performance by treatment condition.

A visual analysis of the data by group only supports the observation that the control group outperformed the treatment group across the three listening assessments. 
While this gap narrowed slightly throughout the study period, explaining the elevated experimental gain score from posttest to delayed posttest, it was never overcome (see Figure 3).

\section{Reaction Time by Group and Metacognitive Awareness}

An examination of the descriptive statistics for reaction time based on group and metacognitive awareness suggested that from the pretest to the posttest the combination of control group and low metacognitive awareness led to the steepest drop in reaction time, with the largest gap existing between this group and the control/high combination. Scores from the posttest to the delayed posttest were more comparable, with no evident frontrunner for decreased reaction time.

Table 6

Descriptive Statistics: Reaction Time (in seconds) by Group \& Metacognitive Awareness

\begin{tabular}{llllll} 
& Group & MALQ & N & Mean & SD \\
\hline Pre-Post & Experimental & Low & 11 & -50.95 & 56.24 \\
& & High & 22 & -42.21 & 66.24 \\
& Control & Low & 15 & -97.22 & 66.67 \\
Post-Del & & High & 11 & -11.73 & 57.89 \\
& Experimental & Low & 11 & -34.70 & 59.70 \\
& & High & 22 & -66.68 & 76.60 \\
& Control & Low & 15 & -53.78 & 68.22 \\
Pre-Del & High & 11 & -51.71 & 77.77 \\
& \multirow{2}{*}{ Experimental } & Low & 11 & -85.65 & 82.37 \\
& & High & 22 & -108.89 & 54.40 \\
& Control & Low & 15 & -151.00 & 90.42 \\
& & High & 11 & -63.44 & 75.13 \\
\hline
\end{tabular}

Across the overall study, both the experimental/high and control/low combinations evidenced considerable negative gains in reaction time. 
Results of the ANOVA indicated a main effect for metacognitive awareness from the pretest to the posttest $(F=7.57, p=.008)$. Again, however, the effect of metacognitive awareness must be situated within the context of the significant interaction between that variable and the treatment condition. In this case, there was a significant interaction from pretest to posttest $\left(F=5.02, p=.029, \eta_{p}^{2}=.084\right)$ and from pretest to delayed posttest $\left(F=7.63, p=.008 \eta_{p}^{2}=.122\right)$. The combination of control/low had the biggest impact on reaction time over time.

An interesting aspect of this result is that the standard deviation of reaction time scores for the control/low combination was high relative to the sample means between the pretest and the delayed posttest $(S D=90.42)$ when compared to the other groups.

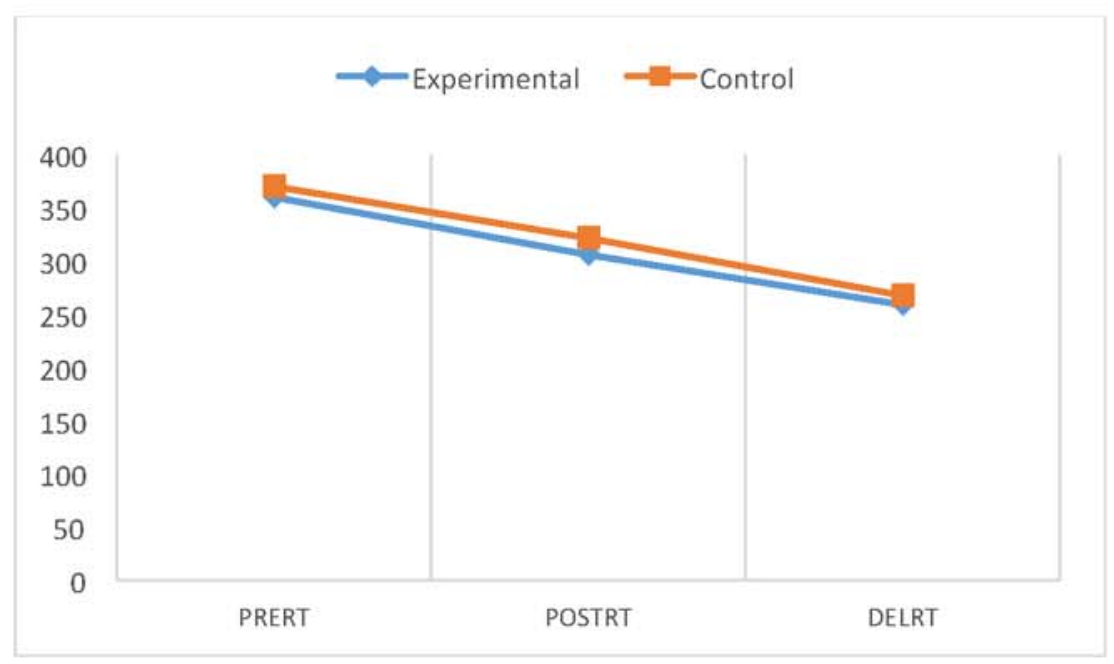

Figure 4: Reaction time by treatment condition.

A visual analysis of reaction times by group only showed that the control group nevertheless did not outperform the experimental group in reaction time drop-offs, indicating a steady decrease in both groups over time (see Figure 4). The difference in reaction time is very slightly wider in favor of the experimental group at the posttest; 
however, mean data (see Table 6) indicate that the experimental group only had a lower gain score between the posttest and the delayed posttest. This supports the finding that rather than a main effect for group, it is the interaction between group and metacognitive awareness that impacted reaction times in the present study.

\section{Impact of Initial Listening Proficiency Level and Metacognitive Awareness}

In light of the assertion by Goh (2000) that high-proficiency learners are able to use directed attention (a metacognitive device) to get back on track when they lose the thread of the input while low-proficiency learners do not use this strategy, it follows that metacognitive instruction can have a different impact on low- versus high-level learners. Specifically, I would expect to see low-proficiency learners in the metacognitive group make higher gains in listening proficiency than their high-proficiency counterparts. In order to investigate this possibility, participants were divided into listening proficiency subgroups based on their score on the listening pretest. This was accomplished by finding the median of scores on the pretest, which was 17 . I then categorized those participants with a score of 17 or above as high-level listeners and those with a score of 16 and below as low-level listeners and created four listening proficiency subgroups: experimental low, experimental high, control low, and control high.

Once the listening proficiency subgroups were established, these were used as an independent variable in a two-way mixed factorial ANOVA of listening gain scores and reaction time scores. The second independent variable was subgroup of initial metacognitive awareness. I again divided the participants into subgroups, this time based on the median score on the MALQ. As the median score was 92, I categorized those who 
scored 92 and below as having low metacognitive awareness and those who scored 93 and above as having high metacognitive awareness. I used this information to create four subgroups of metacognitive awareness: experimental low, experimental high, control low, and control high.

The Shapiro-Wilk test demonstrated that the data were normally distributed from the pretest to the posttest, and Levene's test confirmed homogeneity of variance between the various subgroups. I address only the main effects of initial listening proficiency and metacognitive awareness in this analysis, because the interaction between these two variables was not statistically significant.

Listening scores and reaction times by listening proficiency. Because of the unequal sizes of the groups involved in the analysis, estimated marginal means were used in the calculation of significance and effect sizes. Tables 7 and 9 report the means and standard deviations from the original descriptive statistics of these subgroups for listening gain scores and reaction times respectively.

Dividing the groups in this way had the effect of revealing differences in listening comprehension gains that had not been apparent when comparing solely the two larger treatment groups. It can be seen from the descriptive statistics that both low-proficiency groups outperformed the high-proficiency groups in listening gains. Standard deviation was fairly consistent across groups and was not large relative to the sample means. Reaction time data, on the other hand, did not produce new information in this analysis. Subgroup means did not differ greatly; however, the standard deviation of these scores again demonstrated higher variation in the control group. More specifically, the control 
high-proficiency subgroup demonstrated more variability in the data in the overall time frame of the study, from pretest to delayed posttest, when compared to the other three subgroups.

Table 7

Descriptive Statistics: Listening Gain Scores by Listening Proficiency Subgroup

\begin{tabular}{llrrc}
\hline & Subgroup & N & Mean & Standard Deviation \\
\hline \multirow{5}{*}{ Pre-Post } & Experimental Low & 13 & 2.78 & 1.64 \\
& Experimental High & 25 & .36 & 1.63 \\
& Control Low & 14 & 3.00 & 1.75 \\
& Control High & 16 & .25 & 1.06 \\
\multirow{5}{*}{ Pre-Del-Del } & Experimental Low & 9 & .78 & 1.64 \\
& Experimental High & 24 & .96 & 1.71 \\
& Control Low & 14 & .71 & 1.33 \\
& Control High & 12 & .33 & 1.15 \\
& Experimental Low & 9 & 3.56 & 2.30 \\
& Experimental High & 26 & 1.27 & 1.22 \\
& Control Low & 15 & 3.73 & 1.53 \\
& Control High & 13 & .77 & .93 \\
\hline
\end{tabular}

Results of a mixed factorial ANOVA with listening proficiency subgroup and MALQ subgroup as the independent variables revealed significant between-group differences in listening gains from the pretest to the posttest $\left(F=9.06, p=.000, \eta_{p}^{2}=\right.$ $.352)$ and from the pretest to the delayed posttest $\left(F=10.44, p=.000, \eta_{p}^{2}=.385\right)$ based on initial listening proficiency. The period between the posttest and the delayed posttest did not produce significant results. These data were submitted to post hoc comparisons using a Bonferroni adjustment in order to assess the direction of the differences. These post hoc comparisons revealed that the difference in mean gains from the pretest to the posttest was significant between the experimental low and experimental high subgroups $(p=.001)$; between the experimental low and the control high subgroups $(p=.007)$; 
between the experimental high and control low subgroups $(p=.000)$; and between the control low and control high subgroups $(p=.001)$.

Specifically, when examining the period of time from the pretest to the posttest, low-level listeners in the experimental group made stronger gains than the high-level listeners in the same group. The experimental low group also outperformed the highlevel listeners in the control group during this time period. Further, listeners in the control low group had higher gains in listening compared to both high-level listeners in the experimental group and high-level listeners in the control group. No significant differences were found between experimental low and control low or between experimental high and control high subgroups.

Table 8

Estimated Marginal Means of Listening Gains by Listening Proficiency Subgroup

\begin{tabular}{llrc}
\hline & Subgroup & Mean & Standard Deviation \\
\hline \multirow{5}{*}{ Pre-Post } & Experimental Low & 2.83 & .57 \\
& Experimental High & .28 & .35 \\
& Control Low & 2.47 & .62 \\
& Control High & -- & .62 \\
Post-Del & Experimental Low & .92 & .52 \\
& Experimental High & 1.06 & .32 \\
& Control Low & .74 & .58 \\
& Control High & .80 & .57 \\
& Experimental Low & 3.75 & .53 \\
& Experimental High & 1.44 & .32 \\
& Control Low & 3.21 & .58 \\
& Control High & .80 & .57 \\
\hline
\end{tabular}

While there were no significant between-group differences for the period from the posttest to the delayed posttest, no negative gain scores were reported for the four subgroups either. In other words, while no subgroup outperformed another during this period, they all continued to improve slightly in their listening performance. 
Subsequently, overall results from the pretest to the delayed posttest continued to display significant between-group differences $(p=.000)$. Post hoc comparisons showed that these differences concerned the same subgroups mentioned above: the experimental low and experimental high subgroups $(p=.003)$; the experimental low and control high subgroups $(p=.000)$; the experimental high and control low subgroups $(p=.000)$; and the control low and control high subgroups $(p=.000)$. The experimental low subgroup made higher gains than either experimental high or control high. The control low subgroup also had higher gains compared to both experimental high and control high. There were no significant differences between experimental low and control low or between experimental high and control high.

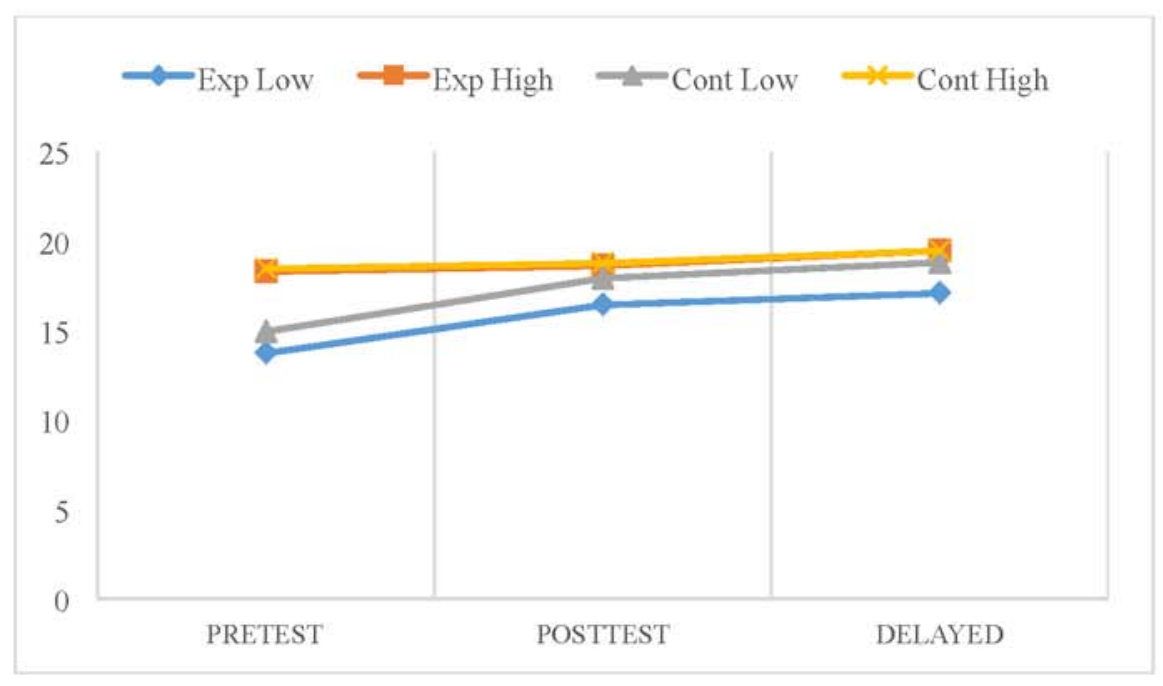

Figure 5: Listening gains by listening proficiency subgroup.

These results were not echoed in the reaction time data, which indicated that there were still no significant between-group differences in gain scores at any point during the study (pretest to posttest: $p=.303$; posttest to delayed posttest: $p=.769$; pretest to delayed posttest: $p=.244$ ) 
Table 9

Descriptive Statistics: Reaction Time by Listening Proficiency Subgroup

\begin{tabular}{llrrc}
\hline & Subgroup & N & Mean & Standard Deviation \\
\hline Pre-Post & Experimental Low & 13 & -30.12 & 46.43 \\
& Experimental High & 25 & -52.68 & 66.78 \\
& Control Low & 14 & -41.02 & 81.22 \\
& Control High & 17 & -61.20 & 68.48 \\
Post-Del & Experimental Low & 9 & -52.14 & 71.40 \\
& Experimental High & 24 & -57.47 & 73.83 \\
& Control Low & 14 & -60.40 & 76.94 \\
& Control High & 12 & -44.16 & 65.37 \\
& Experimental Low & 10 & -91.74 & 73.65 \\
& Experimental High & 26 & -102.85 & 60.81 \\
& Control Low & 15 & -97.06 & 83.82 \\
& Control High & 14 & -115.51 & 104.38 \\
\hline
\end{tabular}

This data suggests that while listening proficiency has the potential to predict gains in listening performance, it does not have an effect on automaticity of listening processes as measured by reaction time.

Table 10

Estimated Marginal Means of Reaction Time by Listening Proficiency Subgroup

\begin{tabular}{lllc} 
& Subgroup & Mean & Standard Deviation \\
\hline Pre-Post & Experimental Low & -32.37 & 22.96 \\
& Experimental High & -51.91 & 14.06 \\
& Control Low & -86.24 & 25.26 \\
\multirow{5}{*}{ Post-Del } & Control High & -60.86 & 25.15 \\
& Experimental Low & -38.08 & 26.07 \\
& Experimental High & -55.42 & 15.96 \\
& Control Low & -54.94 & 28.67 \\
& Control High & -30.59 & 28.56 \\
& Experimental Low & -70.45 & 26.51 \\
& Experimental High & -107.33 & 16.24 \\
& Control Low & -141.19 & 29.16 \\
& Control High & -91.45 & 29.05 \\
\hline
\end{tabular}




\section{Listening gains and reaction time by metacognitive awareness.}

Returning to my third hypothesis concerning metacognitive awareness and its potential impact on both the listening and automaticity measures of the study, just as level of initial listening proficiency had an impact on listening performance over time, I hypothesized that those who began the study with a low level of metacognitive awareness (as measured by the MALQ) would experience a swifter improvement in listening proficiency and automaticity, causing them to outperform their counterparts with high metacognitive awareness and the control low awareness subgroup on the listening posttests and measures of reaction time. Subgroups based on initial metacognitive awareness were thus included in the two-way mixed factorial ANOVA in order to determine if there indeed any main effects based on this variable.

As stated above, using listening proficiency and metacognitive awareness subgroups as independent variables resulted in unequal group sizes. SPSS thus provided estimated marginal means which were used for the statistical analysis. Tables 11 and 13 report the original descriptive statistics for listening and reaction gain scores by metacognitive awareness subgroups. The listening gain score data revealed significant between-group differences from the pretest to the posttest and from the pretest to the delayed posttest. Post hoc comparisons indicated that these pretest/posttest differences were present between the experimental low and control high subgroups $(p=.052$, marginal); the experimental high and control high subgroups $(p=.010)$ and between the control low and control high subgroups $(p=.015)$. 
Table 11

Descriptive Statistics: Listening Gain Scores by Metacognitive Awareness Subgroup

\begin{tabular}{lllcc}
\hline & Subgroup & $\mathrm{N}$ & Mean & Standard Deviation \\
\hline Pre-Post & Experimental Low & 14 & 1.29 & 2.20 \\
& Experimental High & 25 & 1.16 & 1.86 \\
& Control Low & 18 & .67 & 1.24 \\
& Control High & 11 & 2.91 & 2.30 \\
Post-Del & Experimental Low & 12 & 1.25 & 1.82 \\
& Experimental High & 22 & .68 & 1.55 \\
& Control Low & 14 & .64 & 1.39 \\
& Control High & 11 & .45 & 1.13 \\
& Experimental Low & 13 & 2.15 & 1.57 \\
& Experimental High & 23 & 1.70 & 1.94 \\
& Control Low & 15 & 1.53 & 1.96 \\
& Control High & 12 & 3.42 & 1.56 \\
\hline
\end{tabular}

Specifically, these data show that, with regard to listening, the experimental low group outperformed the control high subgroup, and the control high awareness group had higher gains than both the experimental high awareness group and the control low awareness group.

Table 12

Estimated Marginal Means of Listening Gains by Metacognitive Awareness Subgroup

\begin{tabular}{lllc} 
& Subgroup & Mean & Standard Deviation \\
\hline \multirow{5}{*}{ Pre-Post } & Experimental Low & 1.75 & .64 \\
& Experimental High & 1.49 & .38 \\
& Control Low & 1.13 & .47 \\
& Control High & 1.58 & .63 \\
Post-Del & Experimental Low & .90 & .60 \\
& Experimental High & .63 & .36 \\
& Control Low & 1.05 & .44 \\
& Control High & .86 & .58 \\
& Experimental Low & 2.65 & .60 \\
& Experimental High & 2.21 & .36 \\
& Control Low & 2.18 & .44 \\
& Control High & 2.44 & .58 \\
\hline
\end{tabular}


Significant differences were reported from the pretest through the delayed posttest for two of the same groups. The control high awareness group outperformed both the experimental high $(p=.033)$ and the control low $(p=.018)$ subgroups.

Table 13

Descriptive Statistics: Reaction Time by Metacognitive Awareness Subgroup

\begin{tabular}{lllrc}
\hline & Subgroup & N & Mean & Standard Deviation \\
\hline Pre-Post & Experimental Low & 14 & -55.34 & 60.48 \\
& Experimental High & 25 & -44.08 & 65.60 \\
& Control Low & 18 & -76.20 & 67.46 \\
\multirow{5}{*}{ Post-Del } & Control High & 12 & -6.26 & 58.36 \\
& Experimental Low & 12 & -35.10 & 56.94 \\
& Experimental High & 22 & -66.68 & 76.60 \\
& Control Low & 14 & -54.80 & 70.67 \\
& Control High & 11 & -51.71 & 77.77 \\
& Experimental Low & 13 & -93.51 & 82.79 \\
& Experimental High & 24 & -107.64 & 54.97 \\
& Control Low & 16 & -133.23 & 96.28 \\
& Control High & 12 & -61.15 & 72.07 \\
\hline
\end{tabular}

In contrast to the reaction time scores by listening proficiency subgroup, reaction times gains between MALQ subgroups showed significance from the pretest to posttest $\left(F=3.01, p=.039, \eta_{p}^{2}=.153\right)$, and from the pretest to delayed posttest $(F=3.53, p=$ $\left..021, \eta_{p}^{2}=.175\right)$. Again, the standard deviation of the control group was large relative to the sample means for the control group, this time for those participants with low metacognitive awareness.

Post hoc comparisons showed significant differences between the control low and control high awareness subgroups both from the pretest to the posttest $(p=.020)$ and in the overall period from pretest to delayed posttest $(p=.048)$. Specifically, in both 
instances the control low subgroup experienced steeper declines in reaction time compared to the control high awareness subgroup.

Table 14

Estimated Marginal Means of Reaction Time by Metacognitive Awareness Subgroup

\begin{tabular}{lllc}
\hline & Subgroup & Mean & Standard Deviation \\
\hline Pre-Post & Experimental Low & -85.81 & 26.14 \\
& Experimental High & -39.56 & 15.55 \\
& Control Low & -89.14 & 19.21 \\
& Control High & -17.09 & 25.39 \\
Post-Del & Experimental Low & -28.21 & 29.68 \\
& Experimental High & -70.92 & 17.65 \\
& Control Low & -57.70 & 21.81 \\
& Control High & -35.58 & 28.82 \\
Pre-Del & Experimental Low & -114.02 & 30.19 \\
& Experimental High & -110.47 & 17.95 \\
& Control Low & -146.84 & 22.18 \\
& Control High & -52.67 & 29.31 \\
\hline
\end{tabular}

\section{In-class Listening Scores}

My fourth hypothesis concerned the extent to which the listening scores obtained in the present study would match those obtained in the students' regular in-class listening assessments during the same time period. This information was collected for two reasons. First, it would provide additional evidence regarding the potential effectiveness of the experimental instructional treatment. If the scores of the participants in the experimental condition differed from those of the control condition on the in-class assessments as well as the empirical tests, it would provide strong evidence that the experimental method had in fact been effective. Secondly, obtaining participants' scores on a separate listening assessment establishes a reference point for analyzing the empirical validity of the listening measurement tool created for the present study. 
To test this hypothesis, I collected listening data from five regular, in-class assessments only for those students who participated in the study. Two final analyses were then performed using listening proficiency and MALQ subgroups as independent variables. These assessments took place on September 17, October 7, October 29, November 13, and December 4, roughly corresponding to the pretest, midway point of the study, immediate posttest, delayed posttest, and two weeks beyond the delayed posttest. For simplicity, these five assessments are labeled Test 1, Test 2, Test 3, Test 4, and Test 5 in the following tables and figures.

These data consisted of the listening scores from four chapter tests and a midterm exam. Since the total point value of the listening assessments was not equal across tests, I calculated percentage scores and used these in the statistical analysis. Two one-way ANOVAs were performed: one using listening subgroup as the independent variable and the other using metacognitive awareness subgroup. The variation in performance across tests was similar in all subgroups, indicating that Test 2 elicited the lowest scores while Test 4 generally elicited the highest scores (see Figure 6).

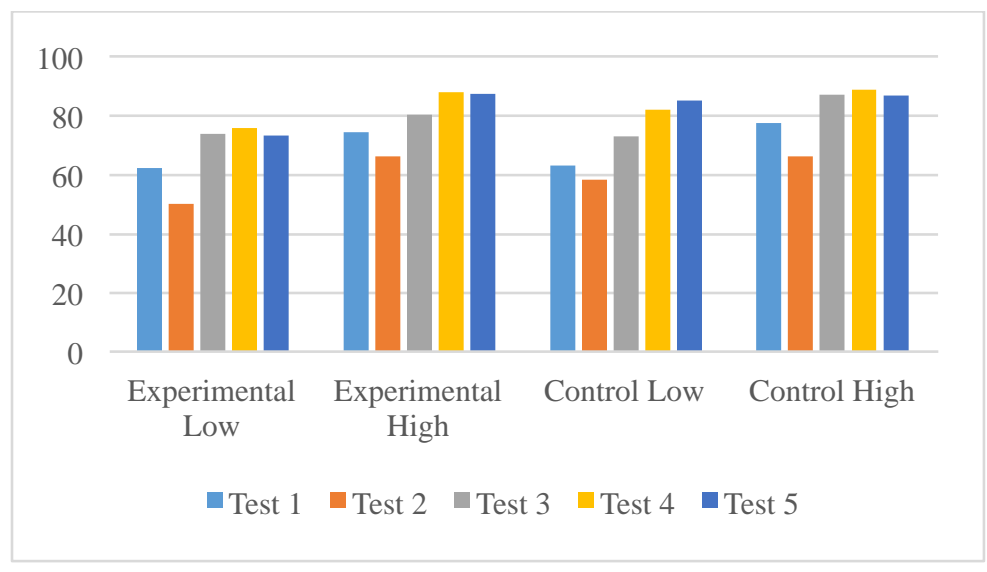

Figure 6: In-class listening scores by listening proficiency subgroup. 
Results of the first one-way ANOVA revealed significant between-group differences for all five of the in-class listening assessments (Test 1: $F=2.72, p=.050$; Test 2: $F=3.66, p=.016$; Test 3: $F=4.77, p=.004$; Test 4: $F=6.13, p=.001$; Test 5: $F$ $=2.88, p=.042$ ) based on listening proficiency subgroup. Although Test 1 returned a marginally significant result, post hoc comparisons found no significant differences between subgroups on that test. On the other hand, Test 2 demonstrated significance between the experimental low subgroup and both the experimental high $(p=.021)$ and control high subgroups $(p=.032)$, indicating that both the experimental and control highproficiency subgroups outperformed the experimental low-proficiency subgroup. On Test 3 the scores of the control high subgroup continued to exceed those of the experimental low subgroup $(p=.017)$. Additionally, the control high subgroup scored higher than control low $(p=.008)$. Test 4 again showed differences between experimental low and high $(p=.002)$ and between experimental low and control high $(p$ $=.002$ ). Subgroup means indicated that at this point, both high proficiency subgroups outperformed the experimental low subgroup. Finally, on Test 5 a significant difference persisted between the experimental low and high subgroups $(p=.038)$, but the difference between experimental low and control high became nonsignificant $(p=.069)$. In other words, the scores of the experimental high subgroup continued to exceed those of the experimental low subgroup; however, the control high subgroup's scores were no longer significantly higher than those of the experimental low subgroup. 


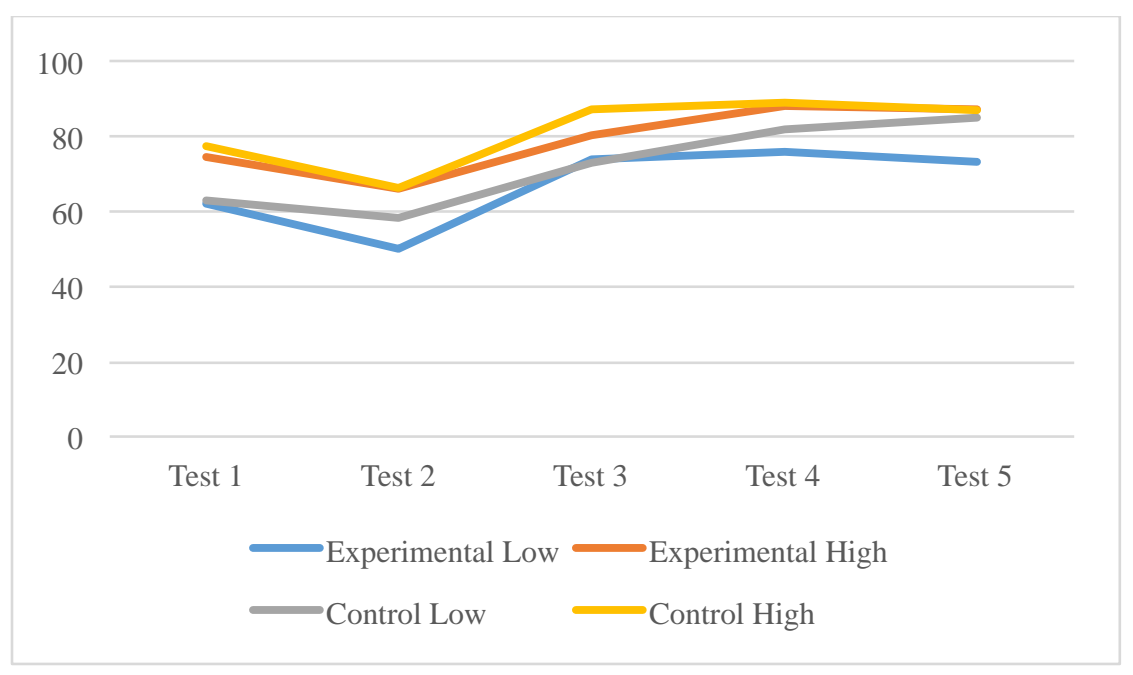

Figure 7: Comparison of in-class scores by listening proficiency subgroup.

This analysis was repeated using MALQ subgroup as the independent variable, yielding no significant results. Again, performance across tests was similar in all subgroups with Test 2 yielding the lowest scores and Test 4 generally yielding the highest scores. In this case it was the control high metacognitive awareness group that reversed this trend by performing higher on Test 5 than Test 4 .

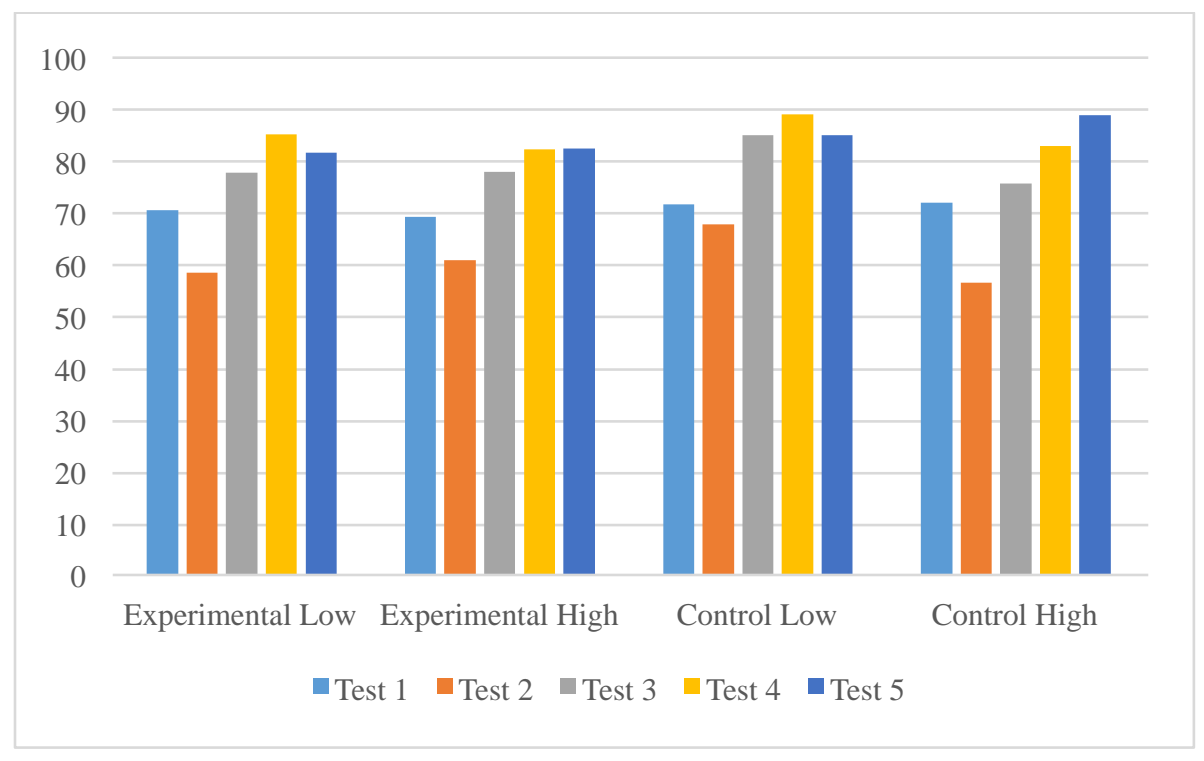

Figure 8: In-class listening scores by metacognitive awareness subgroup. 
Results of the one-way ANOVA of listening by MALQ subgroup revealed no significant between-group differences on any of the five in-class listening assessments. Although the control low awareness subgroup scored higher than the rest on Tests 2,3 , and 4, this difference was not significant.

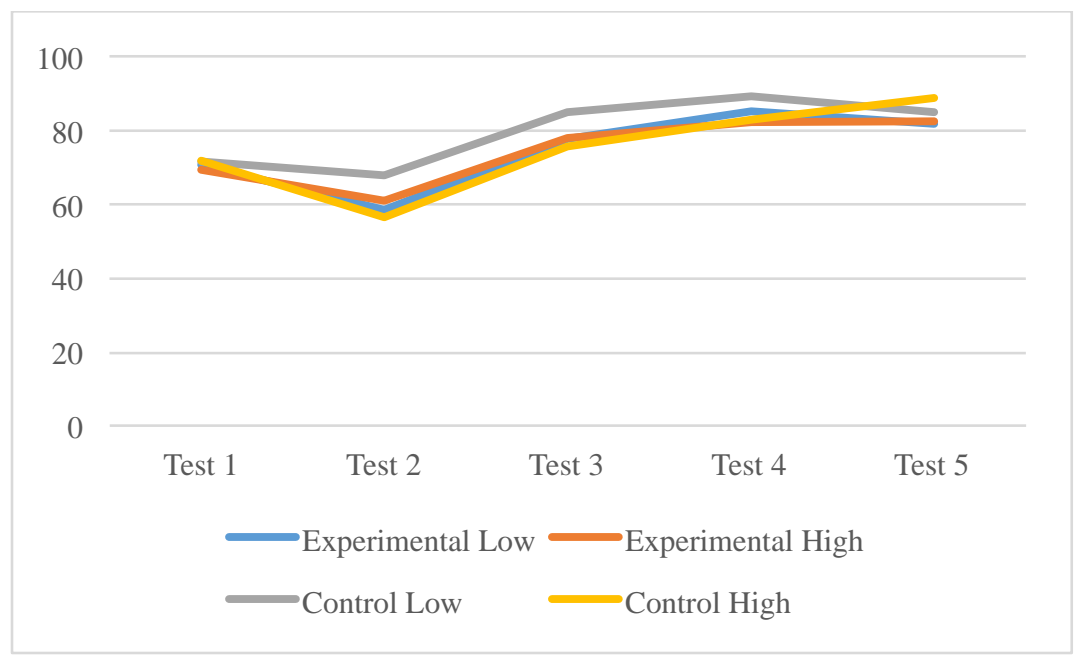

Figure 9: Comparison of in-class scores by metacognitive awareness subgroup.

In order to statistically evaluate the empirical validity of the listening instrument, Pearson correlation coefficients were found between the three empirical tests, which were each considered separately since the sections were counterbalanced, and each of the five in-class listening assessments. An analysis of the $r$-values shows moderate to strong correlations in all but two comparisons. These were significant at the $p<.01$ level, and are displayed in Table 9.

Table 15

Correlation Analysis (r-values) between Empirical and In-Class Assessments

\begin{tabular}{llllll}
\hline & Test 1 & Test 2 & Test 3 & Test 4 & Test 5 \\
\hline Pretest & $.437 * *$ & $.367^{* *}$ & $.370^{* *}$ & $.416^{* *}$ & $.336^{* *}$ \\
Posttest & $.509 * *$ & .225 & .192 & $.330^{* *}$ & $.381^{* *}$ \\
Delayed & $.392^{* *}$ & $.343^{* *}$ & $.309^{* *}$ & $.515^{* *}$ & $.680^{* *}$ \\
\hline
\end{tabular}

$* * \mathrm{p}<.01, * \mathrm{p}<.05$ 


\section{Discussion}

The initial hypotheses regarding listening comprehension and automaticity were not borne out in the data. Mean scores of listening and reaction time indicated that both the control group and the treatment group improved their listening comprehension over the course of the study and reduced their reaction time. The control group's listening scores were consistently higher than those of the experimental group while the experimental group's reaction times were consistently lower than those of the control group. Although both group and initial metacognitive awareness showed the possibility of producing main effects, these could not be interpreted due to a statistically significant interaction between the two.

With regard to listening gains, the interaction between the two independent variables was significant from the pretest to the posttest and from the pretest to the delayed posttest. The highest mean gain scores at these points in the study were demonstrated in the interaction of the control condition and high metacognitive awareness. The lowest mean gain scores were displayed in the control condition and low metacognitive awareness. This means that learners in the control condition with high metacognitive awareness experienced the largest improvements in listening while those in the control condition with low metacognitive experienced the smallest gains. This would seem to indicate that whatever benefits high metacognitive learners gained from being in the control condition were mitigated for those with low metacognitive awareness. That a combination of the control condition and low awareness resulted in the lowest gains is consistent with the hypotheses of the study, which hold that learners 
with low metacognitive awareness will show large gains in listening only in the experimental condition.

With regard to reaction time drop-offs, a significant interaction was again found from the pretest to the posttest and from the pretest to the delayed posttest. This time, however, it was the combination of the control condition and low metacognitive awareness that proved most successful in decreasing reaction time, while the combination of control condition and high metacognitive awareness led to the smallest declines in reaction time. This suggests that while learners with low awareness in the control condition did not improve in listening performance, they did lower their reaction time. Conversely, while learners with high awareness in the control condition improved their listening performance, they became slower.

Standard deviation in the listening gain scores was not large relative to the sample means at any point in the study, indicating that there was not too much variability between the means of different samples over time. Reaction time results, on the other hand, indicated that across the overall time frame, i.e. from the pretest to the delayed posttest, the variability in the control/low combination $(S D=90.42)$ was larger compared to the other combinations. In other words, although the control/low combination had the biggest drops in reaction time over the course of the study, it also displayed a wider range of gains in reaction times in this condition. Whereas all groups' reaction times decreased throughout the study, the standard deviation data would seem to indicate that the control/low group did so less consistently. 


\section{Listening by Listening Proficiency Subgroup}

Given Goh's (2000) and Hasan's (2000) observations that high-proficiency students tend to use metacognitive strategies during listening while low-proficiency students do not report using these strategies, it is reasonable to assume that explicit instruction in the use of metacognitive skills may be more beneficial for low-proficiency students. Based on this ancillary hypothesis, statistical analyses based on listening proficiency subgroups provided additional ways of interpreting the current data.

A two-way mixed factorial ANOVA of listening performance and reaction times based on listening proficiency subgroup and metacognitive awareness subgroup did not show significant interaction between the two independent variables. Main effects were found, however, for each. Listening proficiency acted as a predictor for listening performance for several group combinations, as did metacognitive awareness.

These results showed that in terms of listening gain scores, at the conclusion of the treatment period the experimental low proficiency subgroup had performed significantly better than both the experimental high proficiency $(p=.001)$ and the control high proficiency subgroups $(p=.006)$. The same is true, however, of the control low proficiency subgroup, which made higher gains than the experimental high $(p=.000)$ and the control high subgroups $(p=.001)$. These same results apply across the overall study (i.e. from pretest to delayed posttest) and there were no significant differences between the posttest and the delayed posttest. These results indicate that all lower proficiency L2 listeners made greater strides over time than their higher proficiency counterparts regardless of treatment condition. It is possible, then, that the mere fact of being exposed to additional input was sufficient to improve listening comprehension. While this result 
does not support the initial hypothesis regarding metacognitive instruction, it does underline the need for instructional approaches that take into account the varying proficiency levels represented in a group of students and that provide techniques that lead to improvement for all learners.

\section{Reaction Time by Listening Proficiency Subgroup}

While a comparison of reaction time drop-offs based on listening proficiency subgroup did not produce any significant results, the subdivision of participants did help to illuminate the issue of variability between the control and experimental groups. Most of the standard deviations were not overly large based on the sample means. However, from the pretest through the delayed posttest, the control group had considerably higher variance in scores. Analyzing the results by listening proficiency revealed that it was the control high proficiency subgroup that evidenced much higher variability than the other three subgroups (experimental low: $S D=73.65$; experimental high: $S D=60.81$; control low: $S D=83.82$; control high: $S D=104.38$ ). This suggests that high proficiency learners in the control group had a wider range of reaction times, an indication of less stability in reaction time over the course of the study. In other words, some participants' reaction times went up while others' went down. Conversely, this suggests that both of the experimental subgroups' reaction times decreased in a more consistent manner over the course of the study. While this cannot provide support for the hypothesis regarding automaticity because the between-group differences were not significant, it does provide an interesting avenue to pursue in future research regarding within-group variability. 


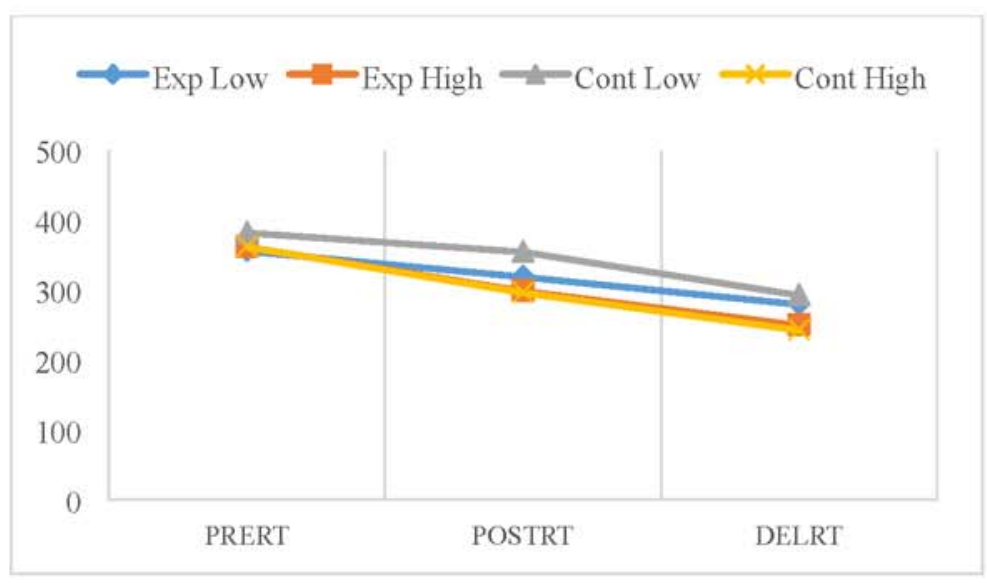

Figure 10: Reaction time by listening proficiency subgroup.

\section{Listening by Metacognitive Awareness Subgroup}

By subdividing participants based on treatment condition and MALQ score, I hoped to uncover any differences in sensitivity to the experimental treatment as a result of initial metacognitive awareness. Specifically, I would expect learners with a high level of initial metacognitive awareness to experience less benefit from metacognitive instruction than those with a low level of awareness at the outset, especially in the metacognitive group. I also sought to uncover any relationship that might exist between level of listening proficiency and level of initial metacognitive awareness. While this last element was not supported in the data since there was no significant interaction, the results partially supported the hypothesis that learners with low awareness in the experimental condition would outperform learners with a high level of initial awareness. Results also showed, however, that the control high awareness subgroup experienced the highest gains.

The analysis of listening gain scores based on MALQ subgroups indicated that, from the pretest to the posttest, the experimental low subgroup outperformed the control 
high subgroup ( $p=.052$, marginal), suggesting that the treatment received in the experimental condition aided learners with low metacognitive awareness in improving their listening performance. This provides important information to supplement the initial analysis of group and metacognitive awareness. That test showed that those who were in the control low condition improved their listening least; here, data demonstrate that the opposite happened for the low awareness learners in the experimental group, suggesting an effect for the experimental treatment.

That the control high awareness subgroup outperformed the control low subgroup ( $p=.015)$ supports the hypothesis that learners with low initial metacognitive awareness would outperform their high-level counterparts only in the treatment condition, since these learners were instructed in applying metacognitive strategies to the listening process. Because learners in the control condition were merely exposed to listening passages and encouraged to discuss the production of comprehension, they did not develop the tools to improve their listening performance in relation to their classmates with high metacognitive awareness.

Interestingly, the control high awareness subgroup also outperformed the experimental high awareness subgroup (pretest to posttest: $p=.010$ ). If Goh's (2000) observation is correct, this could be due to the fact that participants in the experimental group who began the study at a higher level of metacognitive awareness were already naturally applying metacognitive strategies to their listening performance. That they were then made to focus on these strategies may have interrupted their natural listening process, leading to a smaller increase in listening comprehension scores compared to the 
control high awareness subgroup, who were allowed to listen in their own way and naturally improve the listening process.

These results from pretest to posttest were mostly echoed in the broader time frame from pretest to delayed posttest. Control high continued to outperform both experimental high $(p=.033)$ and control low $(p=.018)$ in listening gains, but the difference between experimental low and control high became nonsignificant. Although the experimental low awareness subgroup $(M=1.75, S D=.64)$ obtained higher listening gain scores than the control low awareness subgroup $(M=1.13, S D=.47)$ between the pretest and the posttest, this difference was not statistically significant $(p=1.00)$. Nor was it significant from the pretest to the delayed posttest $(p=.961)$. Additionally, there were no significant differences between the experimental low and high subgroups from pretest to posttest $(p=1.00)$ or from pretest to delayed posttest $(p=1.00)$ although the slight difference in means favored the low awareness learners.

So how does one explain these results, which indicate that the high awareness learners in the control group outperformed not only the experimental high subgroup but also the low awareness learners in the same condition? Some indication of the reason for the first of these contexts can be found by analyzing the mean scores of the subgroups, as opposed to gain scores. Both the experimental high and the control low subgroups had higher mean scores on the pretest $(M=16.86, S D=2.85$ and $M=17.73, S D=2.00$, respectively) compared to the control high subgroup $(M=16.07, S D=1.90)$. Although none of these differences was significant, they may indicate that learners in the control high subgroup began the study at a lower level of listening proficiency, thereby allowing for larger gains over time. With regard to the second part of this query regarding the 
difference between the control high versus control low subgroups, the results suggest that learners with low initial metacognitive awareness in the control group were not provided with the right tools over the course of the study to improve their listening in relation to their high-level counterparts.

\section{Reaction Time by Metacognitive Awareness Subgroup}

With regard to reaction time, I expected learners with low initial metacognitive awareness, especially those in the experimental condition, to reduce their reaction time more dramatically than those who began the study with high metacognitive awareness, as they began to refine and automatize the listening process. This hypothesis was only partially supported in the data: it was borne out in the case of low versus high metacognitive awareness, but it was not upheld with regard to condition. The only significant post hoc comparison between groups revealed that it was in fact the low awareness learners in the control condition who decreased their reaction in comparison to the high awareness learners in the same condition. The experimental low subgroup did not differ significantly from the others.

The analysis of reaction time results based on initial metacognitive awareness paints quite a different picture from that of listening gain scores. In this case, the control high awareness subgroup had by far the smallest decrease in reaction time from the pretest to the posttest $(M=-6.26$, in seconds). Although all three remaining subgroups had considerably steeper drops in reaction time (experimental low: $M=-55.43$, experimental high: $M=-44.08$, and control low: $M=-76.20)$, the only difference that reached statistical significance in this time period was between control low and control 
high $(p=.020)$. This indicates that the low metacognitive awareness learners in the control group improved their reaction time significantly compared to the high awareness learners.

These results were repeated in the time frame from pretest to delayed posttest $(F=$ $\left.3.53, p=.021, \eta_{p}^{2}=.175\right)$, and the standard deviation provided further information regarding the relationship between the subgroups. The control low awareness subgroup continued to have the largest variation, indicating that while some learners in this subgroup lowered their reaction time dramatically, for others it decreased more modestly. Another interesting difference can be found between the high awareness learners in the control and experimental groups. The experimental high subgroup decreased their reaction times more steeply than the control high subgroup $(M=-107.64$ versus $M=-$ 61.15 , respectively). Though this difference was not significant $(p=.642)$, the standard deviations revealed that there was also less variation in the experimental high subgroup relative to the sample means $(S D=54.97)$, whereas standard deviation was higher in the control high subgroup $(S D=72.07)$.

Again, this data cannot support the hypothesis regarding reaction times based on metacognitive awareness; however, it can provide additional information about what is happening within the different experimental subgroups. In this case, the learners with high metacognitive awareness in the experimental group developed shorter reaction times than those in the control group and those reaction times decreased more consistently than those of the high awareness learners in the control group. In addition, since the data for reaction time by listening proficiency subgroup did not provide any significant results, the data presented in this section indicate that it is metacognitive awareness more so than 
initial listening proficiency that is a predictor of reaction time, thus supporting the hypothesis that increased metacognition can impact the automaticity of listening processes.

\section{In-class Listening Scores by Listening Proficiency Subgroup}

Listening scores from the in-class assessments were collected as a way to provide additional insight into the potential effects of the experimental treatment. Additionally, if between-group differences varied largely between the empirical tests and the in-class assessments, this would have been an indication that they did not measure the same construct. This result would suggest that the listening measurement tool created for the present study lacks empirical validity. All of this being considered, I expected that the results of Tests 1, 3, and 4 would resemble those of the three empirical assessments, situated as they were on similar dates. Test 2 would provide a glimpse into how the groups fared around the halfway point of the study, and Test 5 would act as a sort of second delayed posttest approximately three weeks after the end of the treatment period.

Since the in-class listening assessments differed from test to test, it would not have been appropriate to analyze them in terms of gain scores or to look at the trajectory of each group over time. Rather, I submitted them to a one-way ANOVA based on listening proficiency subgroup and analyzed between-group differences on each test. I also graphed the scores of all assessments in order to visually compare mean scores at different points in the study. It is important to note that in this analysis I utilized the mean scores of each subgroup on the empirical tests, as opposed to gain scores, in order to compare them appropriately to the in-class assessments. 
Results of a one-way ANOVA indicated that there were statistically significant results on all five of the in-class listening assessments; however, post hoc comparisons revealed that for Test 1 , which occurred approximately two weeks after the start of the study, none of the listening proficiency subgroups differed significantly from the others. This may indicate that any effects of the study had yet to take hold, and that the groups were still approximately equal in their listening performance at this point.

Test 2 took place approximately halfway through the study (i.e. four weeks after the pretest). At this point in time it can be seen that both of the high proficiency subgroups were outperforming the experimental low subgroup (experimental high: $p=$ .021 and control high: $p=.032$ ).

Test 3 corresponded to the posttest of the study, at which time the control high proficiency subgroup continued to outperform the experimental low learners $(p=.017)$. In addition, control high was outperforming control low $(p=.008)$. There is an overlap between these results and those of the posttest, which also indicated that the control high subgroup scored higher than the experimental low subgroup $(p=.014)$, but which also showed that the experimental high subgroup performed higher than the experimental low $\operatorname{subgroup}(p=.015)$.

Around the same time as the delayed posttest, Test 4 again showed that both the experimental high subgroup and the control high subgroup were outperforming the experimental low subgroup ( $p=.002$ for both comparisons). This was also true of the delayed posttest ( $p=.000$ for both comparisons).

Finally, Test 5 took place approximately three weeks after the end of the treatment period of the study (two weeks after the delayed posttest). At this time only 
one significant difference remained: the experimental high group scored higher than the experimental low group $(p=.038)$. This was true at both the posttest and the delayed posttest as well, suggesting that the high proficiency learners in the experimental condition maintained the strongest effect from the treatment.

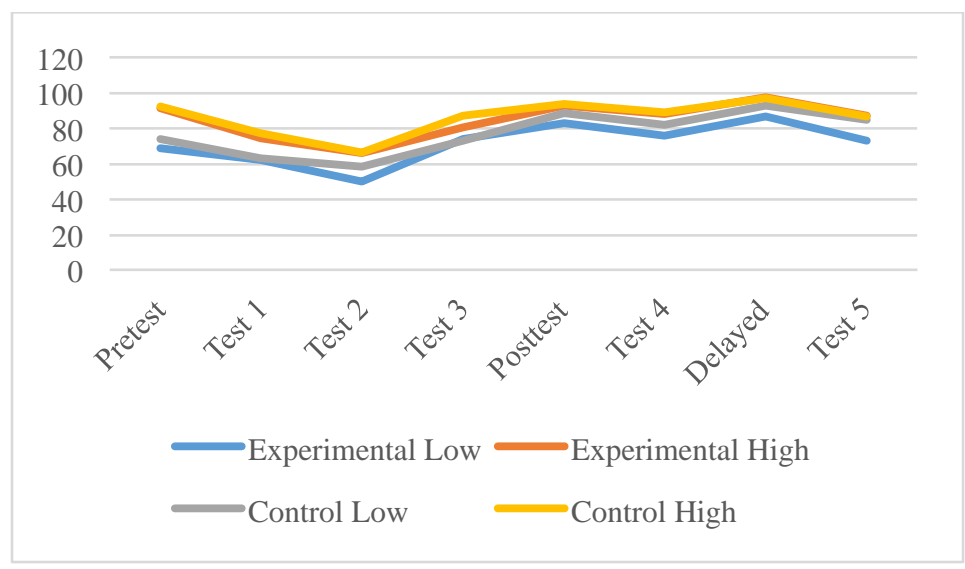

Figure 11: Comparison of all listening scores by listening proficiency subgroup. In order to more easily compare all measures, the mean scores of the pretest, posttest, and delayed posttest were converted to percentages and graphed alongside the in-class assessments in chronological order. By comparing these data visually (see Figure 9), it is possible to get a better understanding of how the in-class listening scores compared to the three measures used in the empirical study.

The main observation that can be made from this data is that throughout the five in-class assessments the two high proficiency subgroups consistently outperformed the two low proficiency subgroups. This trend is also evident in the three empirical tests, which follow the same pattern. While this data does not provide support for the hypotheses of the study, it upholds the similarity of the listening assessments.

This close resemblance in performance across the eight assessments suggests that the empirical assessment has construct validity, since it correlated with the other five tests 
that purport to measure the same construct, in this case listening. This is further supported by the results of a correlation analysis, which indicated significant correlations between the three empirical tests and all five in-class assessments. (Because the listening instrument study was slightly different every time the participants completed it due to the counterbalancing of the passages, each test was considered separately in this correlation analysis.) Thirteen of the fifteen correlations were significant at the $\mathrm{p}<.01$ level; interestingly, the posttest version of the instrument did not correlate at a significant level with either Test 2 or Test 3 . This could be related to the order of the passages in the posttest version of the instrument.

\section{In-class Listening Scores by Metacognitive Awareness Subgroup}

The same procedure was conducted for the listening data based on initial metacognitive awareness. Again, the expectation was that trends in the data would prove similar regardless of listening measure, demonstrating consistency between the listening tests used in class and those used in the empirical study. Data were submitted to a oneway ANOVA and were charted in order to visually compare mean scores across assessments.

Results of the one-way ANOVA revealed no significant differences among the five in-class listening assessments, and consequently there were no significant post hoc comparisons between the MALQ subgroups. While this may not seem to reflect the earlier results regarding metacognition and listening, it is important to remember that what is being compared in this section are the mean listening scores as opposed to gain scores. 


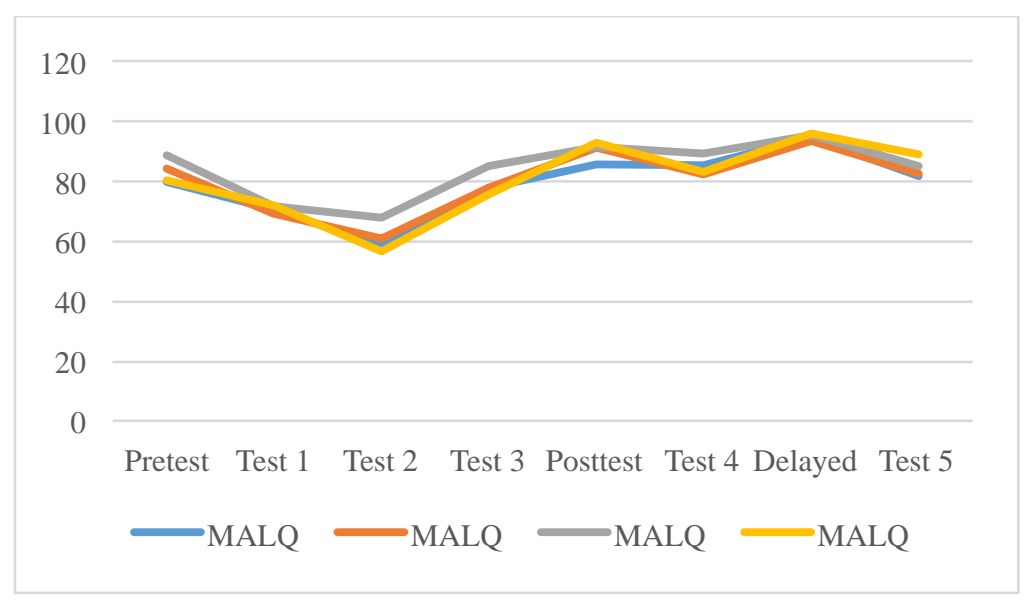

Figure 12: Comparison of all listening scores by metacognitive awareness subgroup. In fact, the pattern of listening scores based on MALQ subgroup supports the statistical analysis that metacognitive awareness alone cannot account for differences between groups. This is true of both the in-class assessments and the empirical listening measures used for the study. One slight trend that can be seen is that the learners in the control condition who started with a low level of metacognitive awareness tended to perform slightly better than the rest of the groups in the center portion of the study.

\section{Conclusions}

With respect to the hypotheses of the present study, the results of the data analysis are mixed. The first two hypotheses were not supported in the data, the third hypothesis was partially supported, and the fourth hypothesis was supported. Ancillary hypotheses based on existing research regarding proficiency level provided a basis for additional analysis that consequently furnished more detailed and interesting results. To summarize these results, I will briefly address them as they relate to each hypothesis. 
Hypothesis \#1: The group that receives explicit metacognitive instruction will outperform the control group on both the immediate and delayed posttests of listening comprehension performance.

Hypothesis \#1 was only partially supported by the data analysis. While there was a potential main effect for group in the ANOVA with respect to gains in listening, there was also significant interaction between group and level of metacognitive awareness across the study. It was in fact a combination of the control condition and high metacognitive awareness that provided the best overall results in this time frame. Worth noting, however, is that learners in the experimental condition with low metacognitive awareness showed the highest gains from the posttest to the delayed posttest. Although this result was not significant, it was in stark contrast to the relationship between groups in the other time periods. It may represent a delayed effect of the experimental treatment.

An ancillary hypothesis was thus developed, based on existing research on the use of metacognitive strategies used by L2 learners. In this hypothesis, learners with low initial listening proficiency should outperform those with high initial listening proficiency, especially in the experimental condition. When the groups were subdivided in order to test this hypothesis, it was partially supported by the data. It was indeed the lower level listeners who outperformed all high level listeners throughout the study; however, this was true in both the experimental condition and the control condition.

Hypothesis \#2: The metacognitive treatment group will experience a decrease in reaction time on the immediate and delayed posttests, indicating increasing automaticity. This decrease in reaction time will be significantly steeper than that of the control group. 
Reaction time data did not support the second hypothesis. In the initial analysis, there was a significant interaction between group and metacognitive awareness indicating that it was the combination of the control condition and low metacognitive awareness which provided the biggest drops in reaction time over the full course of the study. It should be noted again, however, that the combination of the experimental condition and high metacognitive awareness resulted in the highest drop in reaction time from the posttest to the delayed posttest, suggesting the potential for a delayed effect of the treatment. No significant between-group differences were found for reaction time when it was analyzed by subgroup of listening proficiency.

Hypothesis \#3: Because students with high metacognitive awareness will outperform those with low metacognitive awareness in the same condition on both measures at the beginning of the study, students with low metacognitive awareness in both conditions will have stronger gains in both listening performance and reaction time compared to their high-level counterparts over time. This will be more marked in the experimental condition.

Results of the initial analysis were unable to support the possible main effect for metacognitive awareness, because there was a significant interaction with group. In this case, high metacognitive awareness appeared to lead to listening comprehension gains over time. This contradicts Hypothesis \#3, since it predicted greater gains from low level learners; however, since high level listeners have been observed to use metacognitive strategies while they listen, it is possible that this natural inclination helped them in making greater gains over time. Reaction times, however, partially supported the third 
hypothesis. Students with low initial metacognitive awareness made greater gains (i.e. negative gains) in reaction time over the course of the study.

These results were echoed in the additional analysis of listening and reaction by subgroup of metacognitive awareness. Over the course of the study, the control high awareness group outperformed the experimental high group and the control low group on listening performance. Importantly, though, the experimental low awareness group obtained one significant result: they outperformed the control high awareness group on listening performance from pretest to posttest with the highest score of any subgroup. This result supported Hypothesis \#3, which predicted that the experimental low subgroup would show more marked differences on listening gains. Also worth noting is that the experimental low subgroup had the highest score from the posttest to the delayed posttest at which point the control high subgroup actually had the lowest listening gain score, but this was not significant.

With respect to reaction time, it was again the control low subgroup that outperformed the control high subgroup from the pretest to the posttest and from the pretest to the delayed posttest. Again, this partially supports the third hypothesis since low awareness learners decreased their reaction time more than high awareness learners; however, that this happened in the control rather than the experimental condition refutes a portion of the hypothesis.

One thing that can be said for automaticity, as measured by reaction time, is that it differed significantly only as a result of varying levels of initial metacognitive awareness, whereas it was not affected whatsoever by initial level of listening proficiency. Since reaction time can be used to measure the automaticity of a process, this would seem to 
support the hypothesis that there is a relationship between metacognition and automaticity of listening.

Hypothesis \#4: Student performance will not vary significantly based on listening assessment. In other words, the listening assessments created for the study will prove as effective as those used in the classroom based on correlation analyses.

Whereas metacognitive awareness was related to reaction time, there was a strong relationship between initial listening proficiency and gains in listening performance. Learners with high initial listening proficiency in both treatment conditions performed significantly better than their low-level counterparts on all five of the in-class listening assessments. Similar relationships were found between subgroups on the in-class assessments and the empirical tests. Additionally, a correlational analysis of these assessments and the three empirical tests indicated that they measured the same construct, giving the instruments created for the present study a measure of empirical validity.

The overall results for listening performance and reaction time are summarized in Table 16. Though no significant differences were found in the period between the posttest and the delayed posttest, listening proficiency continued to rise and reaction time continued to fall. For this reason, I have included information to show which subgroups made the strongest gains in that time period, because it can aid in the interpretation of the overall scores.

To summarize, listening performance over the course of the study improved most for learners in both conditions who began with low listening proficiency. This result suggests that for low-level listeners, type of listening instruction is less important than exposure to and practice with listening input when it comes to improving comprehension. 
Table 16

Summary of Overall Results

\begin{tabular}{|c|c|c|c|}
\hline Testing Period & Analysis & Listening & Reaction Time \\
\hline \multirow[t]{5}{*}{ Pre-Post } & Initial & Control x High* & Control x Low* \\
\hline & Subgroup LP & $\mathrm{EL}>\mathrm{EH}^{* *}, \mathrm{EL}>\mathrm{CH}^{* *}$ & $\mathrm{CH}(\mathrm{ns})$ \\
\hline & & $\mathrm{CL}>\mathrm{EH}^{* *}, \mathrm{CL}>\mathrm{CH}^{* *}$ & \\
\hline & Subgroup Meta. & $\mathrm{EL}>\mathrm{CH}^{*}$ & $\mathrm{CL}>\mathrm{CH}^{*}$ \\
\hline & & $\mathrm{CH}>\mathrm{EH}^{* *}, \mathrm{CH}>\mathrm{CL}^{*}$ & \\
\hline \multirow[t]{3}{*}{ Post-Del } & Initial & Exp. x Low (ns) & Exp. x High (ns) \\
\hline & Subgroup LP & None & CL (ns) \\
\hline & Subgroup Meta. & CL (ns) & $\mathrm{EH}(\mathrm{ns})$ \\
\hline \multirow[t]{4}{*}{ Pre-Del } & Initial & Control x High* & Control x Low** \\
\hline & Subgroup LP & $\mathrm{EL}>\mathrm{EH}^{* *}, \mathrm{EL}>\mathrm{CH}^{* *}$ & $\mathrm{CH}(\mathrm{ns})$ \\
\hline & & $\mathrm{CL}>\mathrm{EH}^{* *}, \mathrm{CL}>\mathrm{CH}^{* *}$ & \\
\hline & Subgroup Meta. & $\mathrm{CH}>\mathrm{EH}^{*}, \mathrm{CH}>\mathrm{CL}^{*}$ & $\mathrm{CL}>\mathrm{CH}^{*}$ \\
\hline
\end{tabular}

Note: $\mathrm{LP}=$ listening proficiency, Meta. $=$ metacognitive awareness, $\mathrm{EL}=$ experimental low, $\mathrm{EH}=$ experimental high, $\mathrm{CL}=$ control low, $\mathrm{CH}=$ control high, $\mathrm{ns}=$ nonsignificant $* * \mathrm{p}<.01, * \mathrm{p}<.05$

Further, learners who began the study with low metacognitive awareness seem to have benefited most from the experimental treatment while those who began with high metacognitive awareness benefited from being in the control condition. This result suggests that for learners with low metacognitive awareness listening comprehension improves as a result of metacognitive instruction. Since the high awareness learners in the control condition outpaced those in the experimental condition, however, it would seem that metacognitive instruction may actually impede improvement in listening for those who already have a high level of metacognitive awareness.

Reaction time data provided fewer significant differences between groups; however, what is apparent is that metacognitive awareness (as a function of group) was important when it came to decreasing reaction time. Initial listening proficiency did not seem to affect the development of automaticity, regardless of treatment condition. 
Having low metacognitive awareness, on the other hand, led to increased automaticity for those learners in the control condition. This is contrary to my hypothesis, which predicted that automaticity would increase most for those learners who had low initial awareness in the experimental condition. Experimental low awareness learners did in fact demonstrate the greatest gains in listening performance at the posttest; it is possible that while their listening improved during this time, their attention became more focused on the process of listening, leading them to spend more time thinking about their answers compared to the control group. Although this could be interpreted as an indication that automaticity does not improve as a result of metacognitive instruction, it is also possible that the effect is delayed and would be revealed over the course of a longitudinal study. These data do indicate that metacognitive awareness is related to reaction time and should be studied further.

Overall, these results suggest that initial listening proficiency is a reliable predictor for gains in listening over time regardless of instruction type. Initial metacognitive awareness, on the other hand, is more effective in explaining listening gains as a factor of treatment condition. The case of reaction time is more complex and will require further research. 


\section{CHAPTER 5: CONCLUSIONS}

\section{Summary of the Study}

The present study was designed to examine the overarching hypothesis that it is through the use of metacognitive devices to focus and direct attention during L2 listening that learners can refine the attendant perceptual and cognitive processes, leading to improved listening performance and increased automaticity. This hypothesis is based on existing research in attention and noticing, memory, repetition, and controlled versus automatic processing. Because metacognitive instruction utilizes repetition of the input in a context that supports focused attention on input and cognitive processes, it provides the practice necessary to transform the procedure of listening from one that requires controlled processing to one that is processed automatically. This is in line with the assertions made by listening scholars (Goh, 2000; Hasan, 2000; Vandergrift, 2007), who have suggested that instructing learners to utilize top-down strategies for listening and to focus on the gist of the input helps them to free up attentional resources to concentrate (i.e. use controlled processing) on the parts of the input that are unfamiliar.

Four hypotheses were developed around this concept and were tested through an empirical study conducted in all sections of postsecondary, second-semester French. In these hypotheses, I predicted that learners in the experimental condition would outperform those in the control condition on both listening and automaticity measures. 
Further, I expected learners with low initial metacognitive awareness in the experimental condition to outpace their high awareness counterparts in listening and reaction time at the end of the study. Finally, I expected to see learners perform similarly on their in-class listening assessments, providing additional support for the experimental treatment and validating the listening instrument.

Overall results partially supported the hypotheses of the study. An initial analysis of the data revealed a significant interaction between treatment condition and initial level of metacognitive awareness. Additional statistical analyses were conducted based on initial listening proficiency (low or high) and initial level of metacognitive awareness (low or high). These results provided a more detailed basis for examining the hypotheses and revealed interesting relationships between subgroups, but they did not allow for full support of the hypotheses.

In the initial data analysis using group (treatment condition) and metacognitive awareness (low or high) as independent variables, it was the interaction of these two variables that impacted both listening and reaction time. It wasn't possible, then, to explain either of the dependent variables solely on the basis of treatment condition. An analysis of the dependent variables based on initial listening proficiency, however, demonstrated that in fact those who started the study in the low proficiency group outperformed the high proficiency group on listening performance at the end of the study. This result was tempered by the fact that it was true in both treatment conditions, suggesting that perhaps all low-level listeners benefited from the repeated exposure to listening passages. The influence of metacognitive awareness on listening gain scores, on the other hand, provided some support for the hypotheses of the study. Results showed 
that learners with low initial metacognitive awareness in the experimental condition outperformed the control high awareness subgroup on listening at the end of the study. The experimental low subgroup had the highest gains in listening both from the pretest to the posttest and from the posttest to the delayed posttest, although only the first of these was significant. This suggests that the experimental treatment did give this subgroup of learners an edge in improving listening comprehension.

Conversely, listening proficiency was not a significant factor in reaction time gains between groups, with no significant between-group effects. Results from the initial analysis, however, suggested that metacognitive awareness does impact reaction time. Learners with low metacognitive awareness decreased reaction time more quickly than learners with high initial awareness. This result was echoed in the additional analysis based on subgroups of metacognitive awareness, which showed that the control low subgroup outperformed the control high subgroup across the study. While this result did not support the hypothesis that learners in the experimental low subgroup would decrease their reaction time more than the other subgroups, it did provide potentially interesting information about the relative impact of metacognitive awareness on the automaticity of listening. Specifically, metacognitive awareness had an impact on reaction times while listening proficiency did not, suggesting that metacognitive awareness can play an important role in decreasing reaction time. Further research must be done to investigate this relationship in a more detailed way.

There was a significant relationship between listening proficiency subgroup and scores on the in-class listening assessments indicating that higher proficiency students performed better on these measures. Because five separate assessments were used in 
class, it was not possible to look at listening gains over time in order to compare that to the experimental data; however, many of the post hoc comparisons that proved significant on these assessments corresponded to those that were significant for the three empirical tests. Additionally, a correlation analysis of the eight different listening measures showed significant relationships, indicating that the listening instrument created for the study has empirical validity.

\section{Limitations}

The main limitations of the present study are related to the fact that it was conducted in the L2 classroom, where it is not possible to control for all possible variables. This is a drawback to classroom language acquisition studies in general; however, it is balanced by the fact that classroom studies are more ecologically valid. Because classroom studies investigate learning as it happens and in its usual environment, they are better suited to drawing conclusions that can be generalized to other classrooms. Whereas in laboratory studies it is easier to isolate the variable one is studying, this is not the way real students learn. The complex interactions between the many variables present in the classroom greatly influence the learning that takes place there; conducting research in the classroom is therefore more likely to help us understand how this learning happens.

There are many factors that can influence studies that take place in the classroom, and this study is no exception. Some of these factors include individual student differences such as intelligence, motivation, disabilities, and other personal issues; behavioral issues such as lack of effort in early morning or late afternoon classes, or 
annoyance at being required to take a language course; classroom issues such as the rapport among students and between the students and the instructor; and practical issues such as technological problems, student absences, and environmental factors (e.g. weather). All of these variables interact in different ways each day to create a complex environment that affects learning for every student.

One of the most salient limitations to the present study was the necessity of using several different instructors to teach the experimental lessons. There were both practical and ethical considerations involved in this decision. On the practical side, it made more sense to choose a level that I as the primary researcher was not involved in teaching, because it would lead to a larger sample size. In this way I was able to include seven class sections in the study, whereas I would only have been able to include two sections if I restricted the study to the courses I was teaching myself. From an ethical standpoint, it is widely believed that the primary researcher should not use her own classes in a study because she may subconsciously introduce bias, whether in her interactions with the students or in her analysis of the data. Using the instructors who were assigned to the class sections involved in the study, however, has its own potential problems. The first of these is the mere fact of having different people teaching the same lesson. Each instructor has their own teaching style, their own way of relating to their students, and their own way of organizing each class session. Even if they all followed the training procedure perfectly while teaching the listening activity, the impact may have been lessened or strengthened based on these individual differences in teaching.

On a related note, it is always possible that the instructors may not have followed the training procedure perfectly. On any given day, an instructor in the experimental 
condition may have forgotten to include one of the metacognitive procedures or an instructor in the control condition may have inadvertently brought the students' attention to a reflection strategy. In both conditions it is possible that there may been technical issues in the classroom that interrupted the students' focus or caused the instructor to skip the activity altogether. While I attempted to mitigate this limitation by providing detailed training to all instructors involved in the study, providing them with training materials and maintaining contact with them throughout the study, the only way to truly control the classroom context and the instruction of the activity would have been to do it myself.

Another limitation related to the classroom was the potential for fatigue. The listening activities were implemented into every possible classroom session over eight weeks. While this was necessary in order to provide sufficient contact time with the instructional technique it could very well have become tedious, especially for students in the metacognitive group whose exercises were more detail-oriented than those in the control group.

A limitation to the research design was the lack of a true control group. The group that was labeled "control" in the present study was not a true control group, because there was a manipulation of their lessons as well. This was done in order to ensure that both conditions spent the same amount of time listening and were given equivalent exercises; otherwise it could be said that the experimental group only improved in relation to the control group because of the presence of an additional activity. The control group was created, based on these considerations, to represent a class using the prevailing method of listening instruction, i.e. passive listening followed by a focus on what was understood (as opposed to how they went about understanding it), 
while addressing the issue of equivalent instructional time. This limitation was mitigated to some extent by using gain scores as the basis for statistical analysis rather than comparing group scores on individual assessments. In other words, the research questions in the current investigation did not address difference in performance on each assessment; rather, they concerned the rate of improvement over time in each group. These rates were then compared, eliminating the need for a third group for comparison.

The fact that the instrument used to measure listening comprehension was created for the present study represents a possible limitation as well. While a correlational analysis with outside measures of listening indicated that the instrument had empirical validity and steps were taken to ensure that the design of the test maintained construct validity, it was not possible to establish the reliability of the instrument since this was the first time it was used. This problem can be addressed in the future by conducting testing of the instrument to further establish these parameters.

Finally, a limitation of the data analysis was the way automaticity was measured. Researchers typically use two measures to determine automaticity: reaction time and error rate. Most of those studies, however, have focused on speaking rather than listening. Error rate was therefore calculated based on the number of grammatical errors over the total utterance. This type of scoring is not possible in assessing listening. In the present study, then, reaction time alone was used as a rough estimate of automaticity. It will be necessary in future studies to devise a more precise way of measuring automaticity for listening. 


\section{Pedagogical Implications}

While the results of the present study were inconclusive overall, certain aspects served to illuminate the relative contributions of listening proficiency and metacognitive awareness to the development of listening comprehension and automaticity. The ecological validity of the study provides justification for making a few tentative suggestions for pedagogy. These are tempered by the fact that further research needs to be done in order to clarify these results and obtain more conclusive data.

Because initial listening proficiency impacted gains in listening regardless of treatment condition, no suggestions can be made regarding the use of metacognitive instruction to improving listening performance. Rather, it can be concluded only that providing learners with sufficient opportunities to listen to repeated, authentic L2 input in an audiovisual format leads to improved listening performance, especially for less-skilled listeners. It also underscores the need for instructors to be aware of initial differences in listening proficiency among their students in order to create listening tasks that address the needs of learners with varying degrees of proficiency.

The main implications of the present study concern learners' initial level of metacognitive awareness. Specifically, higher levels of initial metacognitive awareness in the control condition were related to gains in listening comprehension, meaning that in that in the absence of metacognitive instruction it is those with a higher level of metacognitive awareness who make greater strides in listening comprehension. This should indicate that by increasing metacognitive awareness, instruction can concurrently improve listening comprehension for learners with low initial awareness. This assumption is supported by the fact that low awareness learners in the experimental 
condition increased their listening skills to a greater extent than those in the control condition who started with high awareness. It is also supported by the fact that the control low awareness group had the smallest gains in listening comprehension, indicating that they suffered from the lack of metacognitive instruction. It is important to keep in mind, however, that there may be a ceiling effect related to metacognitive instruction for those who already have high levels of metacognitive awareness, as shown by the fact that high awareness learners in the control condition improved listening at a faster rate than those in the experimental condition. In any case, the results of the present study indicate that helping students to improve their metacognitive awareness can lead them to make improvements in listening comprehension.

With regard to automaticity, lower levels of metacognitive awareness were related to gains in reaction time, suggesting that those learners who have lower levels of initial metacognitive awareness are more likely to decrease their reaction times. While this would seem to indicate that metacognitive instruction should improve reaction times, this was not supported in the data since it was only significant in the control condition. This needs to be studied in further detail in order to support making a suggestion for pedagogy.

A general implication that can be drawn from the present study is that it is important to account for learner differences in preparing lessons in listening. Varying activities in order to address differences in metacognitive awareness is particularly important since this can have an impact on both listening and reaction times. In addition, providing multiple repetitions of authentic L2 materials in audiovisual format is beneficial for listeners of all levels. 


\section{Directions for Future Research}

The mixed results of the present study provide several opportunities for future research. These include running further tests to determine the validity and reliability of the listening instrument, developing a more precise way of measuring automaticity in listening, creating a new study design for further investigation of the effects of metacognitive instruction on automaticity, and attempting to replicate the results connecting metacognitive awareness to gains in listening scores. I will address the last three of these here.

Because the overall hypothesis of the study stated that metacognitive instruction should contribute to the automatization of listening, it was particularly interesting when the results showed that reaction time was not affected by initial listening proficiency and that the only significant difference in reaction time based on initial metacognitive awareness was between the control low and control high subgroups. This was further complicated by the fact that the experimental high subgroup showed the steepest drop in reaction time between the posttest and the delayed posttest, although this result was not statistically significant. These results demonstrate the necessity of improving the measurement of automaticity by using a more sensitive instrument.

Qualtrics was employed for the listening tests in the present study for logistical and practical reasons: it is available free through the university's information technology website, the surveys created can be accessed via a URL by each student at his or her computer station, it provides automatic scoring, and it has the capability to record rough reaction time data by analyzing the first and last clicks on each page. Creating a more sensitive tool for measuring automaticity may require software that can accurately 
calculate reaction time data for each individual question rather than for the page as a whole, which in this case included on average five questions. Additionally, in order to more closely approximate the current standard of reaction time plus error rate for determining automaticity, it would be useful to include a short answer or free recall section that can be scored by hand to obtain an error rate measurement. These adjustments would provide an automaticity measure in line with current research.

Using this modified version of the listening test, the study should be replicated in order to see if reaction time data then supports the hypothesis that metacognitive instruction can affect listening and automaticity based on initial listening proficiency or metacognitive awareness. Because the addition of the short answer or free recall section to the instrument could also increase the sensitivity of the listening measurement, I would expect to replicate, if not strengthen, the results of the analysis of listening gains based on metacognitive awareness.

\section{Final Conclusions}

The present paper reported the results of an empirical study that was designed to investigate the potential effects of metacognitive instruction on the subsequent listening and reaction time gains of an experimental group when compared to a control group that represented a typical product-oriented approach to listening instruction. These data were obtained in order to test four hypotheses: that metacognitive instruction, through its use of repetition and conscious attention to cognitive processes, would lead to greater improvement in listening comprehension and development of automaticity (as measured by reaction time) in the experimental condition when compared to the control condition 
where learners participated solely in discussion of comprehension questions.

Additionally, learners in the experimental condition who began the study with a lower level of metacognitive awareness would outperform other subgroups on listening comprehension and automaticity measures. Finally, these results were expected to be mirrored in participants' scores on in-class listening assessments over the same time period, thus supporting the effectiveness of the experimental methodology and establishing its empirical validity.

Results of a series of two-way mixed factorial analyses of variance revealed that initial listening proficiency affected eventual listening gains regardless of treatment condition. Learners in both low proficiency subgroups made greater gains in listening than those in both high proficiency subgroups, indicating that type of instruction is not as important as initial skill level in determining listening gains. Initial level of metacognitive awareness, on the other hand, played an important role in gains in both listening and reaction time. Metacognitive instruction led learners with low metacognitive awareness to outperform all other subgroups in listening at the posttest, indicating that the accumulation of metacognitive knowledge over time leads to an increase in listening comprehension. This was supported by the fact that learners with high awareness in the control condition also made strong gains in listening comprehension throughout the study period. By contrast, there appeared to be a ceiling effect for listeners who began with a high level of metacognitive awareness in the experimental condition. In this comparison, the control condition outperformed the experimental condition, suggesting that high metacognitive awareness on its own may be 
sufficient to improve listening comprehension and explicit instruction may actually impede this development.

Automaticity data was less conclusive than listening data, showing that while low metacognitive awareness led to steeper drops in reaction time, this was most salient in the control condition. A possible reason for this is the way automaticity was measured; however, it does provide support for the idea that metacognition is an important indicator of automaticity. This needs to be investigated in future research with an improved instrument for calculating automaticity, as described above.

The empirical listening tests compared favorably to those employed in the classroom during the period of the study, indicating that the subgroups performed similarly in relation to one another on all measures of listening comprehension. This was confirmed through a correlation analysis, supporting the empirical validity of the listening tests designed for the study.

Overall, the results of the present study suggest that metacognitive instruction has differential effects on listening comprehension depending upon the initial metacognitive awareness of the learners involved, a finding that supports the idea that individual differences can have an impact on language learning and can be more enlightening than overall group means when investigating the efficacy of a certain instructional technique. 
REFERENCES 


\section{REFERENCES}

Abbuhl, R. (2012). Using self-referential pronouns in writing: The effect of explicit instruction on L2 writers at two levels of proficiency. Language Teaching Research, 16(4), 501-518.

Abraham, L. B. (2007). Second-language reading comprehension and vocabulary learning with multimedia. Hispania, 90, 98-108.

Akamatsu, N. (2008). The effects of training on automatization of word recognition in English as a foreign language. Applied Psycholinguistics, 29, 175-193.

Anderson, J. R. (1995). Cognitive psychology and its implications. New York, NY: Freeman.

Becker, S. R. (2012). Effects of audiovisual media on the acquisition of listening comprehension in French (Master's thesis). Retrieved from ProQuest.

Blasco-Mayor, M. J. (2009). CALL-enhanced L2 listening skills - Aiming for automatization in a multimedia environment. Indian Journal of Applied Linguistics, 35(1), 107-120.

Brown, S. (2011). Listening myths: Applying second language research to classroom teaching. Ann Arbor, MI: University of Michigan Press.

Bruer, J. T. (1998). Education. In W. Brechtel and G. Graham (Eds.) A Companion to Cognitive Science (681-690). Massachusettes: Blackwell.

Brunswik, E. (1956). Perception and the representative design of psychological experiments. Berkeley, CA: University of California Press.

Buck, G. (2001). Assessing Listening. Cambridge University Press: Cambridge, UK.

Carrell, P. L. (1989). Metacognitive awareness and second language reading. Modern Language Journal, 73, 121-130. 
Chen, W.-C. (2009). Noticing in text-based computer-mediated communication: A study of task-based telecommunication between native and nonnative English speakers (Doctoral dissertation). Retrieved from ProQuest.

Corder, S. P. (1967). The significance of learners' errors. International Review of Applied Linguistics, 5, 160-170.

Cross, J. (2011). Comprehending news videotexts : The influence of the visual content. Language Learning and Technology, 15(2), 44-68.

Cummins, J. (1979). Linguistic interdependence and the education development of bilingual children. Review of Education Research, 49(2), 222-251.

Cummins, J. (1976). The influence of bilingualism on cognitive growth: A synthesis of research findings and explanatory hypotheses. Working Papers on Bilingualism, 9, 1-43.

de Graaff, R. (1997). The Esperanto experiment: Effects of explicit instruction on second language acquisition. Studies in Second Language Acquisition, 19(2), 249-276.

De la Fuente, M. J. (2014). Learners' attention to input during focus on form listening tasks: the role of mobile technology in the second language classroom. Computer Assisted Language Learning, 27(3), 261-276.

DeKeyser, R. M. (2007). Skill acquisition theory. In B. VanPatten and J. Williams (Eds.), Theories in Second Language Acquisition (pp. 97-113). Mahwah, NJ: Lawence Erlbaum Associates, Inc.

DeKeyser, R. M. (2001). Automaticity and automatization. In P. Robinson (Ed.), Cognition and Second Language Instruction (pp. 125-151). Cambridge: Cambridge University Press.

Desmarais, L., Duquette, L., Renié, D., \& Laurier, M. (1997/1998). Evaluating learning and interactions in a multimedia environment. Computers and the Humanities, 31, 327-349.

Dupuy, B. C. (1999). Narrow listening: An alternative way to develop and enhance listening comprehension in students of French as a foreign language. System, 27(3), 351-361.

Egi, T. (2004). Verbal reports, noticing, and SLA research. Language Awareness, 13(4), 243- 264.

Elkhafaifi, H. (2005). Listening comprehension and anxiety in the Arabic language classroom. The Modern Language Journal, 89, 206-220. 
Ellis, N. C. (1994). Introduction : Implicit and explicit language learning - an overview. In N. Ellis (Ed.) Implicit and Explicit Learning of Languages (pp. 1-31). San Diego, CA: Academic Press.

Ellis, R. (2009). Implicit and explicit learning, knowledge and instruction. In R. Ellis, S. Loewen, C. Elder, R. Erlam, J. Philp, \& H. Reinders (Eds.), Implicit and Explicit Knowledge in Second Langauge Learning, Testing and Teaching (pp. 3-25). Bristol, U.K.: Multilingual Matters.

Ellis, R. (1997). SLA research and language teaching. New York, NY: Oxford University Press.

Ercetin, G., \& Alptekin, C. (2013). The explicit/implicit knowledge distinction and working memory : Implications for second-language reading comprehension. Applied Psycholinguistics, 34, 727-753.

Favreau, M., \& Segalowitz, N. (1983). Automatic and controlled processes in the first and second language reading of fluent bilinguals. Memory and Cognition, 11, $565-574$.

Field, A. (2013). Discovering statistics using IBM SPSS Statistics. London, UK: Sage Publications.

Flavell, J. H. (1979). Metacognition and cognitive monitoring: A new area of cognitivedevelopmental inquiry. American Psychologist, 34(10), 906-911.

Flavell, J. H. (1976). Metacognitive aspects of problem solving. In L. B. Resnick (Ed.), The nature of intelligence (pp. 231-236). Hillsdale, NJ: Erlbaum.

Flege, J. E. (1995). Second language speech learning: Theory, findings, and problems. In W. Strange (Ed.), Speech Perception and Linguistic Experience: Issues in CrossLanguage Research (233-277). Timonium, MD: York Press, Inc.

Flege, J. E., \& MacKay, I. R. A. (2004). Perceiving vowels in a second language. Studies in Second Language Acquisition, 26, 1-34.

Flege, J. E., MacKay, I. R. A., \& Meador, D. (1999). Native Italian speakers' perception and production of English vowels. The Journal of the Acoustical Society of America, 106(5), 2973-2987.

Friederici, A.D., Meyer, M., \& von Cramon, D.Y. (2000). Auditory language comprehension: An event-related fMRI study on the processing of syntactic and lexical information. Brain and Language, 74, 289-300. 
Froehlich, J. (1988). German videos with German subtitles: A new approach to listening comprehension development. Die Unterrichtspraxis, 21,199-203.

Gardner, R. C. (2010). Motivation and second language acquisition: The socioeducational model. New York, NY: Peter Lang Publishing.

Gass, S. M., \& Selinker, L. (1994). Second language acquisition: An introductory course. Mahwah, NJ: Taylor and Francis.

Ginther, A. (2002). Context and content visuals and performance on listening comprehension stimuli. Language Testing, 19(2), 133-167.

Goh, C. (2008). Metacognitive instruction for second language listening development: Theory, practice and research implications. RELC Journal, 39(2), 188-213.

Goh, C. (2002). Learners' self-reports on comprehension and learning strategies for listening. Asian Journal of English Language Teaching, 12, 46-68.

Goh, C. (2000). A cognitive perspective on language learners' listening comprehension problems. System, 28, 55-75.

Goh, C. (1998). How ESL learners with different listening abilities use comprehension strategies and tactics. Language Teaching Research, 2(2), 124-147.

Goh, C. (1997). Metacognitive awareness and second language listeners. ELT Journal, 51(4), 361-369.

Goh, C., \& Taib, Y. (2006). Metacognitive instruction in listening for young learners. ELT Journal, 60(3), 222-232.

Gourgey, A. F. (1998). Metacognition in basic skills instruction. Instructional Science, 26, 81-96.

Graham, S., \& Macaro, E. (2008). Strategy instruction in listening for lower-intermediate learners of French. Language Learning, 58(4), 747-783.

Guikema, J. P. (2009). Discourse analysis of podcasts in French: Implications for foreign language listening development. In Abraham \& Williams (Eds.), Electronic

Discourse in Language Learning and Language Teaching (169-189).

Philadelphia, PA: John Benjamins Publishing Company.

Hanaoka, O. (2007). Output, noticing, and learning: An investigation into the role of spontaneous attention to form in a four-stage writing task. Language Teaching Research, 11(4), 459-479. 
Harlow, L.L., \& Muyskens, J.A. (1994). Priorities for intermediate-level language instruction. The Modern Language Journal, 78(2), 141-154.

Hasan, A.S. (2000). Learners' perceptions of listening comprehension problems. Language, Culture and Curriculum, 13(2), 137-153.

Hulstijn, J. (2002). Towards a unified account of the representation, processing and acquisition of second language knowledge. Second Language Research, 18(3), 193-223.

Hulstijn, J. H., Van Gelderen, A., \& Schoonen, R. (2009). Automatization in second language acquisition: What does the coefficient of variation tell us? Applied Psycholinguistics, 30, 555-582.

Ifatidou, E., \& Matsui, T. (2013). Pragmatic development in L1, L2, L3: Its biological and cultural foundations. Journal of Pragmatics, 59, 1-4.

Izumi, S. (2002). Output, input enhancement, and the noticing hypothesis. Studies in Second Language Acquisition, 24, 541-577.

Jensen, E.D., \& Vinther, T. (2003). Exact repetition as input enhancement in second language acquisition. Language Learning, 53(3), 373-428.

Jin, J. (2011). An evaluation of the role of consciousness in second language learning. International Journal of English Linguistics, 1(1), 126-136.

Johnson-Laird, P. N. (1983). Mental models: Towards a cognitive science of language, inference, and consciousness. Cambridge: Cambridge University Press.

Jones, L.C. (2009). Supporting student differences in listening comprehension and vocabulary learning with multimedia annotations. CALICO Journal, 26(2), 267289.

Jones, L.C., \& Plass, J.L. (2002). Supporting listening comprehension and vocabulary acquisition in French with multimedia annotations. The Modern Language Journal, 86, 546-561.

Jung, E.H. (2003). The role of discourse signaling cues in second language listening comprehension. The Modern Language Journal, 87, 562-577.

Kost, C. R., Foss, P., \& Lenzini, J. J. (1999). Textual and pictorial glosses: Effectiveness on incidental vocabulary growth when reading in a foreign language. Foreign Language Annals, 32(1), 89-113. 
Krashen, S. (1981). Second language acquisition and second language learning. New York, NY: Pergamon.

Krashen, S. \& Terrell, D. (1983). The natural approach. New York, NY: Pergamon.

Kuhl, P.K. (2000). Perceptual magnet and phoneme boundary effects in speech perception: Do they arise from a common mechanism? Perception and Psychophysics, 62(4), 874-886.

Kuhl, P.K. (1991). Human adults and human infants show a 'perceptual magnet effect' for the prototypes of speech categories; monkeys do not. Perception and Psychophysics, 50, 93-107.

Levelt, W. J. M. (1995). The ability to speak: From intentions to spoken words. Interdisciplinary Journal of the Academia Europaea, 3, 13-23.

Li, C.-H. (2006). What you know and see can help you: An examination of the effects of advance organizers, visual images, and gender differences on the video-based listening comprehension of EFL college students (Doctoral dissertation). Retrieved from ProQuest.

Liu, H. J. (2008). A study of the interrelationship between listening strategy use, listening proficiency levels, and learning style. RARECLS, 5, 84-104.

Logan, G. D. (1997). Automaticity and reading: Perspectives from the instance theory of automatization. Reading and Writing Quarterly, 13, 123-146.

Londe, Z.C. (2009). The effect of video media in English as a Second Language listening comprehension tests. Issues in Applied Linguistics, 17(1), 41-50.

MacWhinney, B. (1997). Implicit and explicit processes. Studies in Second Language Acquisition, 19, 277-281.

Magnan, S. S., Martin-Berg, L., Berg, W. J., \& Rochette Ozzello, Y. (2006). Paroles (3rd ed.). Hoboken, NJ: John Wiley \& Sons, Inc.

Margolin, S. J., \& Hover, P. A.. (2011). Metacomprehension and negation: Assessing readers' awareness of the difficulty of negated text. Reading Psychology, 32(2), $158-171$.

Mayer, R.E. (1997). Multimedia learning: Are we asking the right questions? Educational Psychologist, 32(1), 1-19.

McLeod, B., \& McLaughlin, B. (1986). Restructuring or automaticity? Reading in a second language. Language Learning, 36(2), 109-123. 
Mecartty, F. H. (2001). The effects of modality, information type and language experience on recall by foreign language learners of Spanish. Hispania, 84, 265278.

Mendelsohn, D. J. (1998). Teaching listening. Annual Review of Applied Linguistics, 18, $81-101$.

Mendelsohn, D. J. (1994). "A time to break down, and a time to build up": Teacher education in Ontario. TESL Canada/Revue TESL du Canada, 12(1), 81-95.

Mennim, P. (2007). Long-term effects of noticing on oral output. Language Teaching Research, 11(3), 265-280.

Mevarech, Z. R. \& Amrany, C. (2008). Immediate and delayed effects of metacognitive instruction on regulation of cognition and mathematics achievement. Metacognition Learning, 3(2), 147-157.

Morley, J. (1999). Current perspectives on improving aural comprehension. ESL Magazine, 2(1), 1-30.

Mueller, G.A. (1980). Visual contextual cues and listening comprehension: An experiment. The Modern Language Journal, 64(3), 335-340.

Murphy, J. M. (1985). An investigation into the listening strategies of ESL college students. ERIC document Reproduction Service No. ED 278275.

Nagle, S. J., \& Sanders, S. L. (1986). Comprehension theory and second language pedagogy. TESOL Quarterly, 20(1), 9-26.

O’Malley, J.M., \& Chamot, A.U. (1990). Learning strategies in second language acquisition. Cambridge UK: Cambridge University Press.

Osada, N. (2001). What strategy do less proficient learners employ in listening comprehension?: A reappraisal of bottom-up and top-down processing. Journal of Pan-Pacific Association of Applied Linguistics, 5(1), 73-90.

Peckham, D. W. (2001). Attention and consciousness in second language acquisition: An investigation into the effects of instruction on noticing (Doctoral dissertation). Retrieved from UMI.

Power law [image file]. Retrieved from: http://www.hsmagazine.net/2012/06/no-mansland-and-the-challenge-of-pricing-a-home-game/

Radvansky, G. A., \& Copeland, D. E. (2006). Memory retrieval and interference: Working memory issues. Journal of Memory and Language, 55, 33-46. 
Rahimi, M., \& Katal, M. (2012). The role of metacognitive listening strategies awareness and podcast-use readiness in using podcasting for learning English as a foreign language. Computers in Human Behavior, 28, 1153-1161.

Richards, J. C. (2005). Second thoughts on teaching listening. RELC, 36(1), 85-92.

Richards, J. C., \& Schmidt, R. (Eds.) (2002). Longman dictionary of language teaching and applied linguistics $\left(3^{\text {rd }}\right.$ ed.). London: Longman.

Rivera, G.M., \& Matsuzawa, C. (2007). Assessment: Learners' perspectives on first- and second-year college foreign language programs and their implications for program improvement. Foreign Language Annals, 40(4), 569-583.

Robinson, P. (1997). Generalizability and automaticity of second language learning under implicit, incidental, enhanced, and instructed conditions. Studies in Second Language Acquisition, 19, 223-247.

Robinson, P. (1995). Attention, memory, and the "noticing" hypothesis. Language Learning, 45(2), 283-331.

Rodgers, D. M. (2011). The automatization of verbal morphology in instructed second language acquisition. International Review of Applied Linguistics, 49, 295-319.

Rubin, J. (1994). A review of second language listening comprehension research. The Modern Language Journal, 78(2), 199-221.

Sato, T., Matsunuma, M., \& Suzuki, A. (2013). Enhancement of automatization through vocabulary learning using CALL: Can prompt language processing lead to better comprehension in L2 reading? ReCALL, 25(1), 143-158.

Schmidt, R.W. (1995). Consciousness and foreign language learning: A tutorial on the role of attention and awareness in learning. In R. Schmidt (Ed.) Attention and Awareness in Foreign Language Learning (1-63). Honolulu, HI: University of Hawai'i Press.

Schmidt, R.W. (1990). The role of consciousness in second language learning. Applied Linguistics, 11(2), 129-158.

Schmidt, R. W., \& Frota, S. (1986). Developing basic conversational ability in a second language: A case study of an adult learner of Portuguese. In R. R. Day (Ed.), Talking to learn: Conversation in second language acquisition (pp. 237-326). Rowley, MA: Newbury House. 
Segalowitz, N., \& Segalowitz, S. J. (1993). Skilled performance, practice, and the differentiation of speed-up from automatization effects: Evidence from second language word recognition. Applied Psycholinguistics, 14, 369-385.

Segalowitz, S. J., Segalowitz, N. S., \& Wood, A. G. (1998). Assessing the development of automaticity in second language word recognition. Applied Pyscholinguistics, 19(1), 53-67.

Shtyrov, Y. (2010). Automaticity and attentional control in spoken language processing: Neurophysical evidence. The Mental Lexicon, 5(2), 255-276.

Skotara, N., Kugow, M., Salden, U., Hanel-Faulhaber, B., \& Roder, B. (2011). ERP correlates of intramodal and crossmodal L2 acquisition. BMC Neuroscience, 12, 48-64.

Strange, W. (2011). Automatic selective perception (ASP) of first and second language speech: A working model. Journal of Phonetics, 39, 456-466.

Sturm, J. L. (2013). Explicit phonetics instruction in L2 French: A global analysis of improvement. System, 41, 654-662.

Sweller, J. (1994). Cognitive load theory, learning difficulty, and instructional design. Learning and Instruction, 4(4), 295-312.

Tavakoli, M., Dastjerdi, H. V., \& Esteki, M. (2011). The effect of explicit strategy instruction on L2 oral production of Iranian intermediate EFL learners : Focusing on accuracy, fluency and complexity. Journal of Language Teaching Research, 2(5), 989-997.

Uggen, M. S. (2012). Reinvestigating the noticing function of output. Language Learning, 62(2), 506-540.

Vandergrift, L. (2007). Recent developments in second and foreign language listening comprehension research. Language Teaching, 40, 191-210.

Vandergrift, L. (2006). Second language listening: Listening ability or language proficiency? The Modern Language Journal, 90, 6-18.

Vandergrift, L. (2004). Listening to learn or learning to listen? Annual Review of Applied Linguistics, 24, 3-25.

Vandergrift, L. (2003). From prediction through reflection: Guiding students through the process of L2 listening. Canadian Modern Language Review, 59, 425-440. 
Vandergrift, L. (2002). 'It was nice to see that our predictions were right': Developing metacognition in L2 listening comprehension. The Canadian Modern Language Review/La Revue canadienne des langues vivantes, 58(4), 555-575.

Vandergrift, L. (1997). The comprehension strategies of second language (French) listeners: A descriptive study. Foreign Language Annals, 30(3), 387-409.

Vandergrift, L., Goh, C., Mareschal, C. J., \& Tafaghodtari, M. H. (2006). The Metacognitive Awareness Listening Questionnaire: Development and validation. Language Learning, 56(3), 431-462.

Vandergrift, L., \& Tafaghodtari, M. H. (2010). Teaching L2 learners how to listen does make a difference: An empirical study. Language Learning, 60(2), 470-497.

Van Dijk, T., \& Kintsch, W. (1983). Strategies of discourse comprehension. Orlando, FL: Academic Press.

Veenman, M. V. J., \& Spans, M. A. (2005). Relation between intellectual and metacognitive skills: Age and task differences. Learning and Individual Differences, 15, 159-176.

Veenman, M. V. J., Van Hout-Wolters, B. H. A. M., \& Afflerbach, P. (2006). Metacognition and learning: Conceptual and methodological considerations. Metacognition \& Learning, 1, 3-14.

Vogely, A. (1995). Perceived strategy use during performance on three authentic listening comprehension tasks. The Modern Language Journal, 79(1), 41-56.

Worrell, P. J. (1990). Metacognition: Implications for instruction in nursing education. The Journal of Nursing Education, 29(4), 170-175.

Zhang, D., \& Goh, C. (2006). Strategy knowledge and perceived strategy use: Singaporean students' awareness of listening and speaking strategies. Language Awareness, 15(3), 199-219. 
APPENDICES 
Appendix A: Background Questionnaire

\section{PURDUE UNIVERSITY}

School of Languages and Cultures

French Department

Biographical Questionnaire for French Listening Study

Name:

Age: ___ Native language:

1. When and where have you previously studied French? For how long?

2. Do you know any other languages? Yes No

If yes, please list, and describe your experience with those languages in as much detail as possible (number and level of courses taken, study abroad, etc.). 
Appendix B: Transcripts and Listening Test Items

\section{Text 1 :}

Jean demande à Léa comment elle passe une journée typique.

$\mathrm{J}$ : Quand est-ce que tu es en cours ce semestre?

L : Je suis en cours tous les jours, sauf le week-end. Le lundi, par exemple, je suis en cours de midi à trois heures. Je passe la matinée à la bibliothèque.

$\mathrm{J}:$ Et après les cours, qu'est-ce que tu fais en général ?

L : Après, je rentre à la maison. Je travaille ou je dors un peu.

$\mathrm{J}$ : Et le soir ?

L : Le soir je reste à la maison et je révise mes cours ou je surfe sur Internet.

\section{Questions :}

1. What is the main topic of the conversation?
a. Where Léa goes on vacation.
b. Jean's plans for the summer.
c. Léa's typical day this semester.
d. Whether Léa likes her job.

2. How many days a week does Léa have classes?
a. 5
b. 6
c. 4
d. 3

3. Where does Léa spend the morning?
a. At the library.
b. At work. 
c. At home.

d. At a café.

4. Which of the following does Léa do after class?
a. Returns home.
b. Sleeps.
c. Works.
d. All of the above.

5. What does Léa do at night?
a. Goes out with friends.
b. Stays home to study.
c. Goes to the library.
d. Does housework.

\section{Text 2:}

«On va au cinéma?»Vincent demande à Alice si elle voudrait aller au cinéma.

V : On va au cinéma ce soir?

A : Oui, je veux bien. Quel film est-ce que tu voudrais aller voir?

$\mathrm{V}$ : Je ne sais pas. Il y a une comédie d'Alain Shabat (sp ?) au cinéma Gaumont-Parnasse (sp ?). Qu'est-ce que tu en penses?

A : Allons voir quelque chose d'autre. Je n'ai pas tellement envie de voir une comédie. $\mathrm{V}$ : Il y a le nouveau film américain de science-fiction au cinéma Rex. On dit que c'est un très bon film.

A : Tu sais bien que je n'aime pas les films de science-fiction! Ils sont souvent bêtes ou très violents.

$\mathrm{V}:$ Ben, alors, qu'est-ce que tu veux aller voir?

A : Allons voir le nouveau film d'amour au cinéma Rex.

$\mathrm{V}$ : Bon, si tu préfères. C'est à quelle heure ?

A : Il y a trois séances : une à $18 \mathrm{~h} 20$, une à $20 \mathrm{~h} 45$, et la dernière à $23 \mathrm{~h} 15$.

V : Allons à la séance de $18 \mathrm{~h} 20$ et allons manger après.

A : D'accord. 
Questions :

1. When does Vincent want to go to the movies?
a. Tomorrow afternoon
b. Next weekend
c. Wednesday night
d. Tonight

2. What type of movie does Vincent first suggest?
a. suspense
b. action
c. comedy
d. romance

3. Which of the following best describes Alice's reaction to science fiction movies?
a. They frighten her.
b. She thinks they are too violent.
c. She is not in the mood for science fiction.
d. She just saw one the night before.

4. What type of film would Alice like to see?
a. romance
b. musical
c. police film
d. horror

5. What time will they see the film, and why?
a. 20h45, because Vincent has to work
b. $18 \mathrm{~h} 20$, because they can eat afterward
c. $23 \mathrm{~h} 15$, because they are night owls
d. $18 \mathrm{~h} 20$, because Alice has to get up early

\section{Text 3:}

Kathy parle à son frère de ses activités du week-end dernier.

$\mathrm{K}: \mathrm{Tu}$ es sorti ce week-end ?

F : Oui, je suis allé au ciné-club avec Michelle.

$\mathrm{K}$ : Quel film est-ce que vous avez vu? 
F : Nous avons vu La Belle et la Bête de Cocteau.

$\mathrm{K}:$ C'est un classique! Il t'a plu ?

F : Oui, il m'a beaucoup plu. Les acteurs ont bien joué, les effets spéciaux étaient excellents pour l'époque, et il n'y avait pas trop de violence.

Questions :

1. Kathy is asking her brother about what he did at what point in time?
a. Next Wednesday
b. Last weekend
c. Tonight
d. Two weeks ago

2. Where did Kathy's brother go with Michel?
a. To the ciné-club.
b. To the café on the corner.
c. To the Cinéma Gaumont.
d. To Michel's house

3. How does Kathy describe the film her brother saw?
a. a classic
b. silly
c. a flop
d. boring

4. Which of the following did Kathy's brother appreciate about the film?
a. The director is well-known.
b. He likes the actors in the film.
c. It had a happy ending.
d. Its special effects were great. 


\section{Text 4:}

«Au Restaurant» Deux touristes sont dans un restaurant français.

F : Bonsoir, messieurs. Vous désirez ?

M1: Quelle est la soupe du jour, s'il vous plaît?

F : C'est la soupe à l'oignon.

M1 : Alors, je vais prendre le menu à 18 euros avec la soupe à l'oignon, le poulet à la crème, et les carottes au beurre.

$\mathrm{F}$ : Très bien, monsieur. Et pour vous, monsieur ?

M2 : Moi, j'hésite entre le poulet et le poisson. Quel est le poisson du jour ?

F : C'est du saumon avec une sauce hollandaise.

M2 : Je vois qu'il y a un supplément pour le poisson. C'est combien ?

F : Le supplément est de 3 euros, monsieur.

M2 : Bon. Alors, pour moi, la soupe à l'oignon, le saumon, et des pommes frites.

$\mathrm{F}:$ Et comme boisson?

M2 : Du vin blanc. Vous avez du chablis ?

F : Oui, monsieur. Vous préférez une carafe ou une bouteille ?

M2 : Une carafe.

$\mathrm{F}$ : Très bien, messieurs.

Questions :

1. What is the soup of the day?
a. onion
b. chicken
c. potato
d. fish

2. How much does the first man's meal cost?
a. 14 euros
b. 16 euros 

c. 18 euros
d. 20 euros

3. Why does the second man hesitate in choosing his main course?
a. He has had the chicken before and likes it.
b. He is unsure whether to get chicken or fish.
c. He strongly dislikes certain fish.
d. He isn't very hungry.

4. Which of the following statements about the fish is true?
a. The fish of the day is mackerel.
b. It has a beschamel sauce.
c. There is an extra charge of 3 euros.
d. It comes with a side of rice.

5. Which of the following items is not included in the second man's order?
a. onion soup
b. buttered carrots
c. salmon
d. french fries

6. How much and what type of wine does the second man order?
a. red wine, a bottle
b. red wine, a carafe
c. white wine, a bottle
d. white wine, a carafe 
Appendix C: Metacognitive Awareness Listening Questionnaire

\section{Metacognitive Awareness Listening Questionnaire (MALQ)}

Please indicate your agreement with the following statements by circling the appropriate number:

Strongly disagree Disagree Slightly disagree Partly agree Agree Strongly agree 1 2 3

4 5 6

1. Before I start to listen, I have a plan in my head for how I am going to listen.

2. I focus harder on the text when I have trouble understanding.

3. I find that listening in French is more difficult than reading, speaking, or writing in French.

4. I translate in my head as I listen.

5. I use the words I understand to guess the meaning of the words I don't understand.

6. When my mind wanders, I recover my concentration right away.

7. As I listen, I compare what I understand with what I know about the topic.

8. I feel that listening comprehension in French is a challenge for me.

9. I use my experience and knowledge to help me understand.

10. Before listening, I think of similar texts that I may have listened to.

11. I translate key words as I listen.

12. I try to get back on track when I lose concentration.

13. As I listen, I quickly adjust my interpretation if I realize that it is not correct. 
14. After listening, I think back to how I listened, and about what I might do differently next time.

15. I don't feel nervous when I listen to French.

16. When I have difficulty understanding what I hear, I give up and stop listening.

17. I use the general idea of the text to help me guess the meaning of the words that I don't understand.

18. I translate word by word, as I listen.

19. When I guess the meaning of a word, I think back to everything else that I have heard, to see if my guess makes sense.

20. As I listen, I periodically ask myself if I am satisfied with my level of comprehension. 21. I have a goal in mind as I listen. 
Appendix D: Activity Sheets

\section{Control condition}

Date:

Sujet:

\begin{tabular}{|l|l|l|}
\hline Première Ecoute & Deuxième Ecoute & Troisième Ecoute \\
\hline & & \\
& & \\
& & \\
& & \\
& & \\
& & \\
\hline
\end{tabular}


Treatment condition:

Date:

Sujet:

\begin{tabular}{|l|l|l|}
\hline Attentes & Première Ecoute & Deuxième Ecoute \\
\hline & & \\
& & \\
& & \\
\hline Pour améliorer: & & \\
& & \\
\hline
\end{tabular}




\section{Appendix E: In-class Listening Excerpts}

9/9 https://www.youtube.com/watch?v=CbTenX8v4Z8 Paris (0:38-1:07)

9/10 https://www.youtube.com/watch?v=db_XBgSyi44 Quand j'étais jeune (0:52-1:36)

9/11 https://www.youtube.com/watch?v=LIpGZiUimkc La petite fille qui raconte une histoire $(0: 00-1: 00)$

9/12 Episode $6:$ Je t'invite (p. 247) (0:18-1:43)

9/16 https://www.youtube.com/watch?v=fY5cWL4SUmw Un film français : Bienvenue chez les Ch'tis $(0: 00-1: 00)$

9/18 https://www.youtube.com/watch?v=21Srh18VxRk La démographie de la France (0:17-0:54)

9/19 https://www.youtube.com/watch?v=ffg9OYXI6MQ Se réveiller tôt (0:57-1:38)

9/23 https://www.youtube.com/watch?v=Y57J4WftsHI Les Amoureux (1:45-2:36)

9/24 https://www.youtube.com/watch?v=WsQ6uBSGsiM\&feature=fvsr Les disputes (0:00-1:00)

9/25 https://www.youtube.com/watch?v=0y4s90scd_U Se disputer en couple (0:24-1:20)

9/26 https://www.youtube.com/watch?v=22xLHlnRx0M Qualités et défauts des Français (0:00$0: 56)$

9/30 https://www.youtube.com/watch?v=MNsSMiO65Oo A quoi ça sert les garçons ? (0:001:00)

10/1 Episode 7: Vous vous êtes amusés? P. 289 (0:20-1:28)

10/2 https://www.youtube.com/watch?v=7XeFYtO_Pk0 Les sites de rencontre (0:00-0:58)

10/3 https://www.youtube.com/watch?v=bKcqNC8hd_8 Les Français (0:14-1:10)

10/8 https://www.youtube.com/watch?v=3_6oQte3ZL0 Le Mont-St-Michel (0:33-1:27)

10/9 https://www.youtube.com/watch?v=pa1E2rrxN4s Les commandes (0:42-1:39)

10/10 https://www.youtube.com/watch?v=r9HSLtYDRDg Au marché (0:30-1:31)

10/15 https://www.youtube.com/watch?v=RQcPkkcrn7Q Repas gastronomique (0:16-1:11) 
10/16 https://www.youtube.com/watch?v=BpYWD0ZjbaI\&list=PLxSerSIVE4P7JxLdggnh5CMJguE5ACDe La tarte au chocolat et caramel buerre salé (0:25-1:02)

10/21 https://www.youtube.com/watch?v=HmbifP1SiQk\&feature=related Aquaphobe (0:001:00)

$10 / 22$

https://www.youtube.com/watch?v=lRvs7qpRhRI\&list=UUFcRCAn2PX7SBnIBEm1yfMw Le sommeil (1:03-2:03)

10/23 Episode 8: Qu'est-ce qu'ils servent?, p. 335 (0:25-1:28)

10/24 https://www.youtube.com/watch?v=Fy8b9GfLbNA Les manières à table (0:24-1:10)

10/30 https://www.youtube.com/watch?v=HNw91bMd6dc Les anciens DOM-TOM (1:16-2:26) 
VITA 


\section{VITA}

Shannon Renee (Takacs) Becker was born in DeMotte, Indiana, the daughter of Dave and Donna Takacs. Upon graduating from Kankakee Valley High School in 2001, she enrolled at Western Michigan University where she obtained a Bachelor of Arts in French in 2005. She immediately entered the Professional French Masters Program at the University of Wisconsin, completing her Master of French Studies degree in August 2008. During the following two years, she was employed as an adjunct instructor of French at Indiana University Northwest. In August 2010, she entered the Master's program in French at Purdue University specializing in Applied Linguistics, which she completed in the spring of 2012. She then continued into the Ph.D. program at Purdue, focusing on Second Language Acquisition. 